\title{
The role of accounting and market-based information signals in the bond market
}

Citation for published version (APA):

Hofmann, R. K. (2014). The role of accounting and market-based information signals in the bond market. [Doctoral Thesis, Maastricht University]. Maastricht University. https://doi.org/10.26481/dis.20140328rh

Document status and date:

Published: 01/01/2014

DOI:

10.26481/dis.20140328rh

Document Version:

Publisher's PDF, also known as Version of record

\section{Please check the document version of this publication:}

- A submitted manuscript is the version of the article upon submission and before peer-review. There can be important differences between the submitted version and the official published version of record.

People interested in the research are advised to contact the author for the final version of the publication, or visit the DOI to the publisher's website.

- The final author version and the galley proof are versions of the publication after peer review.

- The final published version features the final layout of the paper including the volume, issue and page numbers.

Link to publication

\footnotetext{
General rights rights.

- You may freely distribute the URL identifying the publication in the public portal. please follow below link for the End User Agreement:

www.umlib.nl/taverne-license

Take down policy

If you believe that this document breaches copyright please contact us at:

repository@maastrichtuniversity.nl

providing details and we will investigate your claim.
}

Copyright and moral rights for the publications made accessible in the public portal are retained by the authors and/or other copyright owners and it is a condition of accessing publications that users recognise and abide by the legal requirements associated with these

- Users may download and print one copy of any publication from the public portal for the purpose of private study or research.

- You may not further distribute the material or use it for any profit-making activity or commercial gain

If the publication is distributed under the terms of Article $25 \mathrm{fa}$ of the Dutch Copyright Act, indicated by the "Taverne" license above, 
THE ROLE OF ACCOUNTING AND MARKET-BASED INFORMATION SIGNALS IN THE BOND MARKET 



\title{
THE ROLE OF ACCOUNTING AND MARKET-BASED INFORMATION SIGNALS IN THE BOND MARKET
}

\author{
DISSERTATION \\ to obtain the degree of Doctor \\ at Maastricht University, \\ on the authority of the Rector Magnificus, Prof. dr. L.L.G. Soete \\ in accordance with the decision of the Board of Deans, \\ to be defended in public \\ on Friday March 28, 2014, at 10.00 hours \\ by
}

Ronny Karl Hofmann 


\section{Promoter}

Prof dr. Frank Moers

\section{Assessment Committee}

Prof dr. Ann Vanstraelen (Chairperson)

Prof dr. Piet Eichholtz

Prof dr. Erik Peek, Erasmus University, Rotterdam 


\section{ACKNOWLEDGMENTS}

Four years ago, I decided to enroll in the PhD program at Maastricht University SBE Department of Accounting \& Information Management (AIM). After gaining experience in practice (Deloitte and KPMG), this decision was basically driven by the intrinsic motivation to conduct meaningful high quality research in the accounting and capital markets area. I knew this would be a long and cumbersome journey, but with the support of many colleagues, friends, and family, although it has indeed been challenging, I enjoyed this rewarding experience.

This dissertation would not have been possible without the support and motivation of my supervisor and promoter Frank Moers. Frank has not only been abundantly supportive with regard to feedback and guidance on all research projects, but also motivated and always reminded me that, using a boxing analogy, a "defeat" in terms of a failed research question or project is not declared when the researcher "falls down", it is declared when s/he refuses to get up and continue with a different, new, and otherwise creative research idea. Or, in other words, "if there is no wind, row!" (Latin proverb). Frank, thank you very much for all your effort and time you have invested into my $\mathrm{PhD}$ education.

I am also indebted to Ann Vanstraelen and Erik Peek for their guidance and advice. I certainly enjoyed the many conversations we had on research topics and methodology, accounting theory, and ways to position a specific research project. Furthermore, I very much appreciated your honest feedback with regard to a career in academia. Your "open door policy" always gave me the opportunity to immediately receive both researchrelated and personal advice and to put aside all sorts of concerns. Ann and Erik, please know that your support has been greatly appreciated.

As I got invited to present the individual studies included in this dissertation at many conferences and universities worldwide, I would like to thank the following colleagues and co-authors for providing precious feedback on all of my projects: Wayne Landsman, Robert Bushman, Eddie Riedl, J.P. Kothari, Joe Weber, Christoph Watrin, Thorsten Sellhorn, Igor Goncharov, Tom Smith, Philip Brown, Ann Tarca, Richard Heaney, Anne Wyatt, Jennifer Francis, Shane Dikolli, Per Olson, Andrew Ferguson, Thomas Loy, Tony van Zijn, and Jean Bedard. Furthermore, I would also like to express my gratitude to Wayne Landsman for his invitation to visit the University of North Carolina at Chapel Hill in fall 2011. The visit at UNC Chapel Hill provided me with great insights into capital markets research. For example, the derivation of the perfect foresight portfolio strategy explained in chapter two has been discussed in Wayne's seminar. Thank you all for your feedback and advice which certainly helped in improving the research quality of my individual working papers.

My thanks and appreciations also go to all my colleagues at the Department of Accounting and Information Management at Maastricht University SBE for their support 
and encouragement to complete this dissertation project. It has been a great pleasure to work and interact with all of you on a daily basis. Although I should mention all colleagues, I would like to provide special thanks to the following colleagues and friends with whom I shared many extremely pleasant events and evenings including seminar and conference visits, carnival celebrations, birthday parties, Oktoberfest gatherings, or just regular champion league public viewings or grill-outs: Julius André, Lisa and Alexander Brueggen, Rick Cuijpers, Christoph Feichter, Reka Felleg, Isabella Grabner, Nadine Funcke, Jonas Heese, Felix Hoeppe, Thomas Keusch, Anant Joshi, Mona Offermanns, Thomas Post, Jeroen van Raak, Abiot Tessema, and Patrick Vorst. Thank you all for my wonderful time in Maastricht.

Finally, I would like to give my deepest gratitude to my beloved family. My wife Isabell and my children, Maximilian and Hannah, always motivated, supported, and inspired me throughout the PhD program. I could not have done it without your enduring encouragement, understanding, patience, and love. To my parents, Hedwig and Reinhold Hofmann, and my siblings, Rita Matthies and Harry Hofmann, it is impossible to express my gratitude to you, as you actually helped me in becoming the person I am today. I am very proud to call you all my family and need to mention that "we often take for granted the very things that most deserve our gratitude" (Cynthia Ozick).

Madrid, February 2014

Ronny K. Hofmann 
CONTENT

\section{INTRODUCTION}

1.1 The informational perspective of accounting signals in capital markets

1.2 Implications of the information approach for debt markets and periods of financial distress

1.3 Outline and contribution of the dissertation

\section{BANK REGULATORY CERTIFICATION AND CAMEL FRAMEWORK-RELATED ACCOUNTING SIGNALS IN THE DEBT MARKET}

2.1 Introduction

2.2 Debt markets and accounting signals

2.2.1 Debt market characteristics

2.2.2 Accounting signals related to the CAMEL framework

2.2.3 Transparency-stability vs. transparency-fragility view

2.3 Prior research

2.4 Hypotheses

2.4.1 Cumulative monthly bond return analysis
2.4.1.1 Association between bond returns and financial ratios related to the CAMEL framework

2.4.1.2 Anticipation of financial indicators related to the CAMEL framework

2.4.1.3 Relative importance of preliminary earnings and 10-K filing announcements for investors in the debt market

2.4.2 Daily bond return analysis

2.5 Methodology, research design, and sample selection

2.5.1 Perfect foresight portfolio strategy

2.5.2 Research design

2.5.3 Sample selection

2.6 Empirical results 
2.6.2 Association of CAMEL ratios with annual bond returns

2.6.3 Value relevance of ratios related to the CAMEL framework for bond holders

2.7 Concluding remarks

ESTIMATED TAXABLE INCOME AND OTHER ACCOUNTING SIGNALS IN THE CORPORATE BOND MARKET

3.1 Introduction 38

3.2 Corporate debt market and tax income related information 40

$\begin{array}{lll}3.3 & \text { Prior research } & 41\end{array}$

3.4 Hypothesis development and research design

3.4.1 Hypothesis development 43

3.4.2 Sample selection and research design $\quad 44$

3.5 Empirical results

3.5.1 Descriptive analysis $\quad 46$

$\begin{array}{ll}3.5 .2 \text { Association test results } & 50\end{array}$

3.6 Concluding remarks 51

\section{DYNAMIC PROPERTIES OF EARNINGS IN THE BOND MARKET}

4.1 Introduction $\quad 56$

4.2 Prior research and hypothesis development

4.2.1 Prior research $\quad 59$

4.2.2 Hypothesis development $\quad 61$

4.3 Methodology

4.3.1 Quantile regression approach $\quad 62$

4.3.2 Research design and sample selection 63

4.4 Descriptive and empirical results

4.4.1 Descriptive statistics $\quad 65$

4.4.2 Ordinary-Least Square (OLS) base model 68

4.4.3 Extended OLS-model including interaction terms 72

4.4.4 Semi-Parametric Model 78

$\begin{array}{lll}\text { 4.4.5 Heteroscedasticity - OLS versus quantile regressions } & 79\end{array}$

4.5 Robustness checks 84

4.6 Summary and limitations $\quad 84$ 
CONCLUSION

5.1 Summary of results and implications 86

5.2 Future research 88

$\begin{array}{ll}\text { APPENDIX } & 90\end{array}$

REFERENCES $\quad 93$

CURRICULUM VITAE $\quad 102$ 



\section{INTRODUCTION}

\subsection{The informational perspective of accounting signals in capital markets}

Functioning capital markets are the backbone of many economies worldwide. Although the Global Financial Crisis (GFC) has had a strong deflating impact on global financial markets, "the total value of the world's financial stock, comprising equity market capitalization and outstanding bonds and loans, has increased from \$175 trillion in 2008 to $\$ 212$ trillion at the end of 2010, surpassing the previous 2007 peak" (McKinsey Global Institute, 2011). Through these global financial markets, comprised of both equity providers and debt holders, firms obtain the funds required to acquire assets and invest in projects that are able to generate profits which are then distributed back to the lenders of capital in the form of interest payments, dividends, and capital gains. To make investment decisions, individual capital suppliers need to obtain information from different sources, including annual certified financial statements, press releases, prospectuses, credit ratings, and other market-based information signals (e.g., VIX volatility).

According to the efficient markets theory, semi-strong form tests reveal that security prices react in a predictable way to new information (e.g., earnings announcements and stock splits) that is publicly available (Fama and Malkiel 1970). With regard to testing the impact of accounting information signals, empirical accounting research adopted a so called information approach in the late 1960's (Ball and Brown 1968; Beaver 1968; Sorter 1969). This approach complements the view of financial statements serving a stewardship function. Under the stewardship perspective, financial statements, based on accrual accounting, inform capital suppliers about how well management uses a firm's resources to maximize firm value. In contrast to the stewardship function, the information approach to decision usefulness addresses capital suppliers' needs to predict an individual investor-specific firm value, which serves as a benchmark for buy/sell decisions (Ball and Brown 1968; Ohlson 1995; Sloan 1996; Healy and Palepu 1993; Scott 2011). The information approach is also incorporated in the Framework of the International Accounting Standards Board (IASB) and the Financial Accounting Standards Board (FASB). Statement of Financial Accounting Concepts (SFAC) No.8 states that:

"The objective of general purpose financial reporting is to provide financial information about the reporting entity that is useful to existing and potential investors, lenders, and other creditors in making decisions about providing resources to the entity. Those 
decisions involve buying, selling, or holding equity and debt instruments and providing or settling loans and other forms of credit" (SFAC No.8 2010).

Although the information approach to decision usefulness (see Appendix B) is embedded in the joint Framework of the IASB and FASB, an important research question is whether different types of capital providers require exactly the same set of information. ${ }^{1}$ Furthermore, investors' information needs are probably subject to change over time attributable to a change in the reliability, timeliness, or precision of all information signals available (e.g., periods of financial distress, such as the GFC, can have an impact on the information set available and useful to investors).

\subsection{Implications of the information approach for debt markets and periods of financial distress}

Albeit equity providers and debt holders are both interested in allocating their capital optimally, their individual investment pay-off functions reveal that their decisions are probably based on a different set of information signals. Shareholders' pay-off function can be replicated by a call option where the strike price is equal to the face value of the bond outstanding (Black and Scholes 1973). In contrast, debt holders' payoff function can be replicated using risk-free debt and a written put option. Thus, attributable to the convexity of their payoff function, equity holders are willing to accept higher levels of risk in comparison to debt holders (Figure 1.1). In the case of a default, equity holders are protected by the limited liability nature of their contract and their payoff will be zero (Jensen and Meckling 1976; De Servigny and Renault 2004). Debt holders, on the other hand, take on legal ownership of the bankrupt firm and receive control rights to extract the remaining value from the firm. From an information signal perspective, it seems logical that debt holders are more interested in accounting signals that inform about downside risk (e.g., risks related to capital structure or debt overhang) whereas equity holders seem to care more about information concerning a firm's upside potential (e.g., changes in sustainable earnings growth). Based on this payoff structure view and investigating the equity market alone, Barth et al. (1998) find that the incremental explanatory power of book values, in contrast to variables related to the income statement, increases as a firm's financial health decreases. ${ }^{2}$ These findings also suggest that investors use different types of information over time to recalibrate their decision processes and to adjust the information set they use to better reflect changes in the external environment (e.g., macroeconomic shocks, industry-wide effects etc.).

\footnotetext{
${ }^{1}$ Statement of Financial Accounting Concepts (SFAC) No.2 includes the hierarchy of accounting qualities which defines decision usefulness.

2 In this dissertation the terms income statement (used under U.S. GAAP) and profit and loss statement/statement of comprehensive income (used under IFRS) are used interchangeably. Furthermore, the term balance sheet is used synonymously to the statement of financial position).
} 
Assuming perfect capital markets, security prices would fully reflect all publicly available information, and thus information conveyed through financial statements and other sources would be irrelevant to capital suppliers. Hence, assuming certainty in the markets, the concept of economic earnings is uniquely specified if markets are complete and perfect. Therefore, an accounting related earnings measure would be "redundant and can be derived from the valuation of the firm and its equity" (Beaver 1998). However, empirical accounting research in the last two decades has shown that, under a more realistic setting referred to as imperfect or incomplete markets, security prices cannot reflect and incorporate all available information as individual capital suppliers' preferences differ. Thus, publicly available accounting information signals justify the above mentioned information approach, as financial statement disclosures are used by capital suppliers in validating security prices and assessing buy/sell decisions. (Schipper 1994; Lambert 1996; Beaver 1998).

The role of accounting information signals in semi-strong efficient markets can also be explained by looking at inside (private) information. If markets were efficient and complete, security prices and fundamental values would be aligned. It is inside information that causes the divergence of fundamental values and market prices (Scott 2011). Thus, enhancing the value relevant information content of financial statements will assist capital providers in estimating future firm performance and thus, reducing private information that is not available to investors. The importance of accounting information signals is even more pronounced the less efficient financial markets become (e.g., distressed and illiquid financial markets, as experienced during the GFC). In this case, not all publicly available information is processed by investors, and the role of financial reporting can be seen as reducing these processing inefficiencies (Scott 2011), as shown in Figure 1.2.

FIGURE 1.1 Payoff Structures of Debt Holders and Equity Investors

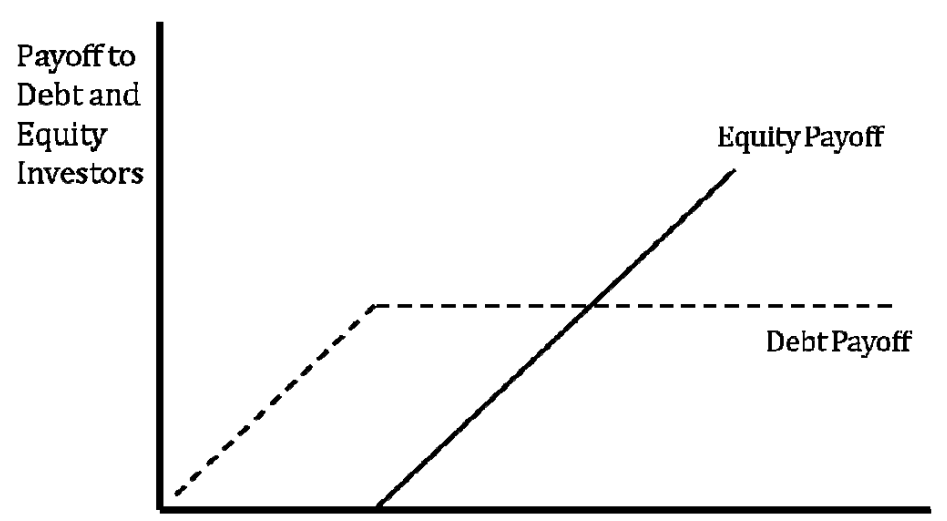

Firm Value 
Given these theoretical insights about the importance of accounting information signals in semi-strong efficient markets and investors' differing payoff structure (Figure 1.1), it is important to obtain more insights about the role of financial reporting for pricing securities, especially in pricing debt market instruments in distressed financial markets. More specifically, this dissertation sheds light on the informativeness and value relevance of accounting information for both the corporate and the financial institutions' bond market. Attributable to the highly regulated nature of the banking sector, bond investors potentially free ride on accounting information signals, as bank regulators provide protection against default risk as their main concern lies in the stability of this important industry. On the contrary, corporate bond investors cannot rely on this downside risk protection and may require other/additional information signals to make buy/sell investment decisions.

Besides exploiting the highly regulated banking sector setting, I am also interested in the role of tax related accounting signals in the corporate bond market. Information related to estimated tax income could be a source of information that is less vulnerable to discretion than net income and thus, could add incrementally to other accrual accounting-related variables in explaining the variation in bond prices. As earnings are a product of the conventional accrual accounting model (Collins et al. 1994), I also examine the informativeness of earnings and earnings components in the corporate bond market to address the mapping of current and future cash flows into current and future earnings. The following section outlines each of the three studies that comprise this dissertation in more detail.

FIGURE 1.2 The Role of Financial Reporting in Periods of Distressed and Illiquid Financial Markets [Source: based on Scott (2011)

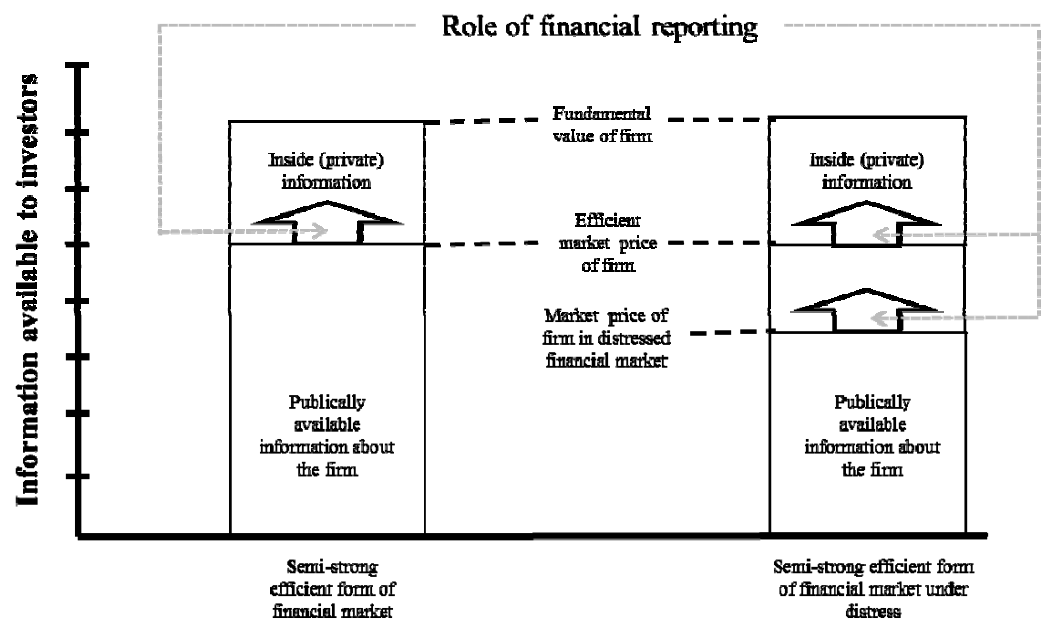

Type of financial market 


\subsection{Outline and contribution of the dissertation}

In summary, in this dissertation I examine the role of accounting information signals in the bond market. To obtain a more complete picture of the overall bond market, I investigate both the financial institutions' and corporate bond market and shed light on the differential information needs investors demand for making their investment decisions. As research results may not be transferred from the corporate to the financial institution bond market, chapter two examines the role of accounting related information signals (e.g., information from both the income statement and the balance sheet) in the banking sector setting. Furthermore, as an additional information source to typical income statement (e.g., earnings) and statement of financial position information (e.g., capital structure), the importance of tax-related information signals is investigated in the corporate bond market (Chapter 3). As bond returns in the corporate bond market show a larger dispersion (in comparison to bond returns in the banking sector setting), sensitivity tests on varying bond return levels reveal interesting insights. Furthermore, non-parametric estimation techniques are used to shed light on the feasibility of traditional OLS-techniques applied in corporate bond market research. In addition to using quantile regressions, I extend the study in chapter three by disentangling earnings information into specific components (e.g., accruals and cash flows) to address concerns that net income as a product of the accrual accounting process is comprised of persistent and non-persistent components (Sloan 1996). Research in the equity market shows that earnings' predictive power is driven by its persistent components as these items recur and are hence not transitory in nature. With regard to the debt market, both transitory and persistent components might be value relevant to bond investors as both components can potentially lead to debt covenant violations, at least short term during financial distress periods. As such, investigating earnings and earnings components in chapter four sheds light on the importance of both persistent and transitory components for bond investors when rebalancing their debt instrument portfolio. These components are then challenged with market-based information signals (e.g., VIX volatility and credit rating information) as these information sources are timelier and probably anticipate information revealed through financial statements (Chapter 4). Underlying all three studies in the dissertation is my interest in shedding light on the "dynamic" composition of information required by bond holders to make optimal buy/sell decisions. To exploit these differential information needs, this dissertation examines the information set composition during the period preceding the recent financial crisis and the GFC, as the composition of the information set seems to be linked to the form of efficiency inherent in specific financial markets and the overall state of the economy (e.g., financial distress versus active capital markets).

Chapter two investigates whether and to which extent bond investors in the financial institution sector use accounting signals in their decision-making process during economic downturns. The recent financial crisis provides a perfect setting to test whether financial institutions' accounting ratios related to the CAMEL framework of the U.S. Federal Bank Regulatory Agencies - capital adequacy, asset quality, earnings ability, 
and liquidity - if at all, enter into the decision-making process of investors holding a portfolio of debt instruments in financial institutions. Applying a perfect foresight portfolio investment strategy (Abarbanell and Bushee 1998), I find evidence that cumulative monthly bond returns are associated with changes in "earning power" and changes in credit ratings only when financial markets are illiquid and not transparent. This is potentially attributable to the diverging interests of bank regulators and institutional bond investors during bank crisis periods with debt holders conceivably relying to a lesser extent on regulatory agencies' private information with regard to the supervision of the banking sector. Moreover, I provide insights on bond prices not fully anticipating accounting signals during periods of financial distress and illiquidity. To draw causal inferences, I also conduct an event study utilizing short-term windows centered on the U.S. Securities and Exchange Commission (SEC) EDGAR 10-K filings announcement dates and preliminary earnings announcement dates and report the value relevance of ratios related to changes in "earning power", liquidity, and capital adequacy for bond holders during the recent financial crisis period.

The study in chapter two reveals three contributions to the literature. First, it sheds light on bond investors' different and dynamic informational needs during financial and non-financial crisis periods. Second, it provides evidence that accounting information signals related to the bank regulatory framework are not fully anticipated and incorporated into contemporaneous bond prices during the recent financial crisis. Third, accounting signals related to core business performance, liquidity, and equity cushion are value relevant to bond holders only during the recent financial crisis period stressing the importance of accounting signals to prevent mispricing especially during periods of financial distress and increased uncertainty (e.g., when efficiency in semi strong financial markets deteriorates even more). ${ }^{3}$

In chapter three I provide evidence on the relative importance of earnings, liquidation values (capital structure), and estimated taxable income in the corporate debt market. Using bond returns of U.S. corporations from 2004 to 2011, I show that, irrespective of the state of the economy, information related to changes in a firm's liquidation value is incrementally and significantly associated with bond returns after controlling for earnings-related accounting information and financial distress indicators. As assumed, these insights deviate from the findings in the banking sector in chapter two, as investors in the corporate bond market are not downside risk protected by regulation authorities. Furthermore, the study in chapter three demonstrates that estimated taxable income is incrementally informative over and above earnings and liquidation values in the period preceding the recent financial crisis.

Overall, through the study in chapter three I provide two contributions to literature. First, I show that liquidation values and estimated taxable income are associated with annual bond returns over and above earnings related information. In comparison to the banking sector setting in chapter two, information on a firm's capital

\footnotetext{
3 In the banking sector setting, both information signals extracted from the income statement and the statement of financial position are not associated with bond prices during the GFC period (April 2007 March 2009).
} 
structure (downside risk measured as leverage) is indeed an important information source for investors in the corporate bond market. Second, I show that the relative importance of earnings-related accounting information increases during periods of distress and illiquidity, as witnessed during the recent GFC.

In chapter four I extend recent accounting research and the findings of the study in chapter three by disentangling earnings into different components as prior "theoretical and empirical papers on the return-earnings relation often characterize accounting earnings as comprising a noise or garbling component and a value-relevant signal component" (Collins et al., 1994).

Furthermore, based on the evidence in chapter three, non-parametric methods (quantile regressions) are used to account for the fact that accounting information signals (accruals and cash flows) influence bond prices differently for debt instruments with low returns than for those with average returns. Controlling for the presence of systematic risk and private information of credit rating agencies, I also provide evidence that accounting accruals and cash flows are not associated with corporate bond returns in the three years preceding the financial crisis. However, using a point estimate of the conditional mean of annual bond returns, I show a positive and significant association of accounting accruals with annual bond returns during the recent financial crisis. Additionally, using a semi-parametric technique to include conditional quantiles of bond returns, I show that the rate of change in the regression coefficients is dependent on those quantiles. Thus, I provide evidence that, conditional on the distribution of bond returns, both changes in cash flows and accruals are positively and significantly associated with annual bond returns during the recent financial crisis. The results suggest that debt market investors base their investment decisions on credible marketbased measures (e.g., VIX volatility and credit rating information) during the prefinancial crisis, but complement these information signals with accounting-based measures during the recent financial crisis. ${ }^{4}$ Therefore, accounting signals may reflect information about a firm's closeness to default and creditworthiness that is not captured by market-based measures.

Overall, I contribute to literature by providing insights on the signaling components of earnings as measured under the accrual accounting principle for bond investors. Furthermore, I incorporate dynamic properties of earnings-related accounting information into the research design. These dynamic attributes reflect a shift in bond investors' information needs during the recent financial crisis. Furthermore, it extends prior research in the debt market and includes additional market-based

\footnotetext{
${ }^{4}$ Credit rating information is provided through credit rating agencies such as Standard \& Poor's, Fitch, and Moody's. In this dissertation, credit rating information is regarded as a market-based measure, as its providers include market-based information (e.g., idiosyncratic information on firm's closeness-to-default, hence examining a firm's asset and funding liquidity risk, credit and counterparty default risk, operational and reputational risk, macroeconomic and sovereign information, and other market risks) to assess firm specific creditworthiness. VIX volatility is measured in percentage points and refers to the Chicago Board Options Exchange (CBOE) Market Volatility Index. This so called 'fear index' captures the implied volatility of S\&P 500 index options.
} 
measures related to information provided by credit rating intermediaries and 'fear' that exists in the economy as measured by the VIX index.

Finally, in chapter five I conclude by summarizing the dissertation and its included three individual research projects. Furthermore, I address limitations and provide potential research extensions for bond market related research as well as implications for research opportunities outside the capital markets boundaries. 


\section{BANK REGULATORY CERTIFICATION AND CAMEL FRAMEWORK-RELATED ACCOUNTING SIGNALS IN THE DEBT MARKET}

\subsection{Introduction}

In this study I examine whether and to which extent bond investors in the financial institution sector use accounting-based information signals related to the CAMEL framework of the U.S. Federal Bank Regulatory Agencies - capital adequacy, asset quality, earnings ability, and liquidity - in their decision-making process during economic downturns. ${ }^{5}$ More specifically, I investigate whether debt market investors potentially free-ride on regulatory certification in 'good' times but not during periods of turmoil and distress (i.e., during the recent GFC). ${ }^{6}$ As bank regulatory information signals became less credible during the GFC, investors arguably had to turn to more fundamental information from the accounting system and other market-based signals (i.e., information in form of credit ratings). Although the focus of this paper is solely on the highly regulated banking sector, it addresses important implications attributable to this sectors' fundamental role for an economy's financial stability. Because exceedingly leveraged individual institutions access the capital markets to a greater extent through debt instruments than equity issues, taking on a bond investor perspective is appealing. ${ }^{7}$ According to the Financial Crisis Inquiry Report of the Financial Crisis Inquiry Commission (2011), "from 1978 to 2007 the amount of debt held by the financial sector soared from $\$ 3$ trillion to $\$ 36$ trillion", indicating the importance of debt financing for financial institutions in the United States.

Furthermore, international and U.S. accounting standard setters (International Accounting Standards Board, IASB and U.S. Financial Accounting Standards Board, FASB) as well as capital markets and bank regulators (U.S. Securities and Exchange

\footnotetext{
5 The acronym CAMEL refers to capital adequacy, asset quality, management capabilities, earnings ability, and liquidity. As bank regulatory agencies do not publish the results of their on-site CAMEL investigations, I use accounting-based information to obtain a proxy that captures each of the framework's main categories.

${ }^{6}$ I define free-riding in this study similar to Millon and Thakor (1985) and Carletti et al. (2007). Since extracting information from individual financial statements is privately costly, investors rely on the bank regulatory certification process as regulators have access to timelier and private information when assessing the soundness of the financial position and performance of a financial institution. This is not the case during periods of severe financial distress as regulators are no longer able to use their private information to improve the creditworthiness of a respective client within the fiscal year.

7 Source: Securities Data Company and the Board of Governors of the Federal Reserve System (http://www.federalreserve. gov/econresdata/releases/corpsecure/current.htm).
} 
Commission, SEC and the Basle Committee on Banking Supervision) are currently deliberating whether information revealed through financial institutions' certified annual financial statements and mandated by the banking supervision framework has been informative and value relevant to both equity and debt investors during the recent financial crisis. ${ }^{8}$

According to the Statement of Financial Accounting Concepts No. 1 Objectives of Financial Reporting by Business Enterprises (SFAC No. 1), one objective of financial reporting is to provide information that is relevant and useful to various stakeholders in making investment decisions. ${ }^{9}$ Stakeholders, among other groups, include both present and potential equity investors as well as creditors although these groups potentially assess the reported earnings and disclosures differently. Especially debt investors with their investments' limited upside potential, attributable to the instruments' inherent concave payoff function, conceivably only assess information signals capturing downside risks. As bank regulatory agencies have access to more timely and private information through their clients' IT-systems, and thus a more complete picture on an individual banks' financial health, investors probably free-ride on that information. If bank regulatory agencies detect discrepancies or threats in a bank's business model or risk management practices, stringent and frequent examinations (e.g., including ceaseand-desist orders) will ensure that the respective bank engages in activities to address these apparent weaknesses. As such, bond investors probably do not base their investment decisions on accounting information as these signals are not timely and do not reflect intra-period events. Bank regulatory agencies act as a safeguard and ensure that financial institutions' business models and risk appetite are appropriate, at least during periods without turmoil and distress.

Notwithstanding, bond investors potentially doubt bank regulators' examinations and assessments of individual financial institutions' going concern during severe bank crisis periods (e.g., the recent GFC). As the stability of the financial sector is of utmost importance to bank regulatory agencies, the dissemination of information with regard to a bank's closeness to default could itself worsen the institutions' prospects. As such, bank failures often came as a surprise and pre-empted the announcements of bank regulatory agencies during the recent financial crisis. As a result, institutional bond holders in the financial sector may prefer accounting signals related to the CAMEL framework of the U.S. Federal Bank Regulatory Agencies - capital adequacy, asset quality, earnings ability, and liquidity - to other less credible information available in the capital markets during bank crisis periods. A possible explanation why bondholders rely more on accounting signals during financial crisis periods is also reflected in

\footnotetext{
${ }^{8}$ The report of the Financial Crisis Advisory Group (2009) presented to the IASB and FASB discusses among other things the limitations of financial reporting during financial crisis periods.

${ }^{9}$ SFAC No. 1 has been superseded by SFAC No. 8 (Conceptual Framework for Financial Reporting Chapter 1, The Objective of General Purpose Financial Reporting, and Chapter 3, Qualitative Characteristics of Useful Financial Information that includes the new conceptual framework). As the time period in this study includes the change from SFAC No. 1 to SFAC No. 8, both concepts need to be mentioned. Nevertheless, there are no implications for the results of this study as both concepts basically incorporate the information approach to decision usefulness (Appendix A).
} 
accounting standard setters' objectives that deviate from bank regulators' overall objectives. Standard setters are concerned with the true and fair view of financial statements, informing investors even in financial distress periods about the true financial position and performance at fiscal-year end, whereas bank regulators are especially interested in rules and regulation providing a sufficient cushion against unexpected losses, because the default of a major player could have a negative impact on the overall financial stability of the capital market and the economy as a whole. During the pre-crisis period, an assessment of accounting-based information appears to be less relevant, as bank regulatory agencies ensure the intactness of individual institutions through frequent and stringent on-site examinations.

Hence, whether bond holders in the banking sector potentially process accounting signals during non- and financial crisis periods because of the already stringent examination procedures of bank regulatory agencies is an empirical question.

In a first analysis, I investigate whether changes in financial indicators related to asset quality, liquidity, core business performance, and equity base are associated with cumulative monthly bond returns for both the recent financial crisis period (April 2007 - March 2009) and the three years preceding the crisis (April 2004 - March 2007). ${ }^{10}$ Applying a perfect foresight portfolio strategy (Abarbanell and Bushee 1998), I provide evidence that neither ratio is associated with bond returns at conventional significance levels for the specified time period preceding the GFC. One possible explanation for the insignificant ratios is that investors rely on other information channels including bank regulators' access to private information and trust in the stringent supervision procedures applied and thus free ride on accounting information. Moreover, I test a different specification by including the average changes in the credit ratings of the financial institutions in the non-crisis period (provided by the credit rating agencies Moody's and Standard \& Poor's) and conclude that this market-based signal is also not associated with annual bond returns. Applying the same analysis to the bank crisis period reveals interesting results. The changes in the core business performance ratio are positively associated with the annual bond returns. Furthermore, controlling for the average changes in credit ratings which itself is significant and negatively associated with bond returns, the changes in the core business performance ratio is still significant and positively associated with the annual bond returns. The results suggest that investors in the bond market of financial institutions prefer accounting signals related to earnings growth measures during financial crises, whereas these ratios seem to be irrelevant during periods where markets are liquid and active. These findings suggest that bond holders probably rely to a lesser extent on (and free-ride on) regulatory agencies' private information and stringent examination procedures during bank crisis periods. Furthermore, I find evidence that bond prices during the recent financial crisis

\footnotetext{
${ }^{10}$ According to the Business Cycle Dating Committee (2010) of the National Bureau of Economic Research (NBER), the recent financial crisis ("Great Recession") started in December 2007 and ended in June 2009 (http://www.nber.org/ cycles/sept2010.html). Attributable to the construction of the annual cumulative bond returns, the period from April 2007 to March 2009 is used as the GFC period in this dissertation. Figure 2.1 supports the period definition of the GFC used in this dissertation - Bank of America (BofA) Merill Lynch Option-Adjusted Spreads (OAS) from January 1996 to March 2013 (Source: Federal Reserve Bank St. Louis).
} 
do not fully anticipate the changes in the ratios related to asset quality, core business performance, equity base, and liquidity, because the hedge portfolio strategy (Ababarnell and Bushee 1998) provides investors with an increase in returns of 49,4\% in the months the 10-K filings are announced.

After testing for associations between the accounting signals of interest and the cumulative bond returns, I conduct an event study utilizing short term windows centered on the $10-\mathrm{K}$ filings announcement date and the four preliminary earnings announcement dates to draw causal inferences regarding the impact of signals related to core business performance, asset quality, liquidity, and capital adequacy on daily bond returns. Association studies only provide correlations which are measured over long time periods and hence, other more timely, and presumably value relevant, information potentially enters into the decision making process of bond investors. Thus, association studies do not allow for causal linkages between accounting signals and bond price movements (Kothari 2001). Applying event study methodologies, I regress daily bond returns on the changes in the liquidity, core business performance, equity base, and asset quality ratio, the event windows itself, and the interactions between the ratios and the window intervals. The results provide evidence that a substantial portion of the core business performance, equity base, and liquidity information gets impounded into bond prices on the $10-\mathrm{K}$ filings announcement window.

\subsection{Debt markets and accounting signals}

\subsubsection{Debt market characteristics}

Financial institutions as well as corporates have to decide among different funding opportunities, including internal funding through cash flows and taking on additional debt or issuing equity securities, when investing in new projects with a positive net present value. Equity and institutional debt investors potentially have different informational needs attributable to their investments' different payoff functions. Given their convex payoff function, equity investors are willing to take on more risk than debtholders. Equity holders' claim to the company can be seen as holding a call option whereas the option is in the money when the value of the firm exceeds its debt (principal which has to be paid back to debt holders). In contrast, bond holders are faced with a concave payoff function giving them priority of payment when the firm value is equal to or smaller than the debt inherent in the respective company.

When analyzing annual financial statements, both equity and bond investors use accounting information from different sources, such as the statement of financial position, income statement, and cash flow statement. Investigating the relative usefulness of accounting signals from these different statements, prior research finds evidence that equity investors shift their focus from earnings as reported in the income statement to book values as reported in the statement of financial position when firms' financial health deteriorates (Barth et al. 1996, Collins et al. 1997). This is in line with 
accounting theory contemplating balance sheet net tangible assets as a proxy for a firms' liquidation value (Jensen and Meckling 1976).

Given their concave payoff function, debt market investors in the primary and secondary bond market should potentially be interested in the liquidation value of their investment portfolio during non-financial crisis periods. Accounting signals about the future cash generating ability or "earning power" appear to be of secondary importance to debtholders, at least during periods in which there is no general doubt about banks' going concern. Thus, attributable to the asset substitution and underinvestment conflict (Myers 1977, Smith and Warner 1979), debt holders demand balance sheet information about the firm's net assets informatory about the liquidation value (Kothari et al. 2009). As firm values deteriorate during periods of severe financial distress, as witnessed during the "Great Recession"11, financial institutions' equity cushions to absorb unexpected losses declined significantly and were no longer regarded as sufficient. When firm values of financial institutions decline rapidly, debtholders potentially shift their focus in contrast to equity investors in the opposite direction from book value ratios related to liquidity, equity base, and asset quality to "earning power" related ratios because these indicate whether the equity cushion to absorb losses can gradually be reinforced through internal financing capabilities.

According to research in finance, prices of debt instruments in the secondary bond market are mainly driven by market interest rates. ${ }^{12}$ As such, a decline in the market interest rates will lead to an increase of outstanding bond prices, and vice versa. In addition to market interest rates, bond prices are also determined by other variables including non-interest rate risk factors. Hull et al. (2004) investigate risk-neutral and real-world default probabilities of corporate bonds exhibiting different credit ratings and shed light on factors relevant to investors for estimating the extra risk premium. Technically, the extra risk premium measured in basis points is equal to the bond yield spread over the treasury rate minus the spread of the risk-free rate used by market participants above the treasury rate and the spread to adjust for the real world default. Hull et al. (2004) also provide explanations for the average risk premium required by bond holders. Factors examined by debt market investors include liquidity, market participants' expectations, non-diversifiable, and diversifiable risk factors. ${ }^{13}$ With regard to liquidity, Chen et al. (2007) provide evidence that this factor is priced in by investors for both investment grade and speculative grade bonds. ${ }^{14}$ Furthermore, other factors such as default risk, the risk of a downgrade, and reinvestment risk could potentially be relevant to bond holders. Credit risk is inherent in almost all forms of debt instruments and simply the threat to a borrower that the respective bond issuer is unable to fulfill its

\footnotetext{
11 The recent GFC is also referred to as the "Great Recession".

12 Both raw and risk-adjusted bond returns using treasury securities with the same maturity are used in this study to control for the impact of varying market interest rates.

13 According to Amato and Remolona (2003), risks in a bond portfolio are problematic to diversify away because of the concave payoff function bond holders are exposed to.

${ }^{14}$ Liquidity risk mainly arises in a secondary bond market with only a few market participants (thin market).
} 
contractual obligations in form of future payments. Thus, bond investors require a higher rate of return for higher default risk levels in bond issuers. Longstaff et al. (2005) provide evidence that corporate bond spreads are to a large extent driven by credit risk information provided through the credit default swap (CDS) market.

To which extent bond holders use financial statement information of financial institutions related to changes in asset quality, liquidity, core business performance, and equity base to investigate the required average risk premium is an underexplored research area. Especially in situations where financial capital markets are illiquid and not transparent, as witnessed in the GFC, bond investors could potentially rely less on credit, liquidity, and market risk information signaled through channels other than annual certified financial statements, including press releases, prospectuses, credit ratings, CDS spreads, and market sentiment. In particular, credit rating agencies instead of reducing information asymmetries between insiders and the capital markets seem to have impaired transparency and make markets even more opaque.

\subsubsection{Accounting signals related to the CAMEL framework}

Research in the debt market (Hull et al. 2004, Longstaff et al. 2005, and Chen et al. 2007) provides evidence that several factors determine bond prices including the issuers' sensitivity to market risks as well as liquidity, operational, and default risk of the issuer. ${ }^{15}$ In capturing these different determinants of bond prices through accounting signals, I use four financial ratios related to four of the five categories from the CAMEL framework. The rational for using these categories relies on the intuition that bondholders potentially rely to a lesser extent on regulatory agencies' private information and stringent examination procedures during bank crisis periods and thus try to mimic bank regulators' CAMEL decision processes and estimate a banks' stability by utilizing accounting signals related to asset quality, liquidity, equity base, and core business performance from the certified annual financial statements.

CAMEL has been established by the Uniform Financial Institutions Rating System in the United States in 1979 and serves as a directive for federal bank regulatory agencies when evaluating the financial condition and performance of financial institutions (Putnam 1983, Cole and Gunther 1995).16 I use insights from this framework to investigate whether four accounting ratios related to the CAMEL framework - ratios related to capital adequacy (equity base), asset quality, earnings quality ("earning power"), and liquidity - are value relevant to investors in the financial institutions' bond market during periods with and without transparent and liquid markets. ${ }^{17}$ Furthermore,

\footnotetext{
15 Information in terms of sensitivity to market risks as well as liquidity, operational, and default risk of the issuer is reflected in the individual credit ratings, as credit rating agencies incorporate idiosyncratic private issuer and market-based information in their stringent rating approval process.

${ }^{16}$ Appendix C illustrates the current U.S. bank regulatory regime.

17 This study ignores management quality which is also used by Federal Bank Regulatory Agencies when examining financial institutions. Management quality refers to a set of managers' abilities including
} 
I shed light on whether bond prices anticipate these ratios before accounting information is published on the fourth quarter preliminary earnings announcement date and the 10-K filings announcement date during financial crisis periods.

According to the Federal Deposit Insurance Company (FDIC), asset quality is an important indicator for investors evaluating the overall condition and robustness of a financial institution against an existing and potential decline of value in the financial assets, especially the quality of the performing and non-performing part of the loan portfolio. ${ }^{18}$ In this study I measure a financial institution's asset quality through the annual changes in the ratio of loan loss reserves to gross loans ( $\triangle A$ Quality). This ratio measures the quality of a banks' individually and collectively assessed loan portfolio. An increase in the ratio signals deterioration in the performing part of the financial assets included in the overall loan portfolio.

The capital adequacy (equity base) ratio measures a financial institutions' leverage and the ability to absorb expected and unexpected losses. To get a measure which informs about the equity cushion available to absorb losses in the individually and collectively assessed loan portfolio books, I use the changes in the ratio of equity to net loans (ACAdequacy). Whereas tier-1 and tier-2 capital ratios, as required by bank regulatory agencies, are a more narrow measure, equity available to absorb overall loan book losses used in this study includes total equity reserves, total share capital, and treasury shares. ${ }^{19}$ Net loans comprise net loans to banks, credit unions, private customers, small businesses and multinational corporations. Overall, a decline in the equity to net loans ratio informs investors about a lower protection available to financial institutions to cover loan losses.

A financial institution is considered "liquid" if its asset and liability management strategy achieves a term structure match between the entity's assets and liabilities. In other words, illiquidity refers to a situation in which financial institutions are not able to obtain additional funding (funding liquidity risk) either by taking on more debt or transforming financial assets into cash and cash equivalents (asset liquidity risk). During severe financial crises, a bank run for example would lead to a situation where deposit withdrawals by customers and corporate clients translate into large cash outflows leaving the bank unable to service its debt. The FDIC released a financial institutions letter in August 2008 stressing the importance of liquidity management especially during disruptions as seen in the recent credit and capital markets crisis. ${ }^{20}$ In this study, I capture the extent to which financial institutions are liquid through the changes in the ratio of net loans to total assets ( $\Delta$ Liquidity). This ratio measures the extent to which the assets of a bank are bound to the individually and collectively assessed loan portfolio. An annual increase in this ratio informs investors about a financial institution having

\footnotetext{
technical competence, leadership qualities, and flexibility to respond to a changing environment.

18 http://www.fdic.gov/regulations/safety/manual/section3-1.html

19 Tier-1 capital is a bank regulatory required disclosure that captures a bank's core capital and nonredeemable non-cumulative preferred stock. This measure is strongly correlated with $\Delta$ CAdequacy, which better reflects the business model of the commercial banks included in this study.

20 http://www.fdic.gov/news/news/financial/2008/fil08084.html
} 
proportionately less short-term assets and cash and cash equivalents available to service its debt.

Most stakeholders in financial institutions and corporates focus on the core business performance when evaluating their individual investments and rebalancing their security portfolio. Core business performance ratios measure a bank's profitability and show how effectively a bank carries out its asset and liability management strategy in form of how efficiently financial assets are used to generate net income. In this study, I use the changes in the ratio of return to average assets ( $\triangle E A$ Ability) as comprehensive measure of core business performance. Based on the assumption that a financial institution keeps a similar risk appetite and strategy from year to year, an increase in this ratio informs about banks being more profitable in the core business lines.

\subsubsection{Transparency-stability vs. transparency-fragility view}

Transparency of and mandated disclosures in the banking sector have been widely discussed among bank regulatory bodies and academics. Proponents of the so-called transparency-stability view (Cordella and Yeyati 1998; Nier 2005; Tadesse 2006) argue that enhanced disclosure requirements contribute to the stability of the banking system. Conversely, discovery of an individual bank's financial weakness may infect the entire banking system (Calomiris and Mason 1997; Chen and Hasan 2006; Gilbert and Vaughan 1998; Goldstein and Sapra 2012; Kaufman 1994), and probably jeopardizes overall economic stability. For example, Goldstein and Sapra (2012) argue that "disclosure of stress test results may actually create more panic, thereby lowering confidence in the banking sector". From a bank regulatory standpoint and according to the transparencyfragility view, greater transparency in terms of greater disclosure and more precise information signals may be seen as a threat to the entire banking system, especially during financial crisis periods. In this study I argue that the bank regulatory certification process probably detected financial weaknesses in individual banks during the recent financial crisis, but has been aware of the negative consequences if these weaknesses were disclosed to the financial market. Press releases on individual banks could have caused contagion and spillover effects within the banking sector. Hence, bond investors may consider information revealed through bank regulatory agencies to be less credible, especially during the recent financial crisis. Thus, institutional bond holders in the financial sector probably prefer accounting signals related to the CAMEL framework of the U.S. Federal Bank Regulatory Agencies to supplement other, arguably less credible, information during financial crisis periods.

\subsection{Prior research}

Prior research on the importance of 'earning power' and book value related accounting signals focuses primarily on the equity market. Regarding different information needs of investors, Barth et al. (1998) provide evidence that a shift in investors' focus from 
earnings information to book values is observable for firms that are deteriorating in financial health. With regard to research on the value relevance of accounting signals, especially in the banking sector, Venkatachalam (1996) examines fair value disclosures for derivatives mandated by SFAS No. 119, and provides evidence that such information impacts stock prices of financial institutions. Barth et al. (1996) also shed light on the value relevance of financial instrument fair values for equity investors disclosed under SFAS No. 107. Through examining loan loss provisions of financial institutions, Ahmed et al. (1999) find a negative effect of such provisions' discretionary component on equity returns. Furthermore, Ahmed et al. (2006) investigate banks' recognized and disclosed SFAS 133 derivatives information. They show that recognized derivatives are relevant in explaining firm value. Hatfield and Lancaster (2000) focus on the signaling effects of bank loan-loss reserve additions, and find equity market reactions to the announcements of such additions. They conclude that increases in loan loss reserves are associated with negative equity price movements before the announcement, which reverse a few days after the news release. Additionally, Wahlen (1994) examines disclosures related to non-performing loans, loan loss provisions, and loan charge-offs. He presents evidence that managers intentionally inflate the discretionary component of loan loss provisions when they anticipate increased future cash flows.

Research literature on the value relevance of accounting signals for debt market investors in both the primary and secondary bond market is growing rapidly (i.e. Khurana and Raman 2003, Easton et al. 2009, DeFond and Zhang 2011, Amiram and Owens 2011). However, whether the impact of accounting ratios related to 'earning power' and book value on bond returns differs during financial crisis and non-financial crisis periods is still an under-explored research area. Khurana and Raman (2003) present evidence that fundamentals are value relevant to investors in the primary bond market, and thus provide information not captured in published bond ratings. Further, Easton et al. (2009) provide initial evidence on the value relevance of accounting earnings in the bond market. They conclude that bond prices react to the announcement of earnings, and find that annual bond returns are on average positively associated with annual changes in earnings and earnings components.

As debt holders are faced with a non-linear payoff function, macro-economic factors possibly influence the information set used by debt holders to revise and update their investment decisions. During a bull market, in which firm values on average increase, the information content of earnings and earnings components possibly declines from a debt holder's point of view as the creditworthiness of individual firms is less relevant. On the contrary, firms are closer to debt covenant violations during financial distress periods, and hence, debt holders potentially demand information with regard to a firm's financial position, including information on the internal financing strength. Overall, the aim of this study is to extend prior findings in the debt market and to explore the sensitivity of the value relevance of accounting information to macroeconomic scenarios which are linked to the asymmetric payoff function of bond holders. 


\subsection{Hypotheses}

\subsubsection{Cumulative monthly bond return analysis}

2.4.1.1 Association between cumulative monthly bond returns and ratios related to the CAMEL framework

Addressing differential information needs of investors, prior research in the corporate equity market provides evidence that a shift from earnings information to book values is observable for firms deteriorating in financial health (Barth et al. 1998). Although research literature on the value relevance of accounting signals for debt market investors in both the primary and secondary bond market is growing rapidly (i.e. Khurana and Raman 2003; Easton et al. 2009; DeFond and Zhang 2011; Amiram and Owens 2011), it is not clear whether the impact of accounting ratios related to 'earning power' and book value on bond returns differs during financial crisis and non-financial crisis periods.

As such, I investigate whether accounting information related to a bank's performance and financial position is associated with bond returns during the GFC period. Bond investors may free-ride on regulatory certification in 'good' times but prefer accounting signals related to the CAMEL framework of the U.S. Federal Bank Regulatory Agencies, that is, capital adequacy, asset quality, earnings ability, and liquidity, to other less credible information during bank crisis periods (including credit ratings).

More specifically, I examine whether changes in financial indicators related to core business performance ( $\triangle E A$ Ability), equity base ( $\triangle C A$ Adequacy), liquidity ( $\Delta$ Liquidity), and asset quality ( $\triangle A Q$ uality), are associated with annual cumulative bond returns in a GFC and non-GFC setting. I test the following hypothesis ${ }^{21}$ :

Hypothesis 1a: $\quad$ Banks' annual bond returns are associated with annual changes in ratios related to 'earning power' (Core performance ratio: $\triangle E A b i l i t y)$ during the recent financial crisis period (April 2007 - March 2009).

Hypothesis 1b: $\quad$ Banks' annual bond returns are associated with annual changes in ratios related to 'book values' (Equity base: $\triangle$ CAdequacy / Liquidity: $\Delta$ Liquidity / Asset quality: $\triangle A Q$ uality) during the recent financial crisis period (April 2007 - March 2009).

\footnotetext{
${ }^{21}$ The hypotheses are split into $1 \mathrm{a}$ and $1 \mathrm{~b}$ to stress the different sources of the variables. Core performance information is based on the income statement whereas equity base, liquidity, and asset quality are based on information retrieved from the statement of financial position.
} 


\subsubsection{Anticipation of financial indicators related to the CAMEL framework}

In addition to assessing accounting signals from quarterly and certified annual financial statements, bond investors may use several other sources of timely information including but not limited to prospectuses, derivative markets, press releases, and credit ratings. These information channels could provide relevant and timely information to bond investors, and mitigate the importance of accounting variables in the investment evaluation process. Thus, in addition to analyzing the association between ratios related to the CAMEL framework and bond returns, I investigate whether bond prices lead/anticipate the annual changes in the ratios related to asset quality ( $\triangle A Q$ uality), core business performance ( $\triangle E$ EAbility), liquidity ( $\triangle$ Liquidity), and equity base ( $\triangle C A d e q u a c y)$ during non-bank and bank crisis periods. I test the following hypothesis:

Hypothesis 2: $\quad$ During the recent bank crisis period (April 2007 - March 2009), banks' cumulative monthly bond returns are more strongly associated with annual changes in ratios related to the CAMEL framework in the month of the financial statements' public release than in previous months.

2.4.1.3 Relative importance of preliminary earnings and 10-K filing announcements for investors in the debt market

Although the association studies provide evidence on the relationship between annual cumulative bond returns and accounting signals related to liquidity, asset quality, core business performance, and equity base in the month of the $10-\mathrm{K}$ filing public release, one cannot draw causal inferences over such a long time period because other timely and relevant information potentially enters into the decision-making process. Other information channels include but are not limited to prospectuses, derivative markets, press releases, conference calls, and credit ratings. These information channels could provide relevant and timely information to bond investors, mitigating the importance of accounting variables in the investment evaluation process. In a first step to address causal inferences, I examine the relative importance of preliminary earnings and $10-\mathrm{K}$ filing announcements for investors in the debt market by regressing each individual event window return on the annual bond return (similar to Ball and Shivakumar 2008). I test the following hypothesis:

Hypothesis 3: $\quad$ Short-window bond returns centered on the $10-K$ filing announcement dates are more strongly associated with banks' 
annual bond returns than short-window bond returns centered on the preliminary earnings announcement dates during the recent financial crisis (April 2007 - March 2009).

\subsubsection{Daily bond return analysis}

In addition to testing the association of event window bond returns with annual bond returns, I conduct a daily bond return analysis to investigate the importance of accounting signals. The return-on-return regression design (borrowed from Ball and Shivakumar, 2008) addresses the relevance of the individual event windows for the daily bond returns, but does not specifically test the value relevance of changes in financial indicators related to asset quality, liquidity, equity base, and core business performance for bond holders. The recent financial crisis from April 2007 to March 2009 provides a perfect setting to test whether accounting information related to the CAMEL framework enters, if at all, into the decision-making process of investors holding a portfolio of debt instruments in financial institutions. Thus, to draw causal inferences, I test the following hypothesis:

Hypothesis 4: $\quad$ Changes in banks' financial indicators related to the CAMEL framework are value relevant for bond holders only during the recent financial crisis period (April 2007 - March 2009).

\subsection{Methodology, research design, and sample selection}

\subsubsection{Perfect foresight portfolio strategy}

This section derives the regression approach for constructing the zero investment portfolio bond returns (Fama and McBeth 1973; Bernard and Thomas 1990). A zeroinvestment portfolio implies a zero net value because the inherent long and short positions offset each other. Under a perfect foresight portfolio strategy both information not yet publicly available and publicly available information is regressed on the dependent variable. This approach reveals insights on whether specific variables anticipate the information content of some regressors although the information is not yet published through financial statements. Given is a linear function of the expected abnormal bond return (BR) of a reference firm $i$ and the decile ranked accounting information signals (AS1 and AS2), beta risk ( $\beta$ ) and intercept:

$$
E\left(B R_{i}\right)=\gamma_{1}+\gamma_{2} A S 1_{i}+\gamma_{3} A S 2_{i}+\gamma_{4} \beta_{i}
$$


To derive the return to any bond investment portfolio (p) of $\mathrm{n}$ firms, a firm-specific portfolio weight $\left(\mathrm{w}_{\mathrm{jp}}\right)$ needs to be introduced:

$$
\begin{aligned}
& E\left(B R_{p}\right) \\
& =\sum_{i=1}^{n} w_{i p} E\left(B R_{i}\right) \\
& =\gamma_{1} \sum_{i=1}^{n} w_{i p}+\gamma_{2} \sum_{i=1}^{n} w_{i p} A S 1_{i}+\gamma_{3} \sum_{i=1}^{n} w_{i p} A S 2_{i}+\gamma_{4} \sum_{i=1}^{n} w_{i p} \beta_{i}
\end{aligned}
$$

Portfolio weights are chosen so that the following constraints are in place when testing whether accounting information signals (AS1 and AS2) can earn abnormal returns:

Accounting signal 1 portfolio (AS1)

Accounting signal 2 portfolio (AS2)

$$
\begin{array}{ll}
\sum w_{i 2}=0 & \sum w_{i 3}=0 \\
\sum w_{i 2} A S_{1}=1 & \sum w_{i 3} A S_{1}=0 \\
\sum w_{i 2} A S_{2}=0 & \sum w_{i 3} A S_{2}=1 \\
\sum w_{i 2} \beta_{i}=0 & \\
\text { results } & \sum w_{i 3} \beta_{i}=0 \\
E\left(B R_{2}\right)=\gamma_{2} & \text { in: } \begin{array}{l}
\text { results } \\
E\left(B R_{3}\right)=\gamma_{3}
\end{array}
\end{array}
$$

Constructing portfolio weights under these constraints results in a zero-investment portfolio as the long positions (purchases) and short positions (sales) balance. Furthermore, the zero-investment portfolio has a beta risk of zero which implies that the portfolio does not include systematic risk. Finally, under the above constraints the abnormal bond returns only reflect information of one of the two accounting signals.

Using ordinary least square (OLS) portfolio weights to test the perfect foresight portfolio strategy results in: 


$$
B R_{i}=\gamma_{1}+\gamma_{2} A S 1_{i}+\gamma_{3} A S 2_{i}+\gamma_{4} \beta_{i}+\varepsilon \quad, i=1,2, \ldots \ldots, n
$$

Equation (5) expressed in matrix notation gives:

$$
\left[\begin{array}{c}
B R_{1} \\
\vdots \\
\vdots \\
\vdots \\
\vdots \\
B R_{n}
\end{array}\right]=\left[\begin{array}{cccc}
1 & A S 1_{1} & A S 2_{1} & \beta_{1} \\
\vdots & \vdots & \vdots & \vdots \\
\vdots & \vdots & \vdots & \vdots \\
\vdots & \vdots & \vdots & \vdots \\
\vdots & \vdots & \vdots & \vdots \\
1 & A S_{n} & A S 2_{n} & \beta_{n}
\end{array}\right] *\left[\begin{array}{c}
\gamma_{1} \\
\gamma_{2} \\
\gamma_{3} \\
\gamma_{4}
\end{array}\right]+\left[\begin{array}{c}
\epsilon_{1} \\
\vdots \\
\vdots \\
\vdots \\
\epsilon_{n}
\end{array}\right] \text { or } \mathbf{R}=\mathbf{X} \gamma+\varepsilon
$$

$\gamma$ can be further written as (under OLS assumptions): $\gamma=\left(\mathrm{X}^{\prime} \mathrm{X}\right)^{-1} \mathrm{X}^{\prime}(\mathrm{BR})$

$$
\text { Defining } \mathbf{W}=\left(\mathbf{X}^{\prime} \mathbf{X}\right)^{-1} \mathbf{X}^{\prime} \text { results in } \gamma=\mathrm{W}(\mathrm{BR})
$$

Thus, it can be equated:

$$
\gamma_{p}=\sum_{i=1}^{n} w_{i p} B R_{i} \quad, p=1,2,3,4
$$

where $\gamma_{p}$ equals the portfolio return and $\mathrm{w}_{\mathrm{ip}}$ equals firm's i portfolio weight and coincides with the estimated coefficient from the OLS regression.

As a result, the regression of bond returns on accounting information signals provides coefficients which reflect the contribution of each single independent variable to the overall return of the zero investment portfolio strategy. Attributable to the portfolio constructions the individual return contribution of each regressor is not biased by the existence of other accounting information signals in the regression.

The following derivation provides insights into the portfolio return $\gamma_{p}$ :

$$
\mathbf{W X}=\left(\mathbf{X}^{\prime} \mathbf{X}\right)^{-1} \mathbf{X}^{\prime} \mathrm{X}=\mathbf{I}
$$

Equation (10) expressed in vector notation gives:

$$
\left[\begin{array}{cccc}
w_{11} & \ldots & \ldots & w_{1 n} \\
w_{21} & \ldots & \ldots & w_{2 n} \\
w_{31} & \ldots & \ldots & w_{3 n} \\
w_{41} & \cdots & \ldots & w_{4 n}
\end{array}\right] *\left[\begin{array}{cccc}
1 & A S 1_{1} & A S 2_{1} & \beta_{1} \\
\vdots & \vdots & \vdots & \vdots \\
\vdots & \vdots & \vdots & \vdots \\
\vdots & \vdots & \vdots & \vdots \\
1 & A S 1_{n} & A S 2_{n} & \beta_{n}
\end{array}\right]=\left[\begin{array}{cccc}
1 & 0 & 0 & 0 \\
0 & 1 & 0 & 0 \\
0 & 0 & 1 & 0 \\
0 & 0 & 0 & 1
\end{array}\right]
$$


From equation (11) the following key properties can be identified:

$$
\begin{array}{llll}
\sum w_{i p} & \sum w_{i p} A S 1_{i} & \sum w_{i p} A S 2_{i} & \sum w_{i p} \beta_{i}
\end{array}
$$

Furthermore, the desired properties in (12) are in line with the constraints as shown in (3a), (3b), (3c), (3d), and (4):

$$
\begin{aligned}
& \mathrm{p}=1 \quad \mathrm{p}=2 \quad \mathrm{p}=3 \quad \mathrm{p}=4 \\
& \sum w_{i 1}=1 \quad \sum w_{i 2}=0 \quad \sum w_{i 3}=0 \quad \sum w_{i 4}=0 \\
& \sum w_{i 1} A S 1_{i}=0 \quad \sum w_{i 2} A S 1_{i}=1 \quad \sum w_{i 3} A S 1_{i}=0 \quad \sum w_{i 4} A S 1_{i}=0 \\
& \sum w_{i 1} A S 2_{i}=0 \quad \sum w_{i 2} A S 2_{i}=1 \quad \sum w_{i 3} A S 2_{i}=1 \quad \sum w_{i 4} A S 2_{i}=0 \\
& \sum w_{i 1} \beta_{i}=0 \quad \sum w_{i 2} \beta_{i}=0 \quad \sum w_{i 3} \beta_{i}=0 \quad \sum w_{i 4} \beta_{i}=1 \\
& \gamma_{1 t}=\sum w_{i 1} B R_{i t} \quad \gamma_{2 t}=\sum w_{i 2} B R_{i t} \quad \gamma_{3 t}=\sum w_{i 3} B R_{i t} \quad \gamma_{4 t}=\sum w_{i 4} B R_{i t}
\end{aligned}
$$

\subsubsection{Research design}

For the cumulative monthly bond return analysis, I use the above explained perfect foresight investment strategy (Fama and Macbeth 1973, Abarbanell and Bushee 1998) constructing zero-investment portfolios. Cumulative monthly bond returns are calculated for the 9 months leading and the 3 months following the fiscal-year end of the respective financial institution, and are regressed on the decile-ranked changes in the ratios related to asset quality, liquidity, equity base, and core business performance. ${ }^{22}$ The research design provides insights into the extent to which bond prices lead (anticipate) these fundamental accounting signals. As mentioned earlier, the application of the above described zero-investment hedge strategy provides the researcher with regression coefficients that can be interpreted as each regressor's contribution to the total bond return of the hedge portfolio. To test hypotheses $1 \mathrm{a}, 1 \mathrm{~b}$, and 2 , I estimate the

22 Monthly and daily realized bond returns are calculated as the change in bond price (cum accrued interest) plus coupon payments made during the return interval, scaled by the bond price at the start of the return interval. Using risk-adjusted returns instead of raw returns provides similar results (Easton et al. 2009). 
following regression equation for both the financial crisis and non-financial crisis periods (see Figure 2.1):

$$
\begin{aligned}
\text { Cumret }_{N t}= & \beta_{0}+\beta_{1} \Delta \text { CAdequacy }+\beta_{2} \Delta \text { Liquidity }+\beta_{3} \Delta E \text { Ability }+\beta_{4} \Delta \text { AQuality } \\
& +\beta_{5} \Delta \text { CRating }+\varepsilon
\end{aligned}
$$

where, Cumret $_{N, t}$ is the cumulative monthly bond return for the 9 month leading to and the 3 months following the fiscal-year end, $\Delta C$ Adequacy is the decile-ranked change in the equity to net loans ration, $\Delta$ Liquidity is the change in the net loans to total assets ratio, $\triangle E A b i l i t y$ is the change in return on average assets, $\triangle A Q u a l i t y$ is the change in the loan loss reserves to gross loans ratio, and $\triangle$ CRating is the change in the weightedaverage credit rating provided by Standard and Poor's, Fitch, and Moody's.

Instead of running analyses for the separate individual periods, the following regressions reveals the same results using the pooled dataset and including an optionadjusted spread that identifies the period of the recent recession in the U.S and is interacted with the main effects ${ }^{23}$ :

$$
\begin{aligned}
\text { Cumret }_{N t}= & \beta_{0}+\beta_{1} \Delta \text { CAdequacy }+\beta_{2} \Delta \text { Liquidity }+\beta_{3} \Delta E \text { Ability }+\beta_{4} \Delta \text { AQuality } \\
& +\beta_{5} \Delta C \text { Rating }+\beta_{6} O A S+\beta_{7} \Delta C \text { Adequacy* OAS }+\beta_{8} \Delta \text { Liquidity* OAS } \\
& +\beta_{9} \Delta E \text { Ebility* } O A S+\beta_{10} \Delta \text { AQuality* OAS }+\beta_{11} \Delta C \text { CRating*OAS }+\varepsilon
\end{aligned}
$$

$O A S$ is an indicator variable that equals one if the Bank of America (BofA) Merill Lynch Option-Adjusted Spread (OAS) is above 2 percentage points for at least 6 months per specific firm-year observations (FED St. Louis 2013). ${ }^{24}$ Considering the annual cumulative bond return construction, Figure 2.1 shows that OAS equals one for firmyear observations during the recent GFC and zero in the period preceding the GFC.

In addition to testing associations between bond returns and ratios related to the CAMEL framework, I conduct an analysis addressing the relative importance of preliminary earnings and $10-\mathrm{K}$ filing announcements for investors in the debt market, and the value relevance of ratios related to asset quality, liquidity, core business performance, and equity base using event study methodologies.

\footnotetext{
23 The drawback of using regression equation (19) that includes the interaction terms is the impracticality to interpret the relative contribution of the individual financial ratios related to the CAMEL framework to the overall return of the zero investment hedge strategy. Running separate regressions for the GFC and non-financial crisis period using equation (18) provides this information which is used to construct the overall cumulative bond return contribution (see section 2.5.1 perfect foresight portfolio strategy).

24 Option-adjusted spreads are based on economic research of the Federal Reserve Bank of St. Louis (2013) and are constructed using an investment-grade bond index that is corrected for market capitalization and the corresponding treasury rate. Premiums above 2 percentage points reflect financial distress and liquidity in the underlying financial market.
} 
First, I test the relative importance of preliminary earnings and $10-\mathrm{K}$ filing announcements for investors in the debt market by regressing the annual bond returns on short event window returns centered on the preliminary earnings announcement and $10-\mathrm{K}$ filing dates:

$$
A B R=\gamma_{0}+\gamma_{1} R q_{1} q_{3}+\gamma_{3} R q_{4}+\gamma_{4} R \sec +\varepsilon
$$

where, $A B R$ denotes the annual bond return of the respective sample (i.e., financial crisis vs. non-financial crisis), $R q_{1} q_{3}$ the short event window return centered on the preliminary earnings announcement of quarter 1 to quarter $3, R q_{4}$ the short event window return centered on the preliminary earnings announcement of quarter 4 , and Rsec the short event window return centered on the $10-\mathrm{K}$ filing dates. ${ }^{25}$

FIGURE 2.1: Bank of America (BofA) Merill Lynch Option-Adjusted Spreads (OAS) from January 1996 to March 2013 (Source: Federal Reserve Bank St. Louis).

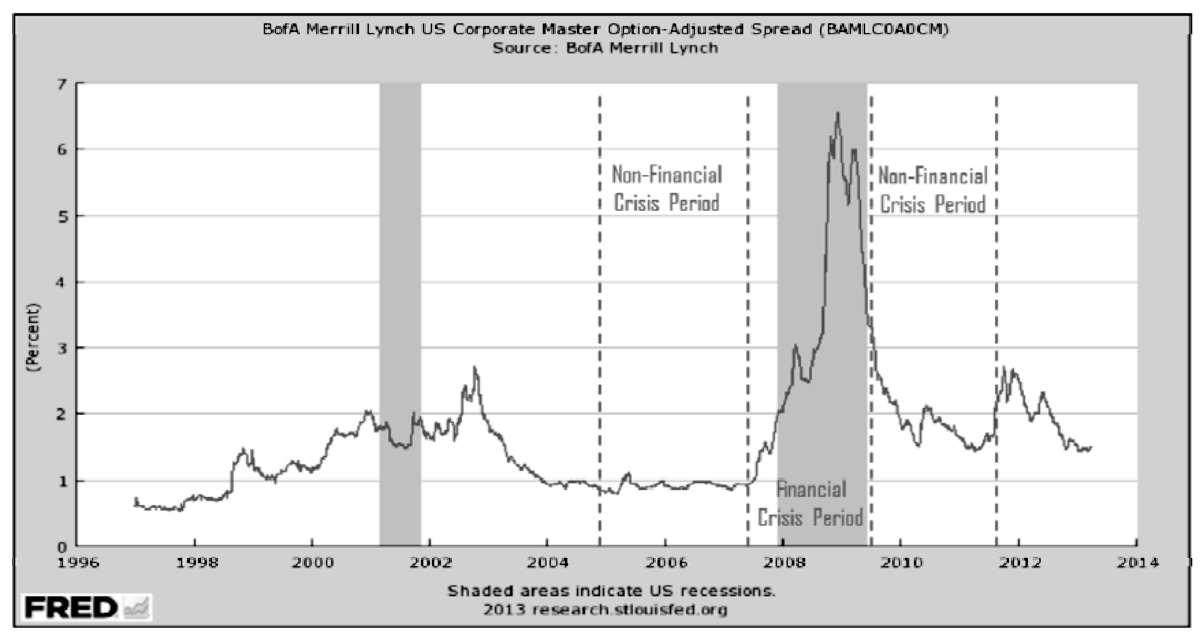

Second, I conduct an event study utilizing short-term windows centered on the 10$\mathrm{K}$ filing announcement date and the four preliminary earnings announcement dates. This is done to draw causal inferences on the impact of signals related to core business performance, asset quality, liquidity, and capital adequacy on daily bond returns. More specifically, I regress daily bond returns on the changes in the liquidity, core business performance, equity base, and asset quality ratio, the event windows itself, and the interactions between the ratios and the window intervals. As the financial ratios included in the regression stem from a bank's accounting system and are annual figures

25 The short-window returns in the first, second, and third quarter are individually regressed on the annual bond returns. As the regression with the aggregated returns (Rq1q3) reveals identical results, equation (20) is shown in the aggregated form. 
in nature, I only expect the interaction term with the window interval in which the information is revealed to explain the variation in the daily bond returns. If preliminary information at the quarterly announcement were significant, the financial reporting information would be anticipated before it is made publicly available. Thus, significant interaction terms including the SEC-reporting window reflect the value relevance of the individual financial ratios for bond holders:

$$
\begin{aligned}
& D B R=\delta_{0}+\delta_{1} \Delta E A \text { Aility }+\delta_{2} \Delta \text { AQuality }+\delta_{3} \Delta \text { Liquidity }+\delta_{4} \Delta C \text { Adequacy } \\
& \delta_{5} q 1 q 3 \text { _win } 15+\delta_{6} q 4 \_w i n 15+\delta_{6} \text { sec_win } 15 \\
& \delta_{11} q 1 q 3 \text { _win } 15 \times \Delta E \text { Ability }+\delta_{12} q 4 \text { _win } 15 \times \Delta E \text { Ability }+\delta_{13} \mathrm{sec} \_w i n 15 \times \Delta E \text { Ability } \\
& \delta_{21} q 1 q 3 \text { _win } 15 \times \Delta \Delta \text { AQuality }+\delta_{22} q 4 \text { _win } 15 \times \Delta \text { AQuality }+\delta_{23} \sec \_ \text {win } 15 \times \Delta \text { AQuality } \\
& \delta_{31} q 1 q 3 \text { _win } 15 \times \Delta \text { Liquidity }+\delta_{32} q 4 \_ \text {win } 15 \times \Delta \text { Liquidity }+\delta_{33} \mathrm{sec} \_ \text {win } 15 \times \Delta \text { Liquidity } \\
& \delta_{41} q 1 q 3 \_ \text {win } 15 \times \Delta C \text { Adequacy }+\delta_{42} q 4 \_ \text {win } 15 \times \Delta C \text { Adequacy }+\delta_{43} \sec \_ \text {win } 15 \times \Delta C \text { Adequacy }+\varepsilon
\end{aligned}
$$

\subsubsection{Sample selection}

This study investigates whether and to what extent bond investors in the financial institution sector use accounting signals related to the CAMEL framework of the Federal Bank Regulatory Agencies in their decision-making process during economic downturns. For the construction of monthly cumulative and daily bond returns, data are retrieved from the Trade Reporting and Compliance Engine (TRACE) and Mergent Fixed Investment Securities Database (FISD) database. FISD comprises information on pricing and trade terms of debt instrument starting in 1995. TRACE was established by the National Association of Securities Dealers (NASD) in 2002 and provides data on financial institution and corporate bonds in the U.S. secondary bond market. I use information from both TRACE and FISD database to construct the cumulative monthly and daily bond returns using trade prices (flat price) and accrued interest scaled by the respective bond price at the beginning of the return interval. The focus of this study is on bonds that are non-redeemable, non-callable, and do not have other step-up clauses or embedded derivatives. If a financial institution placed multiple bond issues, the average bond return reflects the weighted par values of the multiple issues. Data related to the CAMEL framework of Federal Bank Regulatory Agencies in the U.S. is retrieved from the Federal Reserve database and Thomson One Banker. The preliminary earnings announcement dates for the daily bond return analysis come from the Thomson One Banker database, and the SEC filing dates are manually collected from the (SEC) EDGAR $10-\mathrm{K}$ website. Merging all databases provides a sample of 272 firm-year observations for the period 2004 through 2011 and includes both two non-bank crisis windows with 183 bank-year observations and the recent bank crisis period, including 89 bank-year observations. 


\subsection{Empirical results}

\subsubsection{Descriptive analysis}

Table 2.1 presents the descriptives for the first-order-differences in the regressors related to equity base ( $\triangle$ CAdequacy), assets quality ( $\triangle A Q$ Quality), core business performance ( $\triangle E A$ Ability), and liquidity ( $\triangle$ Liquidity) for the period spanning 2004 through 2011. Table 2.2 illustrates the distribution of the annual cumulative bond return for the different time periods representing financial and non-financial crisis periods in the form of quantiles. Furthermore, the full sample of annual cumulative bond returns is also provided.

TABLE 2.1: Descriptive statistics of the differences in the financial ratios related to the CAMEL framework

\begin{tabular}{lcccccc}
\hline \multicolumn{1}{c}{ Variable } & $\mathrm{N}$ & Mean & Median & Max & Min & $\begin{array}{c}\text { Standard } \\
\text { Deviation }\end{array}$ \\
\hline$\Delta$ AQuality (not ranked) & 272 & 0.0022 & 0.0001 & 0.065 & -0.0230 & 0.0083 \\
ALiquidity (not ranked) & 272 & -0.0035 & 0.0000 & 0.1518 & -0.1878 & 0.0418 \\
$\Delta$ CAdequacy (not ranked) & 272 & 0.0078 & 0.0027 & 1.5963 & -1.0481 & 0.1289 \\
$\Delta$ EAbility (not ranked) & 272 & -0.0234 & -0.0005 & 0.5013 & -0.2092 & 0.0043 \\
\hline
\end{tabular}

This table reports the descriptive statistics for the changes in the regressors where $\triangle A Q u a l i t y$ refers to the changes in the loan loss reserves to gross loans ratio, $\triangle$ Liquidity to the changes in the net loans to total assets ratio, $\triangle C A d e q u a c y$ to the changes in the equity to net loans ratio, and $\triangle E A b i l i t y$ for the changes in the return on average assets ratio. The capital adequacy ( $\triangle C$ CAdequacy) ratio measures a financial institutions' leverage and the ability to absorb expected and unexpected losses. The core business performance ratio ( $\triangle E$ EAbility) measures a bank's profitability and shows how effectively a bank carries out its asset and liability management strategy in form of how efficiently financial assets have been used to generate net income. The asset quality ratio ( $\triangle A Q$ Quality) measures the quality of a banks' individually and collectively assessed loan portfolio. The liquidity ratio (4Liquidity) measures the extent to which the assets of a bank are bound to the individually and collectively assessed loan portfolio.

Justifying the split into crisis and non-crisis periods, the impact of the GFC on the banking sector is also reflected in the cumulative bond returns. Cumulative bond returns in the period from April 2004 to March 2007 show that bonds are indeed a rather secure investment in comparison to stocks, with a maximum return of $12.55 \%$, median return of $4.23 \%$, and a negative return only for $1 \%$ of the debt investment portfolio. This is in contrast to the cumulative bond return distribution during the bank-crisis period from April 2007 to March 2009. Although a maximum return of $17.69 \%$ is achieved, the median return is already $1 \%$ lower compared to the preceding non-bank crisis period. Furthermore, one quarter of the cumulative bond returns in the sample is negative and the lower decile of the distribution experiences a significant negative cumulative return of more than 10\%. With regard to the period from April 2009 to March 2011, one can clearly argue that it is a non-bank crisis period; nevertheless, the distribution of the cumulative bond returns presumably outlines a soaring debt market achieving a maximum cumulative return of $125 \%$. In addition, the median cumulative return of $9.13 \%$ is twice as high as the return of the 'normal' period from 2004 to 2006. In 
addition to the CDX distribution and the NBER definition of the GFC period, the distribution of the annual cumulative bond returns in Table 2.2 supports the decision to define the bank crisis timeframe as a period starting in April 2007 and ending in March 2009. 26

${ }^{26}$ According to the Business Cycle Dating Committee (2010) of the National Bureau of Economic Research (NBER), the recent financial crisis ("Great Recession") started in December 2007 and ended in June 2009 (http://www.nber.org/ cycles/sept2010.html). 
TABLE 2.2: $\quad$ Annual Bond Return Distribution

\begin{tabular}{lcccc}
\hline Quantile & $\begin{array}{c}\text { Period preceding } \\
\text { GFC } \\
(\mathrm{n}=95)\end{array}$ & $\begin{array}{c}\text { GFC period } \\
(\mathrm{n}=89)\end{array}$ & $\begin{array}{c}\text { Period following GFC } \\
(\mathrm{n}=88)\end{array}$ & $\begin{array}{c}\text { Full Sample } \\
\text { Period } \\
(\mathrm{n}=272)\end{array}$ \\
\hline 100\% Max & 0.1255 & 0.1769 & 1.2553 & 1.2553 \\
$99 \%$ & 0.0979 & 0.1769 & 1.2553 & 0.6541 \\
$95 \%$ & 0.0788 & 0.0773 & 0.4958 & 0.3231 \\
$90 \%$ & 0.0692 & 0.0699 & 0.3231 & 0.1918 \\
$75 \%$ Q3 & 0.0610 & 0.0551 & 0.1572 & 0.0948 \\
$50 \%$ Median & 0.0423 & 0.0321 & 0.0913 & 0.0594 \\
$25 \%$ Q1 & 0.0226 & -0.0159 & 0.0693 & 0.0306 \\
$10 \%$ & 0.0088 & -0.1379 & 0.0506 & -0.0649 \\
$5 \%$ & 0.0067 & -0.1849 & 0.0364 & -0.1379 \\
$1 \%$ & -0.0063 & -0.3822 & -0.0096 & -0.2621 \\
$0 \%$ Min & -0.0489 & -0.3822 & -0.0096 & -0.3822 \\
\hline
\end{tabular}

This table reports the distribution of the annual bond returns for the period preceding the GFC (April 2004 - March 2007), GFC (April 2007 - March 2009), and the period following the GFC (April 2009 March 2011). Bond returns are calculated as the change in bond price (cum accrued interest) plus coupon payments made during the return interval, scaled by the bond price at the start of the return interval. $\left(A_{n n R e t_{i j t}}=\frac{B P_{i j t}+A I_{i j t}-B P_{i j t-1}}{B P_{i j t-1}}\right) B P_{i j t}$ is the flat price of bond $\mathrm{i}$ of firm $\mathrm{j}$ at time $\mathrm{t}$. $\mathrm{AI}_{\mathrm{ijt}}$ denotes the accrued interest for the respective bond issue. Annual bond returns are calculated for a period that starts nine month before the fiscal year-end of the respective firm and ends three months after the fiscal year-end. Using this time frame ensures that the annual bond returns relate to the respective annual disclosures published in the certified annual reports. Individual bond issues are aggregated to firm-level bond returns by taking a value weighted-average of the bond returns. In the analysis, I use these raw returns in all of the specifications. Easton et al. (2009) report that their results are not altered if raw returns are adjusted for contemporaneous U.S. treasury rates that are subtracted from the respective raw returns.

Table 2.3a and 2.3b address multicollinearity issues among the regressors. Table 2.3a presents the correlations among the cumulative monthly bond returns (Cumret), differences in credit ratings ( $\triangle$ Rating) and differences in the ratios related to asset quality ( $\triangle A Q$ uality), core business performance ( $\triangle E A b i l i t y)$, equity base ( $\triangle C A d e q u a c y)$, and liquidity (LLiquidity). A correlation coefficient of -0.44 between the changes in the liquidity ratio and the changes in the equity base ratio attributable to the net loans component of both ratios seems to be acceptable. To mitigate concerns that the decileranked regressors artificially increase the correlations and could possibly lead to multicollinearity issues, Table 2.3b shows the Variance Inflation Factors (VIF) for both the ranked and non-ranked independent variables. These factors present the extent to which the variance of the coefficient estimates is inflated by multicollinearity. As the VIFs have values below 10, multicollinearity among the regressors is not of concern in this study. 
TABLE 2.3a: Correlations among Dependent and Independent Variables

\begin{tabular}{|c|c|c|c|c|c|c|}
\hline Variables & Cumret & $\Delta$ Rating & $\triangle A Q u a l i t y$ & $\triangle$ CAdequacy & $\Delta$ Liquidity & $\Delta$ EAbility \\
\hline Cumret & 1.0000 & & & & & \\
\hline$\Delta$ Rating (not ranked) & -0.0171 & 1.0000 & & & & \\
\hline$\triangle A Q u a l i t y$ (not ranked) & 0.0259 & 0.1462 & 1.0000 & & & \\
\hline$\triangle C$ Adequacy (not ranked) & 0.0679 & 0.0339 & 0.1370 & 1.0000 & & \\
\hline$\Delta$ Liquidity (not ranked) & -0.0927 & -0.0451 & -0.2808 & -0.4771 & 1.0000 & \\
\hline$\triangle E A b i l i t y$ (not ranked) & 0.1588 & -0.0567 & -0.3917 & 0.1916 & 0.0267 & 1.0000 \\
\hline
\end{tabular}

This table reports the Pearson correlation statistics among the cumulative monthly bond returns (Cumret), differences in credit ratings ( $\triangle$ Rating) and differences in the ratios related to asset quality ( $\triangle A Q$ Quality), core business performance ( $\triangle E A$ Ability), equity base ( $\triangle C A d e q u a c y)$, and liquidity ( $\triangle$ Liquidity). $\triangle \mathrm{AQuality}$ refers to the changes in the loan loss reserves to gross loans ratio, $\triangle$ Liquidity to the changes in the net loans to total assets ratio, $\triangle$ CAdequacy to the changes in the equity to net loans ratio, $\Delta$ EAbility for the changes in the return on average assets ratio. The capital adequacy ( $\triangle C$ CAdequacy) ratio measures a financial institutions' leverage and the ability to absorb expected and unexpected losses. The core business performance ratio ( $\triangle E A b i l i t y$ ) measures a bank's profitability and shows how effectively a bank carries out its asset and liability management strategy in form of how efficiently financial assets have been used to generate net income. The asset quality ratio ( $\triangle$ AQuality) measures the quality of a banks' individually and collectively assessed loan portfolio. The liquidity ratio (LLiquidity) measures the extent to which the assets of a bank are bound to the individually and collectively assessed loan portfolio.

TABLE 2.3b: Variance Inflation Factor (VIF) among (Ranked) Independent Variables

\begin{tabular}{lcc}
\hline \multicolumn{1}{c}{ Variable } & $\begin{array}{c}\text { Variance Inflation (VIF) } \\
\text { Not Ranked }\end{array}$ & $\begin{array}{c}\text { Variance Inflation (VIF) } \\
\text { Ranked }\end{array}$ \\
\hline Intercept & 0.0000 & 0.0000 \\
ARating & 1.0274 & 1.0053 \\
AAQuality & 1.3519 & 1.0732 \\
DLiquidity & 1.1348 & 1.2390 \\
DCAdequacy & 1.0951 & 1.2783 \\
DEAbility & 1.2803 & 1.0922 \\
\hline
\end{tabular}

This table reports the variance inflation parameter for the ranked and raw differences in credit ratings ( $\triangle$ Rating) and the ratios related to asset quality ( $\triangle A$ Auality), core business performance ( $\triangle E A b i l i t y)$, equity base $(\triangle C$ Adequacy), and liquidity ( $\triangle$ Liquidity). The capital adequacy $(\triangle C A d e q u a c y)$ ratio measures a financial institutions' leverage and the ability to absorb expected and unexpected losses. The core business performance ratio ( $\triangle E A b i l i t y$ ) measures a bank's profitability and shows how effectively a bank carries out its asset and liability management strategy in form of how efficiently financial assets have been used to generate net income. The asset quality ratio ( $\triangle A$ Quality) measures the quality of a banks' individually and collectively assessed loan portfolio. The liquidity ratio (LLiquidity) measures the extent to which the assets of a bank are bound to the individually and collectively assessed loan portfolio.

\subsubsection{Association of CAMEL ratios with annual bond returns}

Table 2.4 reports the results of the hedge portfolio investment strategy in terms of the cumulative annual bond returns. The regression coefficients reflect the association of the cumulative annual bond return with the decile-ranked changes in the ratios related to asset quality, liquidity, core business performance, and equity base. The returns 
examined in Table 2.4 are bond returns cumulated over a period of 12 months, ending three months after the fiscal year end. The results illustrate that financial institutions' changes in the ratios related to the CAMEL framework of the U.S. Federal Bank Regulatory Agencies in the non-financial crisis periods cannot explain the variation in the dependent variable, and are thus not associated with cumulative annual bond returns. On the contrary, the changes in core business performance ratio ( $\Delta$ EAbility) appear to be significantly and positively associated with the annual cumulative bond returns during the bank-crisis period. The results are robust even after the inclusion of the changes in the average credit ratings ( $\Delta$ Rating) as an additional independent variable. Furthermore, $\Delta$ Rating itself is significant and as expected negatively associated with annual bond returns.

As mentioned earlier, research literature provides evidence that equity investors are more interested in 'earning power' information than book values (liquidation value), and vice versa for firms deteriorating in financial health (Barth et al. 1998). With regard to debt investors, then, the opposite should be expected. Bond holders with their investments' limited upside potential, attributable to the instruments' inherent concave payoff function, conceivably limit their risk assessment to certified annual disclosures related to liquidity and equity base, and are less concerned with the 'earning power' and future growth opportunities in the respective investee during non-financial crisis periods. When firm values of financial institutions decline rapidly, debt holders potentially shift their focus from book value ratios related to liquidity, equity base, and asset quality to 'earning power' related ratios because these indicate whether the equity cushion to absorb losses can gradually be reinforced through internal financing capabilities.

The results in Table 2.4 support hypothesis 1a by showing that banks' annual cumulative bond returns are associated with annual changes in ratios related to 'earning power' ( $\Delta$ EAbility) during bank crisis periods (April 2007 - March 2009). Furthermore, banks' annual cumulative bond returns are not associated with $\Delta$ EAbility during the period preceding the GFC. With regard to hypothesis $1 \mathrm{~b}$, the null hypothesis that banks' annual cumulative bond returns are not associated with annual changes in ratios related to book values (Equity base: $\Delta$ CAdequacy / Liquidity: $\Delta$ Liquidity / Asset quality: $\triangle \mathrm{AQuality)}$ during non-financial crisis periods cannot be rejected. These initial results of the association study suggest that bond investors favor information related to 'earning power' during financial crisis periods. 
TABLE 2.4: Association of Annual Bond Returns with CAMEL Ratios

\begin{tabular}{|c|c|c|c|c|c|c|}
\hline \multirow{2}{*}{$\begin{array}{l}\text { Model: } \\
\text { Variables }\end{array}$} & \multicolumn{6}{|c|}{ Cumret $_{N t}=\beta_{0}+\beta_{1} \Delta C$ Adequacy $+\beta_{2} \Delta$ Liquidity $+\beta_{3} \Delta$ EAbility $+\beta_{4} \Delta$ AQuality $+\beta_{5} \Delta$ CRating $+\varepsilon$} \\
\hline & $\begin{array}{c}\text { Period } \\
\text { preceding } \\
\text { GFC } \\
\end{array}$ & $\begin{array}{c}\text { Period } \\
\text { preceding GFC }\end{array}$ & GFC & GFC & $\begin{array}{c}\text { Period } \\
\text { following GFC }\end{array}$ & $\begin{array}{c}\text { Period } \\
\text { following GFC }\end{array}$ \\
\hline $\begin{array}{l}\text { Intercept } \\
\text { (t-stat) }\end{array}$ & $\begin{array}{l}0.0508^{* * *} \\
(5.69)\end{array}$ & $\begin{array}{l}0.0090^{* * *} \\
(6.07)\end{array}$ & $\begin{array}{c}-0.0273 \\
(-0.66)\end{array}$ & $\begin{array}{c}-0.0323 \\
(-0.84)\end{array}$ & $\begin{array}{l}0.1989^{* * *} \\
(2.72)\end{array}$ & $\begin{array}{l}0.2157^{* * *} \\
(2.78)\end{array}$ \\
\hline $\begin{array}{l}\triangle E A b i l i t y \\
\text { (t-stat) }\end{array}$ & $\begin{array}{c}-0.0086 \\
(-1.03)\end{array}$ & $\begin{array}{c}-0.0107 \\
(-1.28)\end{array}$ & $\begin{array}{c}0.1006^{* *} \\
(2.42)\end{array}$ & $\begin{array}{c}0.1087^{* * *} \\
(2.75)\end{array}$ & $\begin{array}{c}0.0254 \\
(0.34)\end{array}$ & $\begin{array}{l}0.0115 \\
(0.15)\end{array}$ \\
\hline $\begin{array}{l}\triangle A Q u a l i t y \\
\text { (t-stat) }\end{array}$ & $\begin{array}{c}-0.0013 \\
(-0.16)\end{array}$ & $\begin{array}{c}-0.0049 \\
(-0.59)\end{array}$ & $\begin{array}{c}-0.0039 \\
(-0.09)\end{array}$ & $\begin{array}{c}0.0288 \\
(0.73)\end{array}$ & $\begin{array}{c}0.0594 \\
(0.87)\end{array}$ & $\begin{array}{l}0.0662 \\
(0.91)\end{array}$ \\
\hline $\begin{array}{l}\Delta \text { Liquidity } \\
\text { (t-stat) }\end{array}$ & $\begin{array}{c}-0.0038 \\
(-0.41)\end{array}$ & $\begin{array}{c}-0.0061 \\
(-0.66)\end{array}$ & $\begin{array}{c}-0.0566 \\
(-1.52)\end{array}$ & $\begin{array}{r}-0.0550 \\
(-1.53)\end{array}$ & $\begin{array}{c}-0.0772 \\
(-1.09)\end{array}$ & $\begin{array}{c}-0.0990 \\
(-1.32)\end{array}$ \\
\hline $\begin{array}{l}\triangle C A d e q u a c y \\
\text { (t-stat) }\end{array}$ & $\begin{array}{l}0.0081 \\
(-0.85)\end{array}$ & $\begin{array}{c}-0.0111 \\
(-1.18)\end{array}$ & $\begin{array}{l}0.0154 \\
(0.40)\end{array}$ & $\begin{array}{c}-0.0059 \\
(-0.16)\end{array}$ & $\begin{array}{r}-0.1157 \\
(-1.53)\end{array}$ & $\begin{array}{c}-0.1123 \\
(-1.42)\end{array}$ \\
\hline SRating & - & -0.0098 & - & $-0.135^{* * *}$ & - & -0.0783 \\
\hline (t-stat) & - & $(-1.34)$ & - & $(-4.13)$ & - & $(-0.21)$ \\
\hline
\end{tabular}

This table reports the individual coefficients and the annual cumulative bond return of the perfect foresight portfolio strategy (Abarbanell and Bushee 1998) based on the changes in the four financial ratios related to CAMEL. $\triangle A$ Quality refers to the changes in the loan loss reserves to gross loans ratio, ALiquidity to the changes in the net loans to total assets ratio, $\triangle C A d e q u a c y$ to the changes in the equity to net loans ratio, $\triangle E A b i l i t y$ for the changes in the return on average assets ratio. $\Delta$ Rating refers to the averageweighted credit ratings change provided by Standard and Poor's, Fitch, and Moody's. ALiquidity measures the extent to which the assets of a bank are bound to the individually and collectively assessed loan portfolio. An annual increase in this ratio informs investors about a financial institution having proportionately less short-term assets and cash and cash equivalents available to service its debt. $\triangle A Q u a l i t y$ measures the quality of a banks' individually and collectively assessed loan portfolio. An increase in the ratio signals a deterioration in the performing part of the financial assets included in the overall loan portfolio. $\triangle$ CAdequacy measures a financial institutions' leverage and the ability to absorb expected and unexpected losses. A decline informs investors about a lower protection available to financial institutions to cover loan losses. $\triangle E A b i l i t y$ measures a bank's profitability and show how effectively a bank carries out its asset and liability management strategy in form of how efficiently financial assets have been used to generate net income. An increase in this ratio informs about banks being more profitable in the core business lines. The time periods are defined as the period preceding the GFC (April 2004 - March 2007), GFC (April 2007 - March 2009), and the period following the GFC (April 2009 - March 2011). tvalues in parentheses are based on heteroskedasticity-robust, firm-level clustered standard errors. ${ }^{* * *},{ }^{* *}$, and $*$ denote significance at $1 \%, 5 \%$, and $10 \%$, respectively.

\subsubsection{Value relevance of ratios related to the CAMEL framework for bond holders}

Although association studies provide evidence on the correlation between annual cumulative bond returns and accounting signals related to liquidity, asset quality, core business performance, and equity base in the month of the 10 - $\mathrm{K}$ filing public release, one cannot draw causal inferences over such a long time period because other timely and relevant information potentially enters into the decision-making process. Other information channels include but are not limited to prospectuses, derivative markets, press releases, conference calls, and credit ratings. These information channels could provide relevant and timely information to bond investors mitigating the importance of accounting variables in the investment evaluation process. 
In a first step to examine the value relevance of ratios related to the CAMEL framework, I investigate whether the perfect foresight hedge portfolio strategy provides significant contributions to the overall return in the months the $10-\mathrm{K}$ filings are announced 27 . Figure 2.1 illustrates that for the bank-crisis period the hedge portfolio strategy under perfect foresight achieves a significant return increase of $49.4 \%$ in the months the 10-K filings are announced. Furthermore, Figure 2.1 illustrates that even in the case of perfect foresight of the ratios related to liquidity, asset quality, core business performance, and equity base, bond holders seem not to incorporate accounting information in their investment decisions process during non-financial crisis periods. Overall, these findings seem to support hypothesis 2, that during the 2007-2009 bank crisis period banks' cumulative monthly bond returns were more strongly associated with annual changes in ratios related to the CAMEL framework in the month of the financial statements' public release than in previous months.

FIGURE 2.1 Perfect Foresight Investment Portfolio Returns

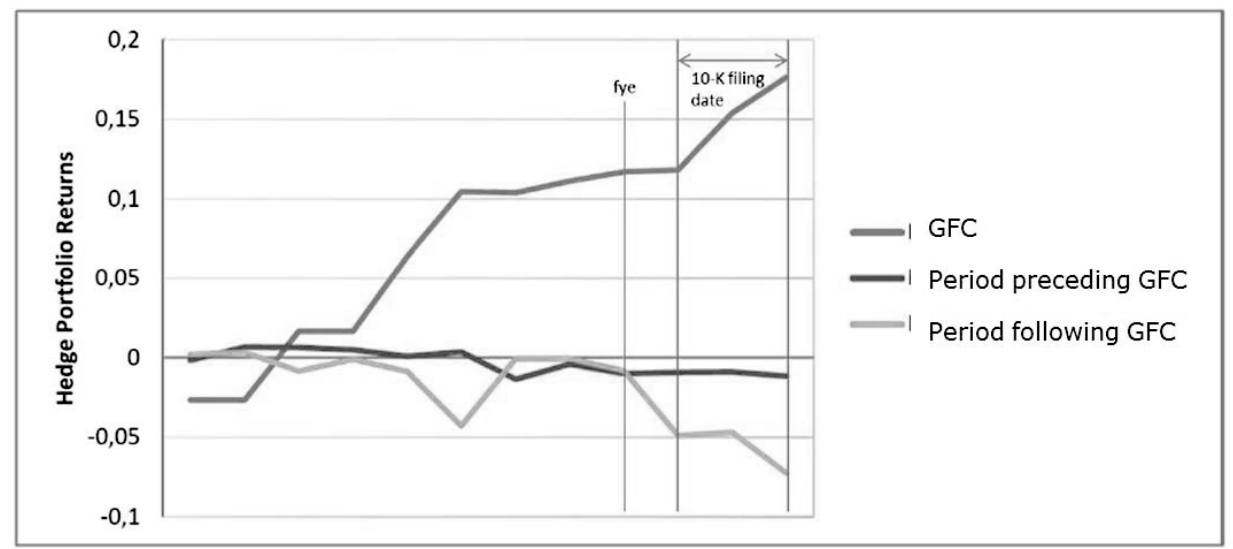

${ }^{27}$ All financial institutions in the sample announce their financial reporting results in the second or third month after fiscal-year end (FYE). 
TABLE 2.5: Importance of Ratios related to the CAMEL framework around the SEC Filing Date

\begin{tabular}{ccc}
\hline Model: & $A B R=$ & $\gamma_{0}+\gamma_{1} R q 1 q 3+\gamma_{3} R q 4+\gamma_{4} R \sec +\varepsilon$ \\
\hline Variables & \pm 7 Day window for period $2007-2008$ (t-stat) \\
\hline Intercept & -0.0002 \\
& $(-0.02)$ \\
$R q 1 q 3$ & 0.2018 \\
& $(0.71)$ \\
& $R q 4$ & $1.0192^{* *}$ \\
& $(2.26)$ \\
Rsec & $1.3352^{* * *}$ \\
& $(5.10)$
\end{tabular}

This table reports the relative importance of the cumulative bond returns of the 15 days centered on the respective preliminary earnings announcement date of quarter 1 to quarter 3 (Rq1q3), quarter 4 (Rq4), and the U.S. Securities and Exchange Commission (SEC) EDGAR 10-K filings announcement dates (Rsec) in explaining the cumulative annual bond return (Ball and Shivakumar 2008). Bond returns are calculated as the change in bond price (cum accrued interest) plus coupon payments made during the return interval, scaled by the bond price at the start of the return interval. $\left(A n n R e t_{i j t}=\frac{B P_{i j t}+A I_{i j t}-B P_{i j t-1}}{B P_{i j t-1}}\right) \mathrm{BP}_{\mathrm{ijt}}$ is the flat price of bond $\mathrm{i}$ of firm $\mathrm{j}$ at time $\mathrm{t}$. $\mathrm{AI}_{\mathrm{ijt}}$ denotes the accrued interest for the respective bond issue. On average, significant coefficients exceeding 1 are indicative of investors' under-reaction to the information disclosed in the certified annual financial statements (Ball and Shivakumar 2008). t-values in parentheses are based on heteroscedasticity-robust, firm-level clustered standard errors. ${ }^{* *}, * *$, and ${ }^{*}$ denote significance at $1 \%, 5 \%$, and $10 \%$, respectively.

To provide evidence that the significant return contribution in the months the $10-\mathrm{K}$ filings are announced is indeed attributable to the $10-\mathrm{K}$ filing announcement dates, I examine the relative importance of preliminary earnings and $10-\mathrm{K}$ filing announcements for investors in the debt market by regressing each individual event window bond return on the annual bond return (Ball and Shivakumar 2008). In Table 2.5, the regression coefficient on the cumulative bond return during the 15-day period around the $10 \mathrm{~K}$-filing date is positive and significant at the $1 \%$ confidence level, signaling the relevance of the 10-K filing for bond holders' investment valuation. The findings support hypothesis 3 , which states that short-window cumulative bond returns centered on the 10-K filings announcement dates are more strongly associated with banks' cumulative annual bond returns than short-window cumulative bond returns centered on the preliminary earnings announcement dates during the recent financial crisis period.

In addition to addressing causal inferences through the relative importance of preliminary earnings and $10-\mathrm{K}$ filing announcements for investors in the debt market, I conduct a daily bond return analysis that includes accounting information signals related to the CAMEL framework. The Ball and Shivakumar (2008) regressions explained above address the relevance of the individual event windows, but do not specifically test the value relevance of changes in ratios related to asset quality, liquidity, equity base, and core business performance for bond holders. Table 2.6 reports the results of the regression analysis of equation (3) and presents the individual coefficients for the main effects ( $\triangle$ EAbility, $\Delta$ AQuality, $\Delta$ Liquidity, and $\Delta$ CAdequacy), the indicator variables for the different event windows (preliminary earnings announcement and SEC 
filing date windows), and the interaction terms of the main effects with the indicator variables with respect to the daily bond return analysis for the financial crisis (April 2007 - March 2009) and the non-financial crisis period (April 2004 - March 2007). The result supports hypothesis 4 which states that changes in banks' financial ratios related to the CAMEL framework are value relevant for bond holders only during the recent financial crisis. The significant and positive coefficients on the interaction terms of $\triangle E A b i l i t y$ and $\triangle C A d e q u a c y$ with the $10-\mathrm{K}$ filing announcement date window suggest that indicators related to 'earning power' and capital adequacy are value relevant for bond holders. Additionally, the negative and significant coefficient on the interaction term of $\Delta$ Liquidity with the 10-K filing announcement date window provides evidence that the liquidity position of financial institutions is value relevant for investors during periods of turmoil and distress. 
TABLE 2.6: $\quad$ Daily Bond Return Analysis for Non-Financial Crisis (April 2004 - March 2006) and Financial Crisis Period (April 2007 - March 2009)

Model:

$$
\begin{aligned}
& D B R=\delta_{0}+\delta_{1} \Delta E A \text { bility }+\delta_{2} \Delta \text { AQuality }+\delta_{3} \Delta \text { Liquidity }+\delta_{4} \Delta C \text { Adequacy } \\
& \delta_{5} q 1 q 3_{-} \operatorname{win}_{15}+\delta_{6} q 4{ }_{-} \text {win } 15+\delta_{6} \mathrm{sec} \_ \text {win } 15 \\
& \delta_{11} q 1 q 3_{-} \text {win } 15 \times \Delta E \text { Ability }+\delta_{12} q 4 \text { _win } 15 \times \Delta E \text { Ability }+\delta_{13} \mathrm{sec} \_ \text {win } 15 \times \Delta E \text { Ability } \\
& \delta_{21} q 1 q 3 \text { _win } 15 \times \Delta \text { AQuality }+\delta_{22} q 4 \text { _win } 15 \times \Delta \text { AQuality }+\delta_{23} \sec \_ \text {win } 15 \times \Delta \text { AQuality } \\
& \delta_{31} q 1 q 3 \text { _win } 15 \times \Delta \text { Liquidity }+\delta_{32} q 4 \text { _win } 15 \times \Delta \text { Liquidity }+\delta_{33} \mathrm{sec} \text { _win } 15 \times \Delta \text { Liquidity } \\
& \delta_{41} q 1 q 3 \text { _win } 15 \times \Delta C \text { Adequacy }+\delta_{42} q 4 \text { _win } 15 \times \Delta C A \text { dequacy }+\delta_{43} \text { sec_win } 15 \times \Delta C A d e q u a c y+\varepsilon
\end{aligned}
$$

\begin{tabular}{|c|c|c|c|c|}
\hline Variables & $\begin{array}{c} \pm 7 \text { Day window for } \\
\text { period preceding } \\
\text { GFC }\end{array}$ & (t-stat) & $\begin{array}{l} \pm 7 \text { Day window } \\
\text { for GFC period }\end{array}$ & (t-stat) \\
\hline
\end{tabular}

\begin{tabular}{|c|c|c|c|c|}
\hline Intercept & $0.0003^{* * *}$ & $(3.11)$ & -0.0000 & $(-0.04)$ \\
\hline$\triangle E$ Ebility & -0.0000 & $(-0.25)$ & 0.0002 & $(0.79)$ \\
\hline$\triangle A Q u a l i t y$ & -0.0001 & $(-0.70)$ & 0.0001 & $(0.36)$ \\
\hline$\Delta$ Liquidity & -0.0000 & $(-0.02)$ & 0.0002 & $(1.22)$ \\
\hline$\triangle$ CAdequacy & 0.0000 & $(0.03)$ & -0.0001 & $(-0.44)$ \\
\hline q1q3_win15 & -0.0002 & $(-0.43)$ & 0.0003 & $(0.45)$ \\
\hline q4_win15 & -0.0002 & $(-0.66)$ & -0.0004 & $(-0.29)$ \\
\hline sec_win15 & 0.0002 & $(0.34)$ & $-0.0020^{*}$ & $(-1.65)$ \\
\hline$\Delta$ EAbility *q1q3_win15 & 0.0004 & $(1.04)$ & -0.0006 & $(-0.85)$ \\
\hline$\Delta$ EAbility $* q 4 \_w i n 15$ & 0.0002 & $(0.34)$ & 0.0019 & $(1.61)$ \\
\hline$\Delta$ EAbility * sec_win15 & 0.0001 & $(0.22)$ & $0.0021^{*}$ & $(1.88)$ \\
\hline$\Delta$ AQuality * q1q3_win15 & 0.0002 & $(0.45)$ & -0.0009 & $(-1.40)$ \\
\hline$\Delta A Q u a l i t y * q 4 \_w i n 15$ & 0.0004 & $(0.76)$ & 0.0001 & $(0.12)$ \\
\hline$\triangle A Q u a l i t y{ }^{*}$ sec_win15 & 0.0001 & $(0.19)$ & 0.0010 & $(-0.96)$ \\
\hline$\Delta$ Liquidity ${ }^{*} q 1 q 3 \_w i n 15$ & -0.0001 & $(-0.25)$ & 0.0000 & $(0.06)$ \\
\hline$\Delta$ Liquidity * q4_win15 & -0.0003 & $(-0.51)$ & -0.0008 & $(-0.72)$ \\
\hline$\Delta$ Liquidity * sec_win15 & -0.0002 & $(-0.33)$ & $-0.0027^{* *}$ & $(-2.44)$ \\
\hline$\Delta$ CAdequacy $*$ q1q3_win15 & -0.0003 & $(-0.65)$ & 0.0008 & $(1.22)$ \\
\hline$\Delta$ CAdequacy $*$ q4_win15 & -0.0004 & $(-0.65)$ & -0.0003 & $(-0.31)$ \\
\hline$\Delta$ CAdequacy ${ }^{*}$ sec_win15 & -0.0004 & $(-0.60)$ & $0.0024^{* *}$ & $(2.32)$ \\
\hline
\end{tabular}

This table reports the individual coefficients for the main effects (AEAbility, $\triangle A Q u a l i t y, \Delta$ Liquidity, and $\triangle$ CAdequacy), the dummy variables indicating the different \pm seven day event windows (preliminary earnings announcement and SEC filing date windows), and the interaction terms of the main effects with the dummy variables with respect to the daily bond return analysis for the financial crisis (April 2007 March 2009) vs. non-financial crisis period (April 2004 - March 2007). Daily bond returns are calculated as the change in bond price (cum accrued interest) plus coupon payments made during the return interval, scaled by the bond price at the start of the return interval. $\triangle A Q u a$ ality refers to the changes in the loan loss reserves to gross loans ratio, $\triangle$ Liquidity to the changes in the net loans to total assets ratio, $\triangle$ CAdequacy to the changes in the equity to net loans ratio, $\Delta E A b i l i t y$ for the changes in the return on average assets ratio. $\Delta$ Rating refers to the average-weighted credit ratings change provided by Standard and Poor's, Fitch, and Moody's. $\triangle A Q$ Quality measures the quality of a banks' individually and collectively assessed loan portfolio. An increase in the ratio signals a deterioration in the performing part of the financial assets included in the overall loan portfolio. $\triangle$ CAdequacy measures a financial institutions' leverage and the ability to absorb expected and unexpected losses. A decline informs investors about a lower protection available to financial institutions to cover loan losses. $\triangle E A b i l i t y$ measures a bank's profitability and show how effectively a bank carries out its asset and liability management strategy in form of how efficiently financial assets have been used to generate net income. An increase in this ratio informs about banks being more profitable in the core business lines. $\mathrm{t}$-values in parentheses are based on heteroskedasticity-robust, firm-level clustered standard errors. ${ }^{* * *},{ }^{* *}$, and ${ }^{*}$ denote significance at $1 \%, 5 \%$, and $10 \%$, respectively. 


\subsection{Concluding remarks}

This study investigates whether and to what extent bond investors in the financial institution sector "free-ride" on regulatory certification in non-financial crisis periods, and whether they use accounting signals in their decision-making process only during economic downturns. The 2007-2009 bank crisis period provides a perfect setting to test whether financial institutions' financial accounting indicators related to the CAMEL framework of the U.S. Federal Bank Regulatory Agencies - capital adequacy, asset quality, earnings ability, and liquidity - enter, if at all, into the decision-making process of investors holding a portfolio of debt instruments in financial institutions. Applying a perfect foresight portfolio investment strategy (Abarbanell and Bushee, 1998), I find evidence that cumulative monthly bond returns are associated with changes in 'earning power' and changes in credit ratings only when financial markets are illiquid and not transparent. This is potentially attributable to diverging interests of bank regulators and institutional bond investors during bank crisis periods, with debt holders conceivably relying to a lesser extent on regulatory agencies' private information and certification. Moreover, I provide insight in terms of bond prices that have not fully anticipated accounting signals during periods of financial distress and illiquidity. To draw causal inferences, I also conduct an event study utilizing short-term windows centered on the U.S. Securities and Exchange Commission (SEC) EDGAR 10-K filing announcement dates and preliminary earnings announcement dates, and report the value relevance of ratios related to changes in 'earning power', liquidity, and capital adequacy for bond holders during the recent financial crisis period (April 2007-March 2009). 


\section{ESTIMATED TAXABLE INCOME AND OTHER ACCOUTING SIGNALS IN THE CORPORATE BOND MARKET $_{28}$}

\subsection{Introduction}

Quarterly and certified annual financial statements serve both equity investors and bond holders in making informed investment decisions. So far, extant literature provides insights about how accounting information is assessed by shareholders to improve their investment decision-process (Kothari 2001). Only recently, the association between earnings and bond returns and the value relevance of earnings related information signals for bond holders in the corporate bond market has been investigated (Easton et al. 2009).

As mentioned in chapter two, as the payoff structure of debt holders differs from those of stockholders in so far as bond holders have a fixed claim to the firm's assets and do not participate in any upside potential of the firm's risky projects. Hence, it is plausible that bond holders have different information needs than shareholders. With a special focus on down side risks, bond holders may use information on the capital structure as it contains information about a firm's specific equity cushion that is able to cover expected and unexpected losses and protect against insolvency. Surprisingly, the association of bond returns with liquidation values in form of capital structure proxies has not yet been investigated to my best knowledge. Additionally, research shows that information signals related to taxable income significantly explains the variation in equity prices (Hanlon 2005). Nevertheless, taxable income has not been dealt with in connection with debt markets although tax payments are a major outflow of a firm's funds and could be of a concern especially to bondholders. Over and above, research in the bond market assumes stable and "non-dynamic" information needs on the side of bond holders. As mentioned in the introduction, periods of distress (e.g., during the GFC) may change the information set used by investors which probably increases the importance of fundamentals (e.g., accounting-based information signals) in valuing a firm. Hence, the study in this chapter investigates the association of corporate bond returns with information signals extracted from the income statement and statement of

${ }^{28}$ This chapter is based on a working paper co-authored with Christoph Watrin. 
financial position, estimated taxable income, and the macroeconomic situation during the recent financial crisis.

Overall, I show that, irrespective of the state of the economy, information related to changes in a firm's liquidation value is incrementally and significantly associated with bond returns of corporates after controlling for earnings-related accounting signals. As assumed, this contrasts the findings in chapter two, as information signals in form of a bank's capital structure appear not to be significant before the recent financial crisis. This is probably attributable to the different information set available for investors in the banking sector, as the stringent regulatory supervision provides a form of down side risk protection. Furthermore, I demonstrate that estimated taxable income is incrementally informative over and above earnings and liquidation values in the period preceding the recent financial crisis. Additionally, I shed light on the association of changes in book-values and taxable income with annual bond returns after controlling for earnings-related accounting information and firm specific distress.

In a first analysis, I examine the association of capital structure (liquidation values) with bond returns after controlling for earnings related accounting information. Prior research provides evidence on the importance of earnings for bond markets. Easton et al. (2009) document the value relevance of earnings announcements for bond markets from 1994 to 2006 and find that bond returns are more sensitive if earnings convey bad news or when the underlying bond is more risky. For the equity market Barth et al. (1998) find that for firms deteriorating in financial health balance sheet information in form of equity book value tends to be incrementally significant in explaining the variation in the market value of equity. Vice versa, income statement related information seems to provide incremental explanatory power for the market value of equity for firms which are financially healthy.

From a theoretical point of view it is not clear whether liquidation values are associated with bond returns. On the one hand, one could argue that information on a firm's leverage is important for bond holders because it contains information about the equity cushion available to cover losses. On the other hand, why should debt holders worry about liquidation values if a firm is remote from debt covenant violation? If, a firm's financial health deteriorates, Easton et al.'s findings (2009) suggest that earnings and not liquidation values are of interest for debt holders because earnings inform about the firm's future cash generating ability to serve the claims of fixed interest holders. The relative importance of leverage in informing bond investors is thus an empirical question. Hence, I investigate whether statement of financial position information in form of leverage contributes in explaining the variation in annual bond returns.

Second, I examine the relationship of estimated taxable income with bond returns. Tax related research sheds light on the association of book-tax differences with earnings growth, equity returns, and earnings persistence (Hanlon 2005; Lev and Nissim 2004). Hanlon et al. (2005) demonstrate that both book and tax income exhibit incremental power in explaining returns in the equity market. Ayers et al. (2009) provide additional insights with regard to the relative importance and association of taxable income and book income in explaining equity returns by using tax planning and earnings quality as 
distinguishing factors. Taxable income may be informative over and above earnings and liquidation values if taxable income is more reliable because it is audited by tax authorities. $^{29}$ If taxable income is an alternative earnings measure, the explanatory power of taxable income and earnings should change with a firm's financial situation in a similar way. According to Easton et al. (2009) earnings are especially informative for distressed firms because they indicate the ability to generate funds for future interest payments. However, if a firm makes losses it should not pay taxes which casts doubts whether tax information is at all relevant for debt markets. After controlling for earnings-related information, and liquidation values I find that taxable income is associated with bond returns and has incremental explanatory power in explaining the variations in annual bond returns in the period before the financial crisis, but not during and after the GFC.

The remainder of chapter three is structured as follows. In the next section I briefly discuss the corporate debt market and information needs of bond holders. Section 3.2 covers prior literature and the hypothesis development. Research design and sample selection are discussed in section 3.3. Section 3.4 includes the empirical results followed by section 3.5 which concludes.

\subsection{Corporate debt market and tax income related information signals}

As mentioned in chapter two, corporations have to decide between different funding opportunities including internal funding through cash flows (retained earnings) and taking on additional debt or issuing equity securities, when investing in new projects with a positive net present value. Equity and institutional debt investors may have different informational needs attributable to their investments' different payoff functions. Given their convex payoff function, equity investors are willing to take on more risk than debt holders. Equity holders' claim to the company can be seen as holding a call option where the option is in the money when the value of the firm exceeds its debt (principal which has to be paid back to debt holders). On the other side, bond holders are given priority of payment when the firm value is equal to or smaller than the debt inherent in the respective company.

When analyzing quarterly and certified annual financial statements, both equity and bond investors use accounting information from different sources, such as the balance sheet, income statement, and cash flow statement. Investigating the relative usefulness of accounting signals from these different statements, prior research finds evidence that equity investors shift their focus from earnings as reported in the income statement to book values as reported in the balance sheet when firms' financial health deteriorates (Barth et al. 1996; Collins et al. 1997). This is in line with accounting theory contemplating balance sheet net tangible assets as a proxy for a firms' liquidation value.

As their investment's upside potential is limited, debt market investors in the

${ }^{29}$ It can be argued that tax authorities provide a more reliable audit as there are no fee-based contracts between the audit team and client. 
primary and secondary corporate bond market should potentially be interested in the liquidation value of borrowing firms in order to assess their default risk. Accounting signals about the future cash generating ability or "earning power" appear to be of secondary importance to debt holders, at least during periods in which there is no general doubt about firms' going concern. Thus, attributable to the asset substitution and underinvestment conflict (Myers 1977; Smith and Warner 1979), debt holders demand balance sheet information about the firm's net assets as these measures inform about the firm-specific liquidation value (Kothari et al. 2009). As firm values deteriorate during periods of severe financial crises, as witnessed during the "Great Recession", firms' equity cushions to absorb expected and unexpected losses declined significantly and were no longer regarded as sufficient. When firm values decline rapidly, bond holders potentially shift their focus from liquidation values to "earning power" related information because these indicate whether the equity cushion to absorb losses can gradually be reinforced through internal financing capabilities. In the study, I empirically test whether these theoretical implications are valid in a real world setting.

Taxable income is audited by tax authorities. The additional review by government agencies could make this accounting-based estimation more reliable than financial earnings (Desai et al. 2007; Hanlon et al. 2011). Taxes constitute a major outflow of firm resources with no corresponding inflow and thus increase the risk exposure of debt holders. If bond holders consider taxable income as a substitute for financial income, both measures should be associated with bond returns in the same way. In contrast, if the importance of taxable income stems from the outflow of tax payments, bond returns should be associated with taxable income in economic boom periods in which most firms pay taxes but not during a recession.

\subsection{Prior research}

Extant research shows that earnings as well as book values are priced in equity markets. In perfect and complete markets valuations based on book value and valuations based on earnings are redundant alternatives. However, under more realistic assumptions both measures frequently lead to distinct assessments of value (Barth and Landsman 1995). The Ohlson model provides a rigorous statement of the relation between value, earnings and dividends. Under clean surplus accounting market value is equal to book value plus the net present value of expected future abnormal earnings (Feltham and Ohlson 1995; Ohlson 1995). However, if book value is equivalent to capitalized normal earnings, then firm value is equivalent to the sum of capitalized normal earnings and capitalized abnormal earnings, or simply capitalized earnings (Burgstahler 1998). Empirical research provides evidence that earnings as well as book values are priced in equity markets. An explanation for this result is that book values serve as a better proxy for future earnings when current earnings contain large transitory components. An alternative explanation is that book values serve as a proxy for the firm's abandonment option (Collins et al. 1997). In line with the second explanation Barth et al. (1998) find 
that the incremental explanatory power of equity book value increases as a firm's financial health decreases. Collins et al. (1997) report evidence that the relative importance of earnings and book values in valuation is conditional on intangible intensity, nonrecurring items, negative earnings, and firm size. I extend this line of research to bond markets and investigate the relative importance of book values for debt markets.

In contrast to book values, prior research analyses the impact of earnings on bond prices. An early study by Plummer and Tse (1999) finds that the association between earnings and stock returns declines when the financial situation weakens and that the association between bond returns and earnings increases when a firm's financial situation deteriorates. Easton et al. (2009) report evidence that bond trades, bond prices, and annual bond returns are associated with earnings and that the importance of earnings is greater if earnings convey bad news or when the underlying bond is more risky. Their event study investigates the years before the recent financial crisis (19942006). DeFond and Zhang (2011) demonstrate the information content of earnings surprises for bond markets. They find that the association of earnings surprises with bond returns is smaller for investment grade than for non-investment grade bonds. Related papers report that hedge funds activism and analysts have influence on debt markets (Billings et al. 2011; De Franco et al. 2009; Graham, Li and Qiu 2008; Klein and Zur 2011). I add to this literature by investigating the importance of earnings over and above liquidation values before, during, and after the recent financial crisis.

Recent tax research shows that taxable income provides incremental explanatory power for equity returns when earnings are controlled for (Hanlon et al. 2005). Ayers et al. (2009) find that the information content of taxable income is lower for tax avoiders and that taxable income is more informative for firms with lower earnings quality. Weber (2009) demonstrates that the information content of taxable income is not fully incorporated in earnings forecasts and stock prices. Thomas and Zhang (2011) report evidence that tax expense surprise is related to changes in future quarterly earnings and changes in tax expense and that those changes are positively related to future returns. A related stream of literature deals with the information content of differences between book and tax income. Book-tax differences are associated with earnings growth, equity returns, and earnings persistence (Lev and Nissim 2004; Hanlon 2005). Ayers et al. (2010) find that changes in book-tax differences are associated with changes in credit ratings. For firms classified as "tax planners" both large positive and large negative changes in book-tax differences are associated with less favorable rating changes. Crabtree and Maher (2008) report findings that both the magnitude of a firm's earnings surprise and the individual analyst forecast dispersion are significantly associated with the firm's bond rating. I extend this research by showing that taxable income exhibits incremental explanatory power for bond returns in the years before the financial crisis, even if I control for accounting information signals such as earnings and capital structure. 


\subsection{Hypothesis development, sample selection, and research design}

\subsubsection{Hypothesis development}

Literature provides evidence on the association with and value relevance of book values for share prices and stock returns. Book values contain information about the equity cushion and the default risk. Thus, I expect book values to be an important information source for debt markets. I investigate the importance of changes in liquidation values defined as book value of liabilities divided by firm value for the bond market. A rising (decreasing) book value of liabilities implies an increase (decrease) in default risk. Since debt holders compete for the firm's resources in the event of a default, any changes in the book value of liabilities potentially presents important incremental information for bond holders.

Prior research sheds light on the importance of earnings numbers for bond holders. Given the nonlinear payoff function of bonds this is surprising on first sight. However, the importance of earnings for bond holders can be explained by analyzing the relation between debt holders and shareholders. Bond holders take a long position in the issuing firm's assets and a short position in a call option on these assets (Figure 2.1). Shareholders, who hold the call option, will exercise their option, if the firm performs well, and make fixed payments to the debt holders (Easton et al. 2009). If the financial situation weakens, shareholders can exercise a liquidation option and abandon the firm to bondholders (Fischer and Verrecchia 1997; Hayn 1997). As a firm's financial health declines, earnings become more relevant for bondholders whose payoff function increasingly depends on firm value (Plummer and Tse 1999). Therefore, I expect that changes in net earnings are an important source of information for bond holders if a default becomes more likely.

A macroeconomic crisis should have an impact on the default risk and the relative importance of book values versus earnings. As stated above, earnings become more important for bond holders if the firm's financial situation weakens. Thus, the focus of bond holders during non-crisis periods should rather be on book values with a potential shift towards earnings during financial crisis periods. I include an indicator variable in the analysis to capture firm specific distress. Without such a control I could possibly not conclude that the findings depend on the state of the economy (non- vs. financial crisis). I hypothesize:

Hypothesis 1a: $\quad$ After controlling for an individual firm's financial distress, annual changes in a firm's leverage have incremental explanatory power over and above changes in net income in explaining the variation of annual bond returns (irrespective of the state of the economy).

Hypothesis 1b: $\quad$ Annual changes in net income are only associated with annual bond returns in periods of financial distress (GFC). 
Besides accounting-related information signals, literature also provides evidence on the importance of taxable income for capital markets participants (Ayers et al. 2009). There are two reasons for taxable income being associated with bond returns. First, taxable income may be seen as a proxy for financial income. Since taxable income is audited by tax authorities it could be more reliable than the income number extracted from the income statement. Second, taxable income is related to taxes and taxes constitute a major outflow of firm resources with no corresponding inflow. Thus, tax authorities compete with bond holders for the firm's resources when the firm approaches default. If the first explanation has merit then taxable income may be incrementally informative in explaining bond returns during the financial crisis and be less relevant in non-financial crisis years. In other words, it should reveal similar results as net income in crisis- and non-crisis periods. If taxable income is of interest to bond holders because it is connected to an outflow, than the proxy should have explanatory power during the period preceding the financial crisis. ${ }^{30}$ Starting with the financial crisis, many firms reported losses and thus did not pay taxes. Tax loss-carry forwards also reduce tax payments in the years following the financial crisis. I test:

Hypothesis 2: $\quad$ After controlling for an individual firm's financial distress, estimated taxable income has incremental explanatory power over and above changes in net income and changes in liquidation value for annual bond returns in non-financial crisis periods (period before the GFC).

\subsubsection{Sample selection and research design}

This study investigates the association of corporate bond returns with accounting-based and tax-related information. For the construction of annual bond returns, data are retrieved from the Trade Reporting and Compliance Engine (TRACE) and Mergent Fixed Investment Securities Database (FISD) database. FISD comprises information on pricing and trade terms of debt instrument starting in 1995. TRACE has been established by the National Association of Securities Dealers (NASD) in 2002 and provides data on financial institution and corporate bonds in the U.S. secondary bond market. I utilize information from both the TRACE and FISD database to construct annual bond returns using trade prices (flat price) and accrued interest scaled by the respective bond price at the beginning of the return interval. The focus of this study is on bonds that are nonredeemable, non-callable, and neither possess other step-up clauses nor embedded derivatives. If a corporation places multiple bond issues, the average bond return reflects the weighted par values of the multiple issues. Accounting and tax information is retrieved from the Compustat database. Merging all databases under the inclusion of accounting variables retrieved from Compustat provides a total sample of 2760 firm-

\footnotetext{
${ }^{30}$ Attributable to the use of tax loss carry forwards, estimated tax income is potentially less informative for bond holders during and after periods of financial distress.
} 
year observations for the period 2004 through 2011 and includes both two nonfinancial crisis windows with 1379 firm-year observations and the recent financial crisis period including 1381 firm-year observations (please see Figure 2.1 for determining the period of the recent financial crisis). ${ }^{31}$ Extending the model to also include estimated taxable income decreases the total sample size to 1253 firm-year observations for the total period from 2004 to 2011 attributable to missing information on the tax loss carry forward position.

Annual bond returns are calculated following Easton et al. (2009):

$$
A n n \operatorname{Ret}_{i j t}=\frac{\mathrm{BP}_{i j t}+A I_{i j t}-\mathrm{BP}_{i j t-1}}{\mathrm{BP}_{i j t-1}}
$$

In the above equation $B P_{i j t}$ is the flat price of bond $\mathrm{i}$ of firm $\mathrm{j}$ at time t. $A I_{i j t}$ denotes the accrued interest for the respective bond issue. Annual bond returns are calculated for a period that starts nine month before the fiscal year-end of the respective firm and ends three months after the fiscal year-end. Using this time frame ensures that the annual bond returns relate to the respective annual disclosures published in the certified annual reports. Individual bond issues are aggregated to firm-level bond returns by taking a value weighted-average of the bond returns.

To test hypothesis $1 \mathrm{a}$ and $1 \mathrm{~b}$, the following regression equation is used for the two non-financial crisis periods and the GFC period. To test hypothesis 2, I only distinguish between the period preceding the GFC and the period thereafter. The reason for pooling the GFC with the period following the GFC is that tax losses which occurred during the GFC will be carried forward to future years and thus tax-related information signals may only carry information content during "normal" market conditions.

$$
\begin{gathered}
\text { AnnRet }_{j t}=\beta_{0}+\beta_{1} \text { DNIncome }+\beta_{2} \Delta \text { BValue }+\beta_{3} \text { PNEarnings }+ \\
\beta_{4} \Delta \text { TaxIncome }+\sum \text { Controls }+\varepsilon
\end{gathered}
$$

$\Delta$ Income refers to the annual change in net income (Compustat item \#170) as reported in the certified annual financial statements scaled by firm value. Since this study focuses on the debt market, I compute firm value as the book value of liabilities plus market value of outstanding shares (market capitalization). Liquidation values are defined as the book value of liabilities divided by firm value. An annual decrease in the book value of liabilities divided by firm value informs about a relative decrease of the

31 My analysis is restricted to firm-year observations with bond returns not exceeding $100 \%$. In a sensitivity analysis I allow the upper-bound of bond returns to be below $100 \%, 80 \%, 60 \%, 40 \%$, and $20 \%$. 
equity cushion and thus about a smaller cushion to absorb expected and unexpected losses. Thus, I expect a negative association between annual bond returns and changes in liquidation values. Prior research in the corporate bond market (i.e., Easton et al. 2009) also includes indicator variables for positive and negative earnings because $\Delta$ NIncome only captures the changes in earnings without informing about the relative position to the zero-earnings threshold. Thus, I include the indicator variable PNEarnings into the regression which is equal to one if earnings are positive and zero otherwise. Furthermore, as I am interested in whether tax-related information signals are incrementally associated with annual bond returns over and above $\Delta$ NIncome and $\triangle B$ Value I calculate estimated taxable income $\left(\mathrm{TI}_{\mathrm{jt}}\right)$ as follows (similar to Ayres et al. 2009):

$$
T I_{j t}=\left[\left(F T E_{j t}+F O T E_{j t}\right) / s t r_{t}\right]-\Delta N O L_{j t}
$$

FTE $_{\mathrm{jt}}$ refers to the current federal income tax expense (Compustat item \#63), FOTE $\mathrm{j}_{\mathrm{jt}}$ to the current foreign tax expense (Compustat item \#64), str ${ }_{t}$ to the top US statutory tax rate for year $\mathrm{t}$, and $\mathrm{NOL}_{\mathrm{jt}}$ to the net operating loss carry forward (Compustat item \#52). ${ }^{32}$

\subsection{Empirical results}

\subsubsection{Descriptive analysis}

Table 3.1 presents the descriptive statistics for the first-order-differences in the independent variables related to the changes in liquidation values ( $\triangle$ BValues), net

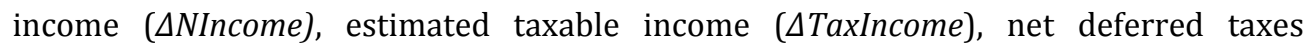
( $\triangle$ DefTax), current income taxes (ACITaxes), and credit ratings ( $\triangle$ CRating) for the period spanning from 2004 through 2011. Descriptive statistics on net deferred taxes (statement of financial position) and current income taxes (income statement) are included as a comparison to and benchmark for the estimated taxable income. As can be seen in Table 3.1, the mean and median of the changes in net income are negative which is attributable to the inclusion of the financial crisis period from 2007 to 2009.

32 The top US statutory tax rate is $35 \%$. 
TABLE 3.1: Descriptive Statistics of the First-Differences in the Independent Variables

\begin{tabular}{lcccccc}
\hline \multicolumn{1}{c}{ Variables } & $N$ & Mean & Std Dev & Median & Minimum & Maximum \\
\hline$\Delta$ BValues & 2787 & 0.0072 & 0.1136 & -0.0021 & -0.7445 & 0.6445 \\
$\Delta$ NIncome & 2787 & -0.0009 & 0.0924 & 0.0014 & -1.0472 & 0.9606 \\
$\Delta$ TaxIncome & 1477 & -0.5266 & 0.3202 & -0.4523 & -1.9405 & 0.0086 \\
$\Delta$ CITaxes & 2477 & -0.4626 & 0.2111 & -0.4422 & -1.0028 & -0.0235 \\
$\Delta$ DefTax & 2773 & -0.4902 & 0.2185 & -0.4727 & -1.1307 & 0.0772 \\
\hline
\end{tabular}

This table reports the descriptive statistics for the first differences of the independent variables scaled by total firm value (book value of total liabilities plus total market capitalization). $\Delta$ BValues refers to the first difference in total liabilities scaled by firm value, $\Delta$ NIncome to the first difference in net income scaled by firm value, $\Delta$ TaxIncome to the first-difference in estimated taxable income scaled by firm value, $\Delta$ CITaxes to the current income tax reported in the income statement scaled by firm value, and $\Delta D e f T a x$ to the net deferred taxes as reported in the statement of financial position scale by total firm value.

Table 3.2 reports both Spearman (below) and Pearson (above) correlations among the first differences of the independent variables scaled by total firm value (book value of total liabilities plus total market capitalization). All correlations among the independent variables suggest that multicollinearity is not present in the analysis. Nevertheless, to mitigate concerns that the significant correlation between estimated taxable income ( $\triangle$ TaxIncome) and positive/negative earnings (PNEarnings) of $46.02 \%$ introduces multicollinearity into the regression results, I conduct an additional analysis by calculating Variance Inflation Factors (VIF) for each model. Table 3.3 presents the VIFs for all independent variables. These factors present the extent to which the variance of the coefficient estimates is inflated by multicollinearity.

TABLE 3.2: Spearman (below) / Pearson (above) Correlations among the FirstDifferences in the Independent Variables

\begin{tabular}{|c|c|c|c|c|c|c|}
\hline Variables & $\triangle B$ Values & $\Delta$ NIncome & $\Delta$ TaxIncome & PNEarnings & DCITaxes & $\Delta$ DefTax \\
\hline$\triangle B$ Values & 1 & -0.3501 & 0.1339 & -0.1637 & 0.2357 & 0.2315 \\
\hline$\Delta N I n c o m e$ & -0.2111 & 1 & -0.0233 & 0.2876 & -0.0527 & -0.0583 \\
\hline$\Delta$ TaxIncome & 0.2002 & -0.0018 & 1 & 0.4823 & 0.8864 & 0.8369 \\
\hline PNEarnings & -0.1154 & 0.2766 & 0.4602 & 1 & 0.3885 & 0.3421 \\
\hline ACITaxes & 0.2535 & -0.0208 & 0.9407 & 0.3742 & 1 & 0.9673 \\
\hline$\triangle D e f T a x$ & 0.2392 & -0.0214 & 0.8908 & 0.3414 & 0.9694 & 1 \\
\hline
\end{tabular}

This table reports the Spearman (below) and Pearson (above) correlations among the first differences of the independent variables scaled by total firm value (book value of total liabilities plus total market capitalization). $\triangle B$ Values refers to the first difference in total liabilities scaled by firm value, $\Delta$ NIncome to the first difference in net income scaled by firm value, $\Delta$ TaxIncome to the first-difference in estimated taxable income scaled by firm value, $\triangle$ CITaxes to the current income tax reported in the income statement scaled by firm value, and $\triangle D e f T a x$ to the net deferred taxes as reported in the statement of financial position scale by total firm value. Bold figures are significant at the $1 \% \mathrm{p}$-level. 
TABLE 3.3: Variation Inflation Factors (VIF) of the Independent Variables

\begin{tabular}{lccc}
\hline \multicolumn{1}{c}{ Variable } & $\begin{array}{c}\text { Variance Inflation (VIF) } \\
\text { Model 1 }\end{array}$ & $\begin{array}{c}\text { Variance Inflation (VIF) } \\
\text { Model 3 }\end{array}$ & $\begin{array}{c}\text { Variance Inflation } \\
\text { (VIF) } \\
\text { Model } 4\end{array}$ \\
\hline Intercept & 0.0000 & 0.0000 & 0.0000 \\
$\Delta$ NIncome & 1.1824 & 1.1920 & 1.1563 \\
$\Delta$ BValues & 1.1344 & 1.1346 & 1.1356 \\
PNEarnings & - & 1.0972 & 1.4150 \\
$\Delta$ TaxIncome & - & - & 1.0084 \\
\hline
\end{tabular}

This table reports the variance inflation parameter for model 1 including $\triangle$ NIncome and $\triangle$ BValues as independent variables, model 2 including $\triangle$ NIncome, $\triangle B$ Values, and PNEarnings, and model 3 including $\triangle N$ Income, $\triangle B$ Values, PNEarnings, and $\triangle$ TaxIncome as independent variables. $\triangle B$ Values refers to the first difference in total liabilities scaled by firm value, $\Delta$ NIncome to the first difference in net income scaled by firm value, $\Delta$ TaxIncome to the first-difference in estimated taxable income scaled by firm value PNEarnings proxies for a firm's individual distress situation and is equal to one if earnings are positive and zero otherwise.

Table 3.4 illustrates the distribution of the annual bond returns for the different time periods representing both financial and non-financial crisis periods in form of quintiles. Furthermore, the full sample of annual cumulative bond returns is also provided. During the financial crisis, $10 \%$ of the bonds experience negative returns. In comparison, during non-financial crisis periods, only $1 \%$ of the bonds have negative returns. Interestingly, the top $10 \%$ of the bonds achieve higher returns during the financial crisis compared to non-financial crisis periods. This increased bond return volatility during periods of financial distress translates directly into higher risks bond investors face in the period from 2007 to 2009.

Table 3.5 reports the distribution of the tax loss carry forward, federal taxes, and foreign taxes for the full sample from 2004 to 2011 . These three variables enter into the estimated taxable income calculation which is included in specification (5). 
TABLE 3.4: Distribution of the Annual Bond Returns

\begin{tabular}{|c|c|c|c|c|}
\hline Quantile & $\begin{array}{l}\text { Period preceding GFC } \\
\qquad(\mathrm{n}=867)\end{array}$ & $\begin{array}{c}\text { GFC } \\
(n=1381)\end{array}$ & $\begin{array}{c}\text { Period following } \\
\text { GFC } \\
(n=512)\end{array}$ & $\begin{array}{c}\text { Full Sample } \\
\text { Period } \\
(n=2760)\end{array}$ \\
\hline $100 \% \operatorname{Max}$ & 0.8350 & 0.9896 & 0.7710 & 0.9896 \\
\hline $99 \%$ & 0.3935 & 0.7361 & 0.4166 & 0.6307 \\
\hline $95 \%$ & 0.1265 & 0.3359 & 0.1873 & 0.2567 \\
\hline $90 \%$ & 0.1026 & 0.2188 & 0.1406 & 0.1530 \\
\hline $75 \%$ Q3 & 0.0779 & 0.1051 & 0.1108 & 0.0948 \\
\hline $50 \%$ Median & 0.0562 & 0.0664 & 0.0881 & 0.0662 \\
\hline $25 \% Q 1$ & 0.0334 & 0.0265 & 0.0701 & 0.0359 \\
\hline $10 \%$ & 0.0157 & -0.0639 & 0.0539 & -0.0026 \\
\hline $5 \%$ & 0.0006 & -0.1554 & 0.0437 & -0.0644 \\
\hline $1 \%$ & -0.0713 & -0.4845 & 0.0068 & -0.3329 \\
\hline 0\% Min & -0.2792 & -0.9122 & -0.7939 & -0.9122 \\
\hline
\end{tabular}

This table reports the distribution of the annual corporate bond returns for the period preceding the GFC (April 2004 - March 2007), GFC (April 2007 - March 2009), and the period following the GFC (April 2009 March 2011). Bond returns above $100 \%$ are excluded. Bond returns are calculated as the change in bond price (cum accrued interest) plus coupon payments made during the return interval, scaled by the bond price at the start of the return interval. $\left(\right.$ AnnRet $\left._{i j t}=\frac{B P_{i j t}+A I_{i j t}-B P_{i j t-1}}{B P_{i j t-1}}\right) \mathrm{BP}_{\mathrm{ijt}}$ is the flat price of bond $\mathrm{i}$ of firm $\mathrm{j}$ at time $\mathrm{t}$. $\mathrm{AI}_{\mathrm{ijt}}$ denotes the accrued interest for the respective bond issue. Annual bond returns are calculated for a period that starts nine month before the fiscal year-end of the respective firm and ends three months after the fiscal year-end. Using this time frame ensures that the annual bond returns relate to the respective annual disclosures published in the certified annual reports. Individual bond issues are aggregated to firm-level bond returns by taking a value weighted-average of the bond returns. In the analysis, I use these raw returns in all of the specifications. Easton et al. (2009) report that their results are not altered if raw returns are adjusted for contemporaneous U.S. treasury rates that are subtracted from the respective raw returns. 
Table 3.5: Distribution of Tax Loss Carryforward, Federal and Foreign Taxes

\begin{tabular}{lccc}
\hline Quantile & $\begin{array}{c}\text { Tax loss carryforward } \\
(\mathrm{n}=2979)\end{array}$ & $\begin{array}{c}\text { Federal taxes } \\
(\mathrm{n}=4119)\end{array}$ & $\begin{array}{c}\text { Foreign taxes } \\
(\mathrm{n}=4127)\end{array}$ \\
\hline 100\% Max & 38200.000 & 10169.000 & 3317.000 \\
$99 \%$ & 7100.000 & 1530.000 & 1326.968 \\
$95 \%$ & 2400.000 & 526.213 & 348.000 \\
$90 \%$ & 1353.200 & 303.000 & 139.000 \\
$75 \%$ Q3 & 375.800 & 77.100 & 33.000 \\
$50 \%$ Median & 99.500 & 10.377 & 4.537 \\
$25 \%$ Q1 & 12.873 & 0.000 & 0.000 \\
$10 \%$ & 0.000 & -3.900 & 0.000 \\
$5 \%$ & 0.000 & -25.442 & 0.000 \\
$1 \%$ & 0.000 & -233.000 & -3.710 \\
$0 \%$ Min & 0.000 & -3253.000 & -119.700 \\
\hline
\end{tabular}

This table reports the distribution of the tax loss carryforward, federal taxes, and foreign taxes for the full sample. Tax loss carryforwards allow firms to report losses up to seven years after they occur which reduces future tax payment obligations. Federal taxes refers to the current federal income tax expense, and foreign taxes to the current foreign tax expense.

\subsubsection{Association test results}

Table 3.6 and 3.7 report the main empirical results. To apply a reasonable level of realized bond returns, I restrict the absolute annual bond return to a maximum of $100 \%$ and furthermore conduct a sensitivity analysis utilizing varying bond return restrictions $(80 \%, 60 \%, 40 \%$, and $20 \%)$ to mitigate concerns that the results are driven by extreme observations within the $100 \%$ range.

As bond holder's claims have to be satisfied out of the firm's liquidation value in the case of a default, I expect that liquidation values in form of leverage ( $\triangle B$ Values) are incrementally informative for bond holders. Table 3.6 indeed shows that $\triangle$ BValues is highly significant and negatively associated with annual bond returns irrespective of the state of the economy (and for all bond return restrictions). Changes in net income ( $\triangle$ NIncome) are predominately associated with bond returns in the GFC period (if bond returns are restricted to $100 \%$ and $20 \%$ ) and not at all associated with bond returns in the non-GFC period (if bond returns are restricted to a maximum of $100 \%, 80 \%, 60 \%$, $40 \%$, and $20 \%$ ). This volatility in the association of $\Delta$ Income with the annual bond returns will be further examined in chapter four which investigates earnings and earnings components (cash-flows and accruals) using OLS and non-parametric estimation methods. Table 3.6 underlines the importance of liquidation values in form of leverage as an information source for bond market investors. For the full sample period as well as the non-financial and financial crisis periods, $\triangle B$ Values is significantly associated with bond returns at the $1 \%$ level and holds for all specifications. Thus, these findings provide evidence that leverage provides important explanatory power over and above changes in net income in explaining annual bond return variation (Hypothesis 
1a). The (firm-specific) financial distress indicator variable PNEarnings is significantly associated with bond returns for the full sample in all but one Panel (E) and for the period before the crisis. During the financial crisis, PNEarnings is associated with bond returns only in two extreme specifications (restriction of bond returns to $100 \%$ or $20 \%$ ). Hence, the level and not the magnitude of earnings seem to be important to bond holders before the crisis. Since bond holders do not participate in any earnings change, their information interest is limited to the fact whether a firm makes losses or profits which is important for a firm's closeness to default assessment. The relative importance of level of earnings vs. magnitude of earnings changes during the GFC. The overall picture suggests that net income becomes more important and the indicator variable PNEarnings loses its significance. This indicates that bond holders potentially take a closer look at earnings and are no longer satisfied with the information about the level of earnings alone (Hypothesis $1 \mathrm{~b}$ ).

Furthermore, I test the associations of bond returns with taxable income (Table 3.7). As expected, taxable income is highly significant in the full sample period and in the period preceding the financial crisis which suggests that taxes as a major outflow contain important information for debt holders. Interestingly, the indicator variable for positive/negative earnings loses its explanatory power in all specifications. Only firms with positive earnings pay taxes and thus taxable income might be a substitute for the indicator variable PNEarnings. During the GFC period and the time after, changes in taxable income are not significantly associated with bond returns. I expect that tax loss carry forwards play a major role in the years after the financial crisis and that many firms do not pay taxes because of tax loss carry forwards. Changes in book value lose some of their explanatory power, but remain significant. Overall the results indicate that earnings levels (PNEarnings) are associated with annual bond returns during non-crisis periods. The magnitude of earnings has explanatory power only during the financial crisis. Taxable income, an indicator for potential tax outflows, is related to bond returns only during the period preceding the GFC. Changes in book values are significantly associated with bond returns in nearly all of the specifications which suggests that leverage is an important information source for bond investors.

\subsection{Concluding remarks}

In chapter three I investigate the relative importance of accounting and tax-based measures for annual bond returns and demonstrate that the explanatory power of the main variables changes with the macroeconomic situation. Overall, information signals related to a firm's capital structure are significantly associated with bond prices. The association of earnings with bond returns seems to be stronger in periods of financial distress. In non-financial crisis periods information about the relative position of earnings above or below the zero-earnings threshold seems to be sufficient for bond markets. Taxable income is significantly associated with bond returns before the recent GFC. I interpret this finding as evidence that bond investors regard taxes as a major 
outflow of firm resources which increases their risk exposure. In chapter four I further examine the interesting results with regard to the association of earnings and bond returns. More specifically, I investigate whether earnings and earnings components (cash-flows and accruals) are associated with bond prices. Sloan (1996) argues that accruals "are more subject to errors of estimation and possible manager bias than cash flows" (Scott, 2012). Furthermore, in chapter four I examine whether other marketbased information signals (e.g., credit ratings and VIX volatility) are able to explain the variation in bond prices.

TABLE 3.6: Association of Annual Bond Returns with Independent Variables

\begin{tabular}{|c|c|c|c|c|}
\hline \multicolumn{5}{|l|}{ Model: } \\
\hline Variables & $\begin{array}{l}\text { Full Sample } \\
\text { Period }\end{array}$ & $\begin{array}{c}\text { Period preceding } \\
\text { GFC } \\
\end{array}$ & $\mathrm{GFC}$ & $\begin{array}{c}\text { Period following } \\
\text { GFC }\end{array}$ \\
\hline \multicolumn{5}{|c|}{ Panel A: Abs (return) $<1.00$} \\
\hline $\begin{array}{c}\Delta \text { NIncome } \\
\text { (t-stat) }\end{array}$ & $\begin{array}{c}0.1916^{* * *} \\
(6.66)\end{array}$ & $\begin{array}{l}0.0107 \\
(0.27)\end{array}$ & $\begin{array}{c}0.2507^{* * *} \\
(5.88)\end{array}$ & $\begin{array}{l}0.0785 \\
(1.25)\end{array}$ \\
\hline$\triangle B$ Values & $-0.4760^{* * *}$ & $-0.1752^{* * *}$ & $-0.5755^{* * *}$ & $-0.3797^{* * *}$ \\
\hline (t-stat) & $(-22.02)$ & $(-5.55)$ & $(-18.02)$ & $(-7.34)$ \\
\hline PNEarnings & $-0.0281^{* * *}$ & $-0.0415^{* * *}$ & $-0.0214^{* *}$ & -0.0088 \\
\hline (t-stat) & $(-4.57)$ & $(-5.51)$ & $(-2.14)$ & $(-0.85)$ \\
\hline Industry Indicator & YES & YES & YES & YES \\
\hline Adj. $R^{2}$ & 0.2022 & 0.0877 & 0.2608 & 0.1327 \\
\hline $\mathrm{N}$ & 2760 & 867 & 1381 & 512 \\
\hline \multicolumn{5}{|l|}{ Panel B: Abs (return) $<0.80$} \\
\hline $\begin{array}{l}\Delta \text { NIncome } \\
\text { (t-stat) }\end{array}$ & $\begin{array}{l}0.1698^{* * *} \\
(6.37)\end{array}$ & $\begin{array}{l}0.0529 \\
(1.55)\end{array}$ & $\begin{array}{l}0.2028^{* * *} \\
(5.13)\end{array}$ & $\begin{array}{l}0.0785 \\
(1.25)\end{array}$ \\
\hline$\triangle B$ Values & $-0.4502^{* * *}$ & $-0.1636^{* * *}$ & $-0.5423^{* * *}$ & $-0.3797^{* * *}$ \\
\hline (t-stat) & $(-22.73)$ & $(-6.02)$ & $(-18.55)$ & $(-7.34)$ \\
\hline PNEarnings & $-0.0166^{* * *}$ & $-0.0384^{* * *}$ & -0.0049 & -0.0088 \\
\hline (t-stat) & $(-2.93)$ & $(-5.91)$ & $(-0.53)$ & $(-0.85)$ \\
\hline Industry Indicator & YES & YES & YES & YES \\
\hline Adj. $R^{2}$ & 0.2107 & 0.1072 & 0.2676 & 0.1327 \\
\hline $\mathrm{N}$ & 2749 & 865 & 1372 & 512 \\
\hline \multicolumn{5}{|c|}{ Panel C: Abs (return) $<0.60$} \\
\hline $\begin{array}{l}\Delta \text { NIncome } \\
\text { (t-stat) }\end{array}$ & $\begin{array}{l}0.0702^{* * *} \\
(3.08)\end{array}$ & $\begin{array}{c}0.0483^{*} \\
(1.65)\end{array}$ & $\begin{array}{l}0.0564 \\
(1.63)\end{array}$ & $\begin{array}{l}0.0857^{*} \\
(1.87)\end{array}$ \\
\hline$\triangle B$ Values & $-0.4189^{* * *}$ & $-0.1655^{* * *}$ & $-0.5097^{* * *}$ & $-0.2642^{* * *}$ \\
\hline (t-stat) & $(-25.44)$ & $(-7.12)$ & $(-20.70)$ & $(-6.92)$ \\
\hline PNEarnings & $-0.0110^{* *}$ & $-0.0324^{* * *}$ & 0.0034 & $-0.0152^{* *}$ \\
\hline (t-stat) & $(-2.33)$ & $(-5.80)$ & $(0.43)$ & $(-2.00)$ \\
\hline Industry Indicator & YES & YES & YES & YES \\
\hline Adj. $\mathrm{R}^{2}$ & 0.2247 & 0.0969 & 0.2794 & 0.1436 \\
\hline $\mathrm{N}$ & 2721 & 863 & 1350 & 508 \\
\hline
\end{tabular}


TABLE 3.6: Continued

\begin{tabular}{ccccc}
\hline Variables & $\begin{array}{c}\text { Full Sample } \\
\text { Period }\end{array}$ & $\begin{array}{c}\text { Period preceding } \\
\text { GFC }\end{array}$ & GFC & $\begin{array}{c}\text { Period following } \\
\text { GFC }\end{array}$ \\
\hline Panel $D:$ Abs (return) $<0.40$ & & & & $(1.22)$ \\
(t-stat) & & & & $(-0.56)$ \\
ABValues & $(0.81)$ & $-0.1639^{* * *}$ & $-0.4284^{* * *}$ & $-0.2465^{* * *}$ \\
(t-stat) & $-0.3587^{* * *}$ & $(-8.21)$ & $(-20.67)$ & $(-7.33)$ \\
PNEarnings & $(-25.92)$ & $-0.0215^{* * *}$ & 0.0036 & $-0.0168^{* *}$ \\
(t-stat) & $-0.0005^{* *}$ & $(-4.46)$ & $(0.55)$ & $(-2.53)$ \\
Industry Indicator & $(-2.38)$ & YES & YES & YES \\
Adj. R $\mathrm{R}^{2}$ & YES & 0.1056 & 0.2645 & 0.1714 \\
$\mathrm{~N}$ & 0.2182 & 859 & 1311 & 505
\end{tabular}

\begin{tabular}{ccccc}
\hline Panel E: Abs (return) $<0.20$ & & & & \\
\hline & & & & \\
$\Delta$ NIncome & -0.0138 & 0.0272 & $-0.0667^{* * *}$ & 0.0361 \\
(t-stat) & $(-0.95)$ & $(1.31)$ & $(-3.09)$ & $(1.45)$ \\
$\Delta$ BValues & $-0.2293^{* * *}$ & $-0.1226^{* * *}$ & $-0.2631^{* * *}$ & $-0.00871^{* * *}$ \\
(t-stat) & $(-22.28)$ & $(-7.50)$ & $(-16.60)$ & $(-4.20)$ \\
PNEarnings & -0.0040 & $-0.0210^{* * *}$ & $0.0108^{* *}$ & $-0.0145^{* * *}$ \\
(t-stat) & $(-1.35)$ & $(-5.26)$ & $(2.16)$ & $(-3.54)$ \\
Industry Indicator & YES & YES & YES & YES \\
Adj. R & 0.1773 & 0.0973 & 0.2049 & 0.1200 \\
$\mathrm{~N}$ & 2507 & 846 & 1175 & 486
\end{tabular}

This table reports the individual coefficients and t-statistics for the independent variables $\triangle N I n c o m e$, $\triangle B$ Values, and PNEarnings for the period preceding the GFC (April 2004 - March 2007), GFC (April 2007 March 2009), the period following the GFC (April 2009 - March 2011), and the full sample. $\Delta$ BValues refers to the first difference in total liabilities scaled by firm value, $\Delta$ NIncome to the first difference in net income scaled by firm value, $\triangle$ TaxIncome to the first-difference in estimated taxable income scaled by firm value PNEarnings proxies for a firm's individual distress situation and is equal to one if earnings are positive and zero otherwise.

Annual Bond returns are calculated as the change in bond price (cum accrued interest) plus coupon payments made during the return interval, scaled by the bond price at the start of the return interval. $\left(A n n R e t_{i j t}=\frac{B P_{i j t}+A I_{i j t}-B P_{i j t-1}}{B P_{i j t-1}}\right) B P_{i j t}$ is the flat price of bond $\mathrm{i}$ of firm $\mathrm{j}$ at time $\mathrm{t} . \mathrm{AI}_{\mathrm{ijt}}$ denotes the accrued interest for the respective bond issue. Annual bond returns are calculated for a period that starts nine month before the fiscal year-end of the respective firm and ends three months after the fiscal year-end. Using this time frame ensures that the annual bond returns relate to the respective annual disclosures published in the certified annual reports. Individual bond issues are aggregated to firm-level bond returns by taking a value weighted-average of the bond returns. In the analysis, I use these raw returns in all of the specifications. Similar to this study, Easton et al. (2009) report that their results are not altered if raw returns are adjusted for contemporaneous U.S. treasury rates that are subtracted from the respective raw returns. $t$-values in parentheses are based on heteroskedasticity-robust, firm-level clustered standard errors. $^{* * *}, * *$, and ${ }^{*}$ denote significance at $1 \%, 5 \%$, and $10 \%$, respectively. 
TABLE 3.7: Association of annual bond returns with independent variables

\begin{tabular}{ll}
\hline Model: & Annret $=\beta_{0}+\beta_{1} \Delta$ NIncome $+\beta_{2} \Delta$ BValues $+\beta_{3}$ PNEarnings \\
& $+\beta_{4} \Delta$ TaxIncome $+\sum$ Controls $+\varepsilon$ \\
\hline
\end{tabular}

Variables Full Sample Period Period preceding GFC GFC and Period following GFC

\begin{tabular}{|c|c|c|c|}
\hline \multicolumn{4}{|c|}{ Panel A: Abs (return) $<1.00$} \\
\hline $\begin{array}{c}\Delta \text { NIncome } \\
\text { (t-stat) }\end{array}$ & $\begin{array}{c}0.0879 * * \\
(2.46)\end{array}$ & $\begin{array}{l}0.0114 \\
(0.20)\end{array}$ & $0.1107^{* * *}$ \\
\hline SBValues & $\begin{array}{l}(2.46) \\
-0.4661^{* * *}\end{array}$ & $-0.0824^{*}$ & $-0.5669 * * *$ \\
\hline (t-stat) & $(-16.19)$ & $(-1.81)$ & $(-16.27)$ \\
\hline PNEarnings & -0.0039 & -0.0021 & -0.0039 \\
\hline (t-stat) & $(-0.42)$ & $(-0.16)$ & $(-0.33)$ \\
\hline$\Delta$ TaxIncome & $-0.0273^{* *}$ & $-0.1118^{* * *}$ & 0.0079 \\
\hline (t-stat) & $(-2.36)$ & $(-7.44)$ & $(0.54)$ \\
\hline Industry Indicator & YES & YES & YES \\
\hline Adj. $\mathrm{R}^{2}$ & 0.1954 & 0.2040 & 0.2483 \\
\hline $\mathrm{N}$ & 1461 & 467 & 994 \\
\hline \multicolumn{4}{|c|}{ Panel B: Abs (return) $<0.80$} \\
\hline $\begin{array}{l}\Delta \text { NIncome } \\
\text { (t-stat) }\end{array}$ & $\begin{array}{c}0.0776^{* *} \\
(2.30)\end{array}$ & $\begin{array}{l}0.0114 \\
(0.22)\end{array}$ & $\begin{array}{c}0.0979^{* *} \\
(2.42)\end{array}$ \\
\hline$\Delta B$ Values & $-0.4550^{* * *}$ & $-0.0856^{* *}$ & $-0.5542^{* * *}$ \\
\hline (t-stat) & $(-16.75)$ & $(-2.09)$ & $(-16.76)$ \\
\hline PNEarnings & 0.0003 & 0.0052 & -0.0013 \\
\hline (t-stat) & $(0.03)$ & $(0.46)$ & $(-0.11)$ \\
\hline$\Delta$ TaxIncome & $-0.0289^{* * *}$ & $-0.1028^{* * *}$ & 0.0029 \\
\hline (t-stat) & $(-2.65)$ & $(-7.56)$ & $(0.21)$ \\
\hline Industry Indicator & YES & YES & YES \\
\hline Adj. $\mathrm{R}^{2}$ & 0.2067 & 0.2111 & 0.2599 \\
\hline $\mathrm{N}$ & 1458 & 466 & 992 \\
\hline \multicolumn{4}{|c|}{ Panel C: Abs (return) $<0.60$} \\
\hline$\Delta$ NIncome & 0.0412 & 0.0075 & 0.0538 \\
\hline (t-stat) & $(1.46)$ & $(0.18)$ & $(1.57)$ \\
\hline$\triangle B$ Values & $-0.4059^{* * *}$ & $-0.1035^{* * *}$ & $-0.4928^{* * *}$ \\
\hline (t-stat) & $(-18.04)$ & $(-3.07)$ & $(-17.89)$ \\
\hline PNEarnings & 0.0004 & 0.0063 & -0.0024 \\
\hline (t-stat) & $(0.06)$ & $(0.68)$ & $(-0.25)$ \\
\hline$\Delta$ TaxIncome & $-0.0200^{* *}$ & $-0.0804^{* * *}$ & 0.0076 \\
\hline (t-stat) & $(-2.20)$ & $(-7.12)$ & $(0.65)$ \\
\hline Industry Indicator & YES & YES & YES \\
\hline Adj. $R^{2}$ & 0.2192 & 0.1547 & 0.2758 \\
\hline $\mathrm{N}$ & 1443 & 464 & 979 \\
\hline
\end{tabular}


TABLE 3.7: Continued

\begin{tabular}{cccc}
\hline Panel D: Abs (return) $<0.40$ & & & \\
\hline & & & \\
$\Delta$ NIncome & -0.0305 & 0.0059 & 0.0342 \\
(t-stat) & $(-1.31)$ & $(0.16)$ & $(-1.21)$ \\
$\Delta$ BValues & $-0.3386^{* * *}$ & $-0.1191^{* * *}$ & $-0.4060^{* * *}$ \\
(t-stat) & $(-18.45)$ & $(-4.02)$ & $(-18.17)$ \\
PNEarnings & 0.0009 & 0.0082 & 0.0018 \\
(t-stat) & $(0.16)$ & $(1.01)$ & $(-0.23)$ \\
$\Delta$ TaxIncome & $-0.0261^{* * *}$ & $-0.0601^{* * *}$ & -0.0086 \\
(t-stat) & $(-3.51)$ & $(-5.99)$ & $(-0.91)$ \\
Industry Indicator & YES & YES & YES \\
Adj. R & 0.2191 & 0.1401 & 0.2704 \\
N & 1418 & 461 & 979
\end{tabular}

Panel E Abs (return) $<0.20$

$\begin{array}{cccc}\Delta \text { NIncome } & -0.0349^{* *} & 0.0373 & -0.0502^{* *} \\ \text { (t-stat) } & (-1.97) & (1.28) & (-2.33) \\ \text { ABValues } & -0.2175^{* * *} & -0.0695^{* * *} & -0.2671^{* * *} \\ \text { (t-stat) } & (-15.62) & (-3.01) & (-15.52) \\ \text { PNEarnings } & 0.0017 & -0.0010 & 0.0008 \\ \text { (t-stat) } & (0.36) & (0.16) & (0.14) \\ \Delta \text { TaxIncome } & -0.0186^{* * *} & -0.0394^{* * *} & -0.0081 \\ \text { (t-stat) } & (-3.39) & (-4.95) & (-1.16) \\ \text { Industry Indicator } & \text { YES } & \text { YES } & \text { YES } \\ \text { Adj. } \mathrm{R}^{2} & 0.1801 & 0.1198 & 0.2266 \\ \mathrm{~N} & 1335 & 452 & 883\end{array}$

This table reports the individual coefficients and t-statistics for the independent variables $\Delta$ NIncome, $\triangle B$ Values, and PNEarnings, and $\triangle$ TaxIncome for the period preceding the GFC (April $2004-$ March 2007), and the pooled period consisting of the GFC (April 2007 - March 2009) and the period following the GFC (April 2009 - March 2011). $\Delta$ BValues refers to the first difference in total liabilities scaled by firm value, $\Delta$ Income to the first difference in net income scaled by firm value, $\Delta$ TaxIncome to the first-difference in estimated taxable income scaled by firm value PNEarnings proxies for a firm's individual distress situation and is equal to one if earnings are positive and zero otherwise. Annual Bond returns are calculated as the change in bond price (cum accrued interest) plus coupon payments made during the return interval, scaled by the bond price at the start of the return interval. (AnnRet $\left.t_{i j t}=\frac{B P_{i j t}+A I_{i j t}-B P_{i j t-1}}{B P_{i j t-1}}\right) \mathrm{BP}_{\mathrm{ijt}}$ is the flat price of bond $\mathrm{i}$ of firm $\mathrm{j}$ at time $\mathrm{t}$. $\mathrm{AI}_{\mathrm{ijt}}$ denotes the accrued interest for the respective bond issue. Annual bond returns are calculated for a period that starts nine month before the fiscal year-end of the respective firm and ends three months after the fiscal year-end. Using this time frame ensures that the annual bond returns relate to the respective annual disclosures published in the certified annual reports. Individual bond issues are aggregated to firm-level bond returns by taking a value weighted-average of the bond returns. In the analysis, I use these raw returns in all of the specifications. Similar to this study, Easton et al. (2009) report that their results are not altered if raw returns are adjusted for contemporaneous U.S. treasury rates that are subtracted from the respective raw returns. $t$-values in parentheses are based on heteroskedasticity-robust, firm-level clustered standard errors. ${ }^{* *},{ }^{* *}$, and ${ }^{*}$ denote significance at $1 \%$, $5 \%$, and $10 \%$, respectively. 
DYNAMIC PROPERTIES OF EARNINGS IN THE BOND MARKET $_{33}$

\subsection{Introduction}

Recent research in the corporate debt market provides evidence that non-persistent and persistent earnings-components, accounting accruals and cash flows respectively, are an important determinant of bond returns, and reports that earnings-related accounting signals are associated with bond returns and value relevant to investors in the corporate bond market (Easton et al., 2009). In this chapter of the dissertation I extend prior research and the study in chapter three by providing insights about whether bond investors probably fail to "discriminate between the different levels of the persistence of the accrual and cash components of earnings" (Dechow et al. 2008). Extant literature identifies a higher persistence of cash flows compared to accruals for future cash flows (e.g., Richardson, 2005). This is likely a result of estimation errors in the formation of accruals (Dechow and Dichev, 2002) or even accrual earnings management (e.g., Dechow et al., 2010; Jones, 1991). Furthermore, I investigate whether the importance of the level of persistence is impacted by the level of financial distress inherent in the economy.

Research in finance related to default models, such as structural models (Merton, 1974) and reduced-form models (Jarrow and Turnbull, 1995), questions the relevance of accounting signals in both the equity and bond market. More specifically, it is argued that bond returns are mainly driven by market-based parameters including but not limited to market interest rates, liquidity, market sentiment, and information provided by third-party intermediaries such as credit rating agencies. Allowing for dynamic properties of accounting signals, I extend recent research (Easton et al., 2009) that focuses on the association (value relevance) of information signals with bond returns (for debt market investors). ${ }^{34}$ The relevance of accounting- and market-based information on which bond holders trade is probably subject to external dynamics including but not limited to the macroeconomic environment and overall 'fear' in the market. Furthermore, I investigate whether the association of annual bond returns with accounting- and market-based information signals is conditional on the distribution of the bond returns itself.

\footnotetext{
33 This chapter is based on a working paper co-authored with Thomas Loy.

${ }^{34}$ With dynamic properties I refer to structural (macroeconomic) breaks and related aspects that alter the credibility of information signals and thus the composition and weighting of the information set from an investor's point of view.
} 
Overall, this study extends recent accounting research in the corporate debt market by incorporating different components with different persistence levels into the investment decision frameworks that is linked to the recent financial crisis. ${ }^{35}$ Controlling for the presence of systematic risk in the economy, I provide evidence that accounting accruals and cash flows are not associated with corporate bond returns in the three years preceding the financial crisis. During this period, the world economy believed in sustained growth and experienced positive capital market performances. However, using a point estimate of the conditional mean of annual bond returns, I find a positive and significant association of accounting accruals with annual bond returns during the recent financial crisis. In addition, I use quantile regression techniques (Koenker and Bassett, 1978; Koenker and Hallock, 2001) to not restrict the analysis to specific point estimates. Hence, this semi-parametric technique allows regression coefficients to explain annual bond returns conditional on their distribution. I find that for the median quantile of the bond return distribution both changes in cash flows and accruals are positively and significantly associated with annual bond returns during the recent financial crisis. The results suggest that debt market investors require additional verification, and thus, at least partly, complement these market-based information signals with accounting-based measures during the recent financial crisis. This is potentially attributable to a perceived lack of reliability and credibility of market-based information, and hence has to be backed up by firm-specific accounting signals.

With regard to market-based measures, I investigate whether systematic risk, as proxied by the Standard \& Poor's 500 volatility index (VIX) (Lyle et al., 2011), and firmspecific changes in creditworthiness explain the variation in annual bond returns. I find that the VIX, commonly known as the 'fear' index, exhibits an interesting dynamic going from the pre-crisis to the crisis period (Figure 4.1). Before the crisis, the VIX has an insignificant negative association with annual bond returns. During the crisis this association increases in magnitude and becomes significant. In the pre-crisis period higher expected volatility in equity returns makes holding stocks more profitable than 'parking' money in the bond market (e.g., Hull, 2011). As a result, investors sell bonds, and thus depress bond prices. During the crisis I observe a significant jump in expected equity return volatility, with the VIX rising from levels between 10 and 30 during the years 2004 through 2007 to levels between 30 and 80 indicating considerably increased fluctuation.

\footnotetext{
35 According to the Business Cycle Dating Committee (2010) of the National Bureau of Economic Research (NBER), the recent financial crisis ("Great Recession") started in December 2007 and ended in June 2009 (http://www.nber.org/ cycles/sept2010.html). Attributable to the construction of the annual bond returns I am using the period from April 2007 to March 2009 as the financial crisis period.
} 
FIGURE 4.1 Standard \& Poor's 500 Volatility Index January 2004 - June 2011

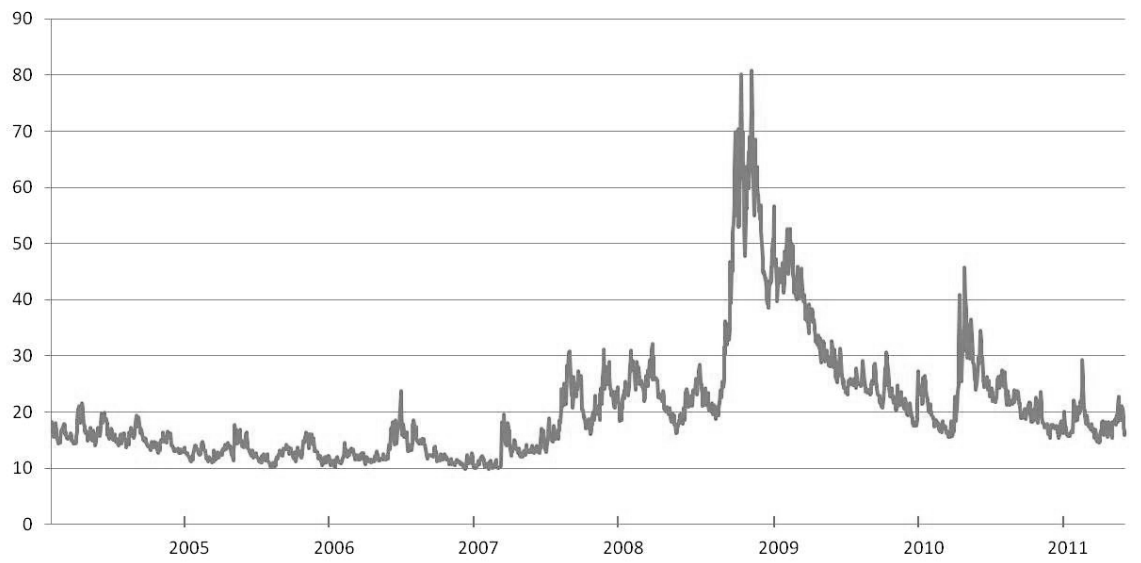

During the financial crisis period with high volatility and declining stock prices, theory tells us that investment grade bonds provide a safe haven, a phenomenon commonly referred to as the 'flight-to-quality' (e.g., Yang et al., 2009). Funds being transferred from the equity to the bond market lead to rising bond prices, resulting presumably in a positive association between stock market volatility and bond returns (Chordia et al., 2005; Connolly et al., 2005). Nevertheless, we show that the association of VIX and bond returns is conditional on the bond return distribution. Hence, I find a negative association of VIX and bond returns for the middle (third) quintile of the bond distribution in both periods. Basing the analysis on the complete bond return distribution, the association is positive in the period before the GFC and negative and significant during the GFC. Arguably, attributable to the increased standard deviation of bond returns, the correlation of stock and bond returns during expansive periods generally is, albeit time-varying, positive but reverses during severe crises such as the Great Depression and the Dotcom bubble (e.g., Ilmanen, 2003; Yang et al., 2009). In line with this evidence, I additionally observe increases in mean bond returns going from the pre- to the crisis period suggesting that funds are indeed shifted from the equity market into the bond market.

In addition to the market sentiment analysis related to systematic risk inherent in the economy, I also include firm-specific information related to an entity's creditworthiness. My results suggest that information provided through credit rating agencies is associated with annual bond returns during both the financial crisis and, even to a larger extent, non-financial crisis period. ${ }^{36}$ Thus, the findings are in line with previous research providing insights on credit rating agencies incorporating private

36 This contradicts arguments concerning reputational losses of credit rating agencies during the global financial crisis (e.g., Mathis et al., 2009). 
information when evaluating firm specifics related to performance and creditworthiness (Boot et al., 2006).

Overall, understanding the role of both accounting-based and market-based information in the corporate bond market is relevant for at least two reasons. First, accounting standard setters such as the Financial Accounting Standards Board (FASB) and the International Accounting Standards Board (IASB) intend information attributable to corporate financial reporting to be relevant and useful to various stakeholders in making investment decisions. Stakeholders include both present and potential equity investors as well as creditors although these groups potentially assess the reported earnings and disclosures differently due to their different exposure to risk (e.g., Barth et al., 1998; Collins et al., 1997). Especially debt investors with their investments' limited upside potential, attributable to the instruments' inherent concave payoff function, may shift their risk assessment to certified annual disclosures when market-based information seems to be less reliable and credible. Second, accounting signals may reflect information about a firm's closeness to default and creditworthiness that is not captured by market-based measures (Das et al., 2009), especially during the recent financial crisis.

Taken together, I investigate whether earnings-related accounting signals are associated with corporate bond returns during both the pre- and financial crisis period. Furthermore, I provide evidence on the association of other market-based information such as market sentiment and firm-specific creditworthiness with firm-specific annual bond returns. The results extend prior research by providing evidence on dynamic properties of earnings-related accounting information that is potentially attributable to a shift in bond investor information sets and needs during the recent financial crisis.

The remainder of chapter four is structured as follows. Section 4.2 provides an overview of the related literature and also includes the hypothesis development. Section 4.3 describes the methodology, including research design (e.g., quantile regressions and sample formation). Section 4.4 discusses the descriptive statistics and empirical results. Section 4.5 concludes.

\subsection{Prior research and hypothesis development}

\subsubsection{Prior research}

Extant literature in the equity market has focused on the association and value relevance of accounting income numbers with equity prices (Ball and Brown, 1968; Beaver, 1968). In a similar vein, recent studies in the debt market have emerged and report that bond prices (yields or returns) respond in a predictable way to new earnings related accounting information published in unaudited preliminary earnings announcements and audited annual financial statements (e.g., Khurana and Raman, 2003; Easton et al., 2009; DeFond and Zhang, 2011; Amiram and Owens, 2011). All these studies rely on the so called information approach to decision usefulness (Beaver, 1998) and acknowledge 
that new information will be incorporated into the investment decision process after its revelation. Easton et al. (2009) shed light on the value relevance of earnings announcements for bond investors and provide evidence that earnings-related accounting signals are more informative to bond holders if they reveal bad news and are related to non-investment grade bonds that are associated with higher default risk. Khurana and Raman (2003) report the usefulness of fundamentals for investors in the primary bond market. With regard to the anticipation of information content incorporated in earnings numbers, DeFond and Zhang (2011) show that bond prices only anticipate earnings surprises that are related to bad news.

The value relevance of accounting earnings in the equity (e.g., Ball and Brown, 1968) and the debt market (Easton et al., 2009) is well established in the accounting literature. Whether the disaggregation of earnings into its components, operating cash flows and accounting accruals, provides incremental value relevant information has been a highly disputed issue for a considerable period. For example, some research indicates that disaggregation provides incremental value-relevant information (Bowen et al., 1987; Wilson, 1986). Conversely, Bernard and Stober (1989) challenge these findings. They conclude that there are no systematically different stock price responses to information in cash flows or accounting accruals. Furthermore, Sloan (1996) shows that investors tend to fixate on aggregate accounting earnings. Although cash flows and accounting accruals contain somewhat different information, these differences are 'ignored' until they are finally reflected in future earnings.

Bond holders, attributable to their concave payoff function, are primarily concerned with the firm's ability to pay interest and repay the principal. Therefore, the ability of contemporaneous earnings and its components to predict future cash flows is crucial to bond investors. Through the accrual process, accounting earnings and its components ideally provide a better approximation of current economic performance than contemporaneous cash flows (Barth et al., 2001). Extant literature identifies a higher persistence of cash flows compared to accruals for future cash flows (e.g., Richardson, 2005). This is likely a result of estimation errors in the formation of accruals (Dechow and Dichev, 2002) or even accrual earnings management (e.g., Dechow et al., 2010; Jones, 1991). Furthermore, Dechow (1994) reports that the importance of accruals, in comparison to cash flows, is increased the shorter the firm performance measurement horizon. Hence, longer measurement windows lead to a more accurate mapping of cash flows with the accrual accounting process. From a debt investor point of view, it is not clear whether persistent earnings components are at all value relevant as the determination of a firm's growth potential is not the primary interest of bond holders. If transitory and/or persistent items provide information on downside-risk protection, especially during periods of financial distress, both components might be of value to bond holders.

Minnis (2011) shows that for relatively opaque firms (i.e., owner-managed firms) financial reporting becomes more decision useful for lenders when it is audited. Audited cash flows and accruals are significantly more persistent than their non-audited counterparts. While the firms in the sample are unanimously audited statutorily, these 
findings are nevertheless relevant in my setting. During the financial crisis, with market information becoming less reliable and credible, bond opaqueness increases. Arguably, audited financial statements serve as a remedy by providing more precise and verifiable information signals for estimating future firm and bond performance. In a similar vein, accounting signals may reflect information about a firm's closeness to default, or its creditworthiness, that is not yet captured by market-based measures (Das et al., 2009).

\subsubsection{Hypothesis development}

A vast literature relevant to the equity market provides evidence that aggregated (e.g., Ball and Brown, 1968; Beaver, 1968) and disaggregated (e.g., Bowen et al., 1987) annual accounting information related to earnings is associated with and value relevant for investor portfolio decisions. Because an equity investor's pay-off function can be modeled as a call option in the respective company, earnings growth prospects are of utmost importance to the average investor. With regard to the bond market, investors are more sensitive to losses because they do not participate in any upside potential which increases firm-value above the amount that has to be repaid to creditors. Because of these different payoff structures, bond investors possibly demand different (marketand accounting-based) information than equity investors. Thus, I investigate whether earnings information, decomposed into cash flow and accrual information, is associated with bond returns during both the recent financial crisis and the three years preceding this crisis. ${ }^{37}$ I expect earnings related information to be associated with annual bond returns during periods of turmoil, as experienced during the recent financial crisis, and not necessarily during non-crisis periods. More specifically, I test:

Hypothesis 1a: Annual changes in accruals ( $\triangle A C C R$ ) are incrementally associated with annual bond returns during the recent financial crisis after controlling for firm-specific distress indicators (LOSS) and credit ratings information (Speculative).

Hypothesis 1b: $\quad$ Annual changes in cash flows ( $\triangle C F)$ are incrementally associated with annual bond returns during the recent financial crisis after controlling for firm-specific distress indicators (LOSS) and credit ratings information (Speculative).

To further analyze hypotheses $1 \mathrm{a}$ and $1 \mathrm{~b}$ I include additional market-based parameters into the analysis. It is possible that market-based information related to the

37 Our analysis is limited to the three years preceding the recent financial crisis because of bond information restrictions in the TRACE database. 
state of the economy (i.e., systematic risks inherent in the economy) and private information as reflected in credit rating changes depresses the importance and association of accounting-based signals with annual bond returns. Especially, credit ratings include information that is timelier than information annually generated by a firm's accounting system and to some extent also include financial reporting disclosures .Thus, I test:

Hypothesis 2a: $\quad$ Annual changes in accruals ( $\triangle A C C R$ ) are incrementally associated with annual bond returns during the recent financial crisis after controlling for market-based information related to the state of the economy (VIX) and changes in credit ratings ( $\Delta$ Rating).

Hypothesis 2b: Annual changes in cash flows ( $\triangle C F$ ) are incrementally associated with annual bond returns during the recent financial crisis after controlling for market-based information related to the state of the economy (VIX) and changes in credit ratings ( $\Delta$ Rating).

\subsection{Methodology}

\subsubsection{Quantile regression approach}

In this study I first analyze the association of accounting information signals with bond returns using traditional ordinary least square (OLS) regression. I then show that using a quantile regression approach seems to be a more suitable research design. Quantile regressions (Koenker and Bassett 1978) may be used to extend ordinary least square (OLS) estimation of conditional mean models, especially if independent variables have an impact on the conditional distribution of the dependent variable potentially affecting the shape of the distribution (e.g., heteroscedasticity, extremely skewed distributions, multimodality etc.). In these cases, quantile regressions provide a more complete picture of the empirical analysis which cannot be captured through OLS estimations. Table 4.1 shows that the OLS estimation is based on the conditional-mean function and the quantile regression (QRA) approach on the conditional-quantile function. In contrast to the QRA, linear regression models ignore the full conditional distributional properties of the dependent variable. In Table 4.1, ( $p$ ) and $\theta$ refers to the area below a specific quantile (Hao and Naiman 2007). In the left column (OLS estimator), the term $\beta_{0}+\beta_{1} x_{i}$ is assigned to the conditional mean of $\mathrm{y}$ given $\mathrm{x}$. Furthermore, the conditional variance is assumed to be homoscedastic. In contrast, QRA "estimates the differential effect of a covariate on the full distribution and accommodates heteroscedasticity" (Hao and 
Naiman 2007). With regard to the error term $u_{\theta i}$ in the QRA, the $\theta$ th quantile of the error term needs to be zero (Table 4.1).

TABLE 4.1 Comparison of OLS versus Quantile Regression Estimators

$$
\begin{aligned}
& \text { OLS estimator } \\
& y_{i}=\beta_{0}+\beta_{1} x_{i}+\varepsilon_{i} \\
& \text { or: } y_{i}=x_{i}^{\prime} \beta_{i}+u_{i} \\
& \min \sum_{i} 1 \times u_{i}^{2}=\sum_{i} 1 \times\left(y_{i}-x_{i}^{\prime} \cdot \beta\right)^{2} \\
& \min \sum_{i} 1 \times\left|u_{i}\right|=\sum_{i} 1 \times\left|y_{i}-x_{i}^{\prime} \cdot \beta\right| \\
& \text { Quantile regression estimator } \\
& y_{i}=\beta_{0}^{(p)}+\beta_{1}^{(p)} x_{i}+\varepsilon_{i}^{(p)} \\
& \text { or: } y_{i}=x_{i}^{\prime} \beta_{\theta}+u_{\theta i} \\
& \text { Quant }_{\theta}\left(y_{i} \mid x_{i}\right) \equiv \inf \left\{y: F_{i}(y \mid x) \theta\right\}=x_{i}^{\prime} \cdot \beta \\
& \operatorname{Quant}_{\theta}\left(u_{\theta i} \mid x_{i}\right)=0 \\
& \min \sum_{i: u_{\theta i>0}} \theta \times\left|u_{\theta i}\right|+\sum_{i: u_{b i<0}}(1-\theta) \times\left|u_{\theta i}\right| \\
& =\sum_{i: y_{i}-x_{i}^{\prime} \cdot \beta_{\theta}>0} \theta \times\left|y_{i}-x_{i}^{\prime} \cdot \beta_{\theta}\right|+\sum_{i: y_{i}-x_{i}^{\prime} \cdot \beta_{\theta}<0}(1-\theta) \times\left|y_{i}-x_{i}^{\prime} \cdot \beta_{\theta}\right|
\end{aligned}
$$

\subsubsection{Research design and sample selection}

I first follow Easton et al. (2009) in testing whether accounting-related information signals, such as cash flows and accruals, are associated with annual bond returns. Applying OLS regression analysis to the model set out below, I test the hypotheses for both the financial crisis period and the three years preceding it. Later, the quantile regression approach is used to address concerns that the OLS regression analysis produces biased results as the full distribution of the dependent variable is neglected.

$$
\begin{aligned}
\text { AnnRet }_{j t=}=\beta_{0} & +\beta_{1} \Delta C F+\beta_{2} \Delta \text { ACCR }+\beta_{3} \text { Negative }+\beta_{4} \Delta C F * \text { Negative } \\
& +\beta_{5} \Delta A C C R * \text { Negative }+\beta_{6} \text { Speculative }+\beta_{7} \Delta C F * \text { Speculative } \\
& +\beta_{8} \Delta A C C R * \text { Speculative }+\sum \text { Year Fixed Effects }+\varepsilon
\end{aligned}
$$

where $\triangle \mathrm{CF}$ denotes the annual change in cash flow from operations and $\triangle \mathrm{ACCR}$ the annual change in accruals. Negative is an indicator variable taking on a value of 1 if a negative change in net income (i.e., a negative earnings surprise) is present for any given period. Speculative is an indicator variable taking on a value of 1 if the average bond ratings for any given firm at time $t$ is below investment-grade (i.e., non-investment grade). Furthermore, interaction terms are included to capture possible associations of the two main accounting-related variables ( $\triangle \mathrm{CF}$ and $\triangle \mathrm{ACCR}$ ) conditional on whether 
firms have negative/positive earnings surprises and investment-grade credit quality. I also add year-fixed effects to control for year-specific differences in the bond market not captured by partitioning the sample. All reported t-statistics are based on robust standard errors clustered at the firm-level.

In a second step, in line with Easton et al. (2009), I expand the previous specification to also include the variable Loss, indicating whether firms are financially distressed (DeFond et al., 2002; Reynolds and Francis, 2000). Additionally, I extend the econometric model and include three-way interactions to capture whether the association between bond returns and accounting signals is moderated by the inclusion of an additional variable.

$$
\begin{aligned}
\text { AnnRet }_{j t}= & \beta_{0}+\beta_{1} \Delta C F+\beta_{2} \Delta \text { ACCR }+\beta_{3} \text { Negative }+\beta_{4} \Delta C F * \text { Negative }+\beta_{5} \Delta \text { ACCR (27) } \\
& * \text { Negative }+\beta_{6} \text { Speculative }+\beta_{7} \Delta C F * \text { Speculative }+\beta_{8} \Delta \text { ACCR } * \text { Speculative } \\
& +\beta_{9} \text { Negative } * \text { Speculative }+\beta_{10} \Delta C F * \text { Negative } * \text { Speculative }+\beta_{11} \Delta A C C R \\
& * \text { Negative } * \text { Speculative }+\beta_{12} \text { Loss }+\beta_{13} \Delta C F * \text { Loss }+\beta_{14} \Delta A C C R * \text { Loss } \\
& +\beta_{15} \text { Loss } * \text { Speculative }+\beta_{16} \Delta C F * \text { Loss } * \text { Speculative }+\beta_{17} \Delta A C C R * \text { Loss } \\
& * \text { Speculative }+\sum \text { Year Fixed Effects }+\varepsilon
\end{aligned}
$$

To address multicollinearity among the two-way and three-way interaction terms, I also use reduced regressions of annual bond returns on changes in annual earnings components. ${ }^{38}$ Furthermore, I include another non-accounting related variable (VIX) which is potentially associated with annual bond returns and could probably mitigate the importance of accounting variables related to changes in annual earnings components. The VIX proxies for macroeconomic fear not associated with a firm's specific bond issue or credit quality which is not captured through year-fixed effects or partitioning the sample. Additionally, I include a variable which captures changes in credit ratings ( $\Delta$ Rating) because this possibly enhances the precision of information signals related to third-party creditworthiness providers. Thus, I run the following specification:

$$
\begin{aligned}
\text { AnnRet }_{j t}= & \beta_{0}+\beta_{1} \Delta C F+\beta_{2} \Delta A C C R+\beta_{3} \text { Negative }+\beta_{4} \text { Speculative }+\beta_{5} \text { Loss } \\
& +\beta_{6} \Delta \text { Rating }+\beta_{7} \text { VIX }+\sum \text { Year Fixed Effects }+\varepsilon
\end{aligned}
$$

To investigate whether the information content of earnings is associated with annual bond returns, I utilize bond trading information and credit rating information from the TRACE and Mergent FISD database and merge this complete universe with

\footnotetext{
${ }^{38}$ Following prior research, I first use the regression models (26) and (27) before introducing the reduced model.
} 
Compustat North America. Annual bond returns are calculated following Easton et al. (2009): ${ }^{39}$

$$
\text { AnnRet }_{i j t}=\frac{B P_{i j t}+A I_{i j t}-B P_{i j t-1}}{B P_{i j t-1}} \quad \text { see equation (14) in chapter } 3
$$

In the above equation $\mathrm{BP}_{\mathrm{ijt}}$ is the flat price of bond $\mathrm{i}$ of firm $\mathrm{j}$ at time $\mathrm{t} . \mathrm{AI}_{\mathrm{ijt}}$ denotes the accrued interest for the respective bond issue. Annual bond returns are calculated for a period that starts nine month before the fiscal year-end of the respective firm and ends three months after the fiscal year-end. Using this time frame ensures that the annual bond returns relate to the respective annual disclosures published in the certified annual reports. Individual bond issues are aggregated to firm-level bond returns by taking a value weighted-average of the bond returns. In the analysis, I use these raw returns in all of the specifications. Easton et al. (2009) report that their results are not altered if raw returns are adjusted for contemporaneous U.S. treasury rates that are subtracted from the respective raw returns. The focus of this study is on bonds which are non-redeemable, non-callable, and do not have other step-up clauses or embedded derivatives. Matching TRACE bond returns with Compustat North America annual firm-specific disclosures, omitting outliers in the top and bottom percentile of the distribution of raw bond returns and net income before extraordinary items scaled by lagged market value of equity, results in 2697 firm-year observations.

\subsection{Descriptive statistics and empirical results}

\subsubsection{Descriptive statistics}

With regard to the descriptive statistics, Table 4.2 shows the two-digit SIC codes of all reference firm-years in the sample. The most prominent two-digit SIC codes refer to the chemicals and allied products category (281 firm-year observations) and electrical, gas and sanitary services (235 firm-year observations). ${ }^{40}$ To focus on firms with a more homogenous business model, I exclude financial institutions (SIC 6x) from the analysis.

Table 4.3 (Panel A) shows the descriptives of the dependent variable (AnnRet ${ }_{j t}$ ) and all included main effects $(\triangle C F, \triangle A C C R$, Rating, Speculative, Negative, and Loss). Overall, the annual return variable shows that bond investments are a rather secure investment form with less than $10 \%$ of the weighted-average firm-specific bond returns being negative. Interestingly, about $50 \%$ of the firm-specific bond investments are to be

\footnotetext{
${ }^{39}$ Bond yields are calculated using both TRACE and Mergent FISD to check the reliability and precision of the firm-specific annual bond returns.

40 The bonds represented in our final sample cover 55 two-digit SIC group industries of which one (SIC 28) represents more than ten percent, and three (SIC 13, 35, 49) more than five percent of total observations.
} 
considered non-investment grade and about $16 \%$ of the firm-year specific observations report a loss.

Table 4.3 (Panel B and C) further compares the pre-crisis and crisis subsample. AnnRet $_{j t}$ exhibits a steep increase in magnitude and variance pointing towards funds being shifted from the equity to the bond market, resulting in rising bond prices. Ratings slightly decrease with $56 \%$ (50\%) of the observations regarded as speculative in the crisis (pre-crisis). The spillover of the financial crisis into the rest of the economy is also followed by a significant increase in the propensity of losses (Loss) and negative earnings surprises (Negative). 
TABLE 4.2 Firm-Year Specific Two-Digit SIC Groups

\begin{tabular}{|c|c|c|c|c|c|}
\hline SIC Description & $\begin{array}{l}\text { Two-digit } \\
\text { SIC group }\end{array}$ & Frequency & Percent & $\begin{array}{l}\text { Cumulative } \\
\text { Frequency }\end{array}$ & $\begin{array}{l}\text { Cumulative } \\
\text { Percent }\end{array}$ \\
\hline Metal Mining & 10 & 13 & 0.48 & 13 & 0.48 \\
\hline Coal Mining & 12 & 12 & 0.45 & 25 & 0.93 \\
\hline Oil and Gas Extraction & 13 & 144 & 5.37 & 169 & 6.30 \\
\hline $\begin{array}{l}\text { Mining and Quarrying of Nonmetallic } \\
\text { Minerals, Except Fuels }\end{array}$ & 14 & 14 & 0.52 & 183 & 6.82 \\
\hline Building Construction & 15 & 34 & 1.27 & 217 & 8.09 \\
\hline Heavy Construction & 16 & 6 & 0.22 & 223 & 8.31 \\
\hline Food and Kindred Products & 20 & 128 & 4.77 & 351 & 13.08 \\
\hline Tobacco Products & 21 & 10 & 0.37 & 361 & 13.46 \\
\hline Textile Mill Products & 22 & 19 & 0.71 & 380 & 14.16 \\
\hline Apparel & 23 & 15 & 0.56 & 395 & 14.72 \\
\hline Lumber and Wood Products & 24 & 20 & 0.75 & 415 & 15.47 \\
\hline Furniture and Fixtures & 25 & 27 & 1.01 & 442 & 16.47 \\
\hline Paper and Allied Products & 26 & 88 & 3.28 & 530 & 19.75 \\
\hline Printing and Publishing & 27 & 57 & 2.12 & 587 & 21.88 \\
\hline Chemicals and Allied Products & 28 & 281 & 10.47 & 868 & 32.35 \\
\hline Petroleum Refining and Related Industries & 29 & 25 & 0.93 & 893 & 33.28 \\
\hline Rubber and Miscellaneous Products & 30 & 40 & 1.49 & 933 & 34.77 \\
\hline Leather and Leather Products & 31 & 4 & 0.15 & 937 & 34.92 \\
\hline Stone, Clay, Glass, and Concrete Products & 32 & 18 & 0.67 & 955 & 35.59 \\
\hline Primary Metal Industries & 33 & 79 & 2.94 & 1034 & 38.54 \\
\hline Fabricated Metal Products & 34 & 63 & 2.35 & 1097 & 40.89 \\
\hline $\begin{array}{l}\text { Industrial and Commercial Machinery and } \\
\text { Computer Equipment }\end{array}$ & 35 & 158 & 5.89 & 1255 & 46.78 \\
\hline Electronic and Electronic Equipment & 36 & 114 & 4.25 & 1369 & 51.02 \\
\hline Transportation Equipment & 37 & 117 & 4.36 & 1486 & 55.39 \\
\hline Mesr/Anlyz/Cntrl Instruments & 38 & 121 & 4.51 & 1607 & 59.90 \\
\hline Misc. Manufacturing Industries & 39 & 21 & 0.78 & 1628 & 60.68 \\
\hline Railroad Transportation & 40 & 19 & 0.71 & 1647 & 61.39 \\
\hline Motor Freight Transportation & 42 & 27 & 1.01 & 1674 & 62.39 \\
\hline Water Transportation & 44 & 31 & 1.16 & 1705 & 63.55 \\
\hline Transportation by Air & 45 & 25 & 0.93 & 1730 & 64.48 \\
\hline Pipelines, Except Natural Gas & 46 & 12 & 0.45 & 1742 & 64.93 \\
\hline Transportation Services & 47 & 3 & 0.11 & 1745 & 65.04 \\
\hline Communications & 48 & 126 & 4.70 & 1871 & 69.74 \\
\hline Electic., Gas and Sanitary Services & 49 & 235 & 8.76 & 2106 & 78.49 \\
\hline Wholesale Trade - Durable Goods & 50 & 59 & 2.20 & 2165 & 80.69 \\
\hline Wholesale Trade - Nondurable Goods & 51 & 31 & 1.16 & 2196 & 81.85 \\
\hline $\begin{array}{l}\text { Building Materials, Hardware, Garden } \\
\text { Supply }\end{array}$ & 52 & 14 & 0.52 & 2210 & 82.37 \\
\hline General Merchandise Stores & 53 & 26 & 0.97 & 2236 & 83.34 \\
\hline Food Stores & 54 & 28 & 1.04 & 2264 & 84.38 \\
\hline $\begin{array}{l}\text { Automotive Dealers and Gasoline Service } \\
\text { Stations }\end{array}$ & 55 & 28 & 1.04 & 2292 & 85.43 \\
\hline Apparel and Accessory Stores & 56 & 26 & 0.97 & 2318 & 86.40 \\
\hline Home Furniture & 57 & 7 & 0.26 & 2325 & 86.66 \\
\hline Eating and Drinking Places & 58 & 36 & 1.34 & 2361 & 88.00 \\
\hline Misc. Retail & 59 & 30 & 1.12 & 2391 & 89.12 \\
\hline Holding and Other Investment Offer & 67 & 6 & 0.22 & 2397 & 89.34 \\
\hline Hotel, Rooming Houses & 70 & 13 & 0.48 & 2410 & 89.82 \\
\hline Personal Services & 72 & 22 & 0.82 & 2432 & 90.64 \\
\hline Business Services & 73 & 91 & 3.39 & 2523 & 94.04 \\
\hline Automotive Repair, Services and Parking & 75 & 11 & 0.41 & 2534 & 94.45 \\
\hline Motion Pictures & 78 & 7 & 0.26 & 2541 & 94.71 \\
\hline Amusement and Recreation Services & 79 & 59 & 2.20 & 2600 & 96.91 \\
\hline Health Services & 80 & 40 & 1.49 & 2640 & 98.40 \\
\hline Social Services & 83 & 2 & 0.07 & 2642 & 98.47 \\
\hline Engineering, Accounting, Research Services & 87 & 25 & 0.93 & 2667 & 99.40 \\
\hline Nonclassifiable Establishments & 99 & 16 & 0.60 & 2683 & 100.00 \\
\hline
\end{tabular}


TABLE 4.3 Descriptive Statistics of Dependent Variables and Main Effects

\begin{tabular}{|c|c|c|c|c|c|c|c|}
\hline \multicolumn{8}{|c|}{ Panel A: Full Sample (April 2004 - March 2009) } \\
\hline Variable & $\mathrm{N}$ & Mean & Std & $5 \%$ & $25 \%$ & $75 \%$ & $95 \%$ \\
\hline AnnRet & 2697 & 0.0775 & 0.1135 & -0.0499 & 0.0356 & 0.0930 & 0.2537 \\
\hline$\Delta \mathrm{CF}$ & 2695 & 0.0039 & 0.0456 & -0.0578 & -0.0117 & 0.0191 & 0.0696 \\
\hline$\triangle \mathrm{ACCR}$ & 2695 & 0.0004 & 0.0713 & -0.0911 & -0.0198 & 0.0167 & 0.0945 \\
\hline Rating & 2697 & 10.0066 & 3.4081 & 5 & 8 & 13 & 15 \\
\hline Speculative & 2697 & 0.5291 & 0.4992 & 0 & 0 & 1 & 1 \\
\hline Negative & 2697 & 0.3811 & 0.4857 & 0 & 0 & 1 & 1 \\
\hline Loss & 2697 & 0.1646 & 0.3709 & 0 & 0 & 0 & 1 \\
\hline \multicolumn{8}{|c|}{ Panel B: Pre-Crisis Period Sample (April 2004 - March 2007) } \\
\hline Variable & $\mathrm{N}$ & Mean & Std & $5 \%$ & $25 \%$ & $75 \%$ & $95 \%$ \\
\hline AnnRet & 1424 & 0.0553 & 0.0622 & -0.0122 & 0.0312 & 0.0736 & 0.1110 \\
\hline$\Delta \mathrm{CF}$ & 1423 & 0.0074 & 0.0395 & -0.0397 & -0.0078 & 0.0192 & 0.0696 \\
\hline$\triangle \mathrm{ACCR}$ & 1423 & -0.0032 & 0.0585 & -0.0782 & -0.0167 & 0.0133 & 0.0585 \\
\hline Rating & 1424 & 9.7429 & 3.4575 & 5 & 7 & 12 & 15 \\
\hline Speculative & 1424 & 0.5 & 0.5001 & 0 & 0 & 1 & 1 \\
\hline Negative & 1424 & 0.3335 & 0.4716 & 0 & 0 & 1 & 1 \\
\hline Loss & 1424 & 0.1186 & 0.3235 & 0 & 0 & 0 & 1 \\
\hline \multicolumn{8}{|c|}{ Panel C: Crisis Period Sample (April 2007 - March 2009) } \\
\hline Variable & $\mathrm{N}$ & Mean & Std & $5 \%$ & $25 \%$ & $75 \%$ & $95 \%$ \\
\hline AnnRet & 1273 & 0.1024 & 0.1477 & -0.0915 & 0.0495 & 0.1254 & 0.3624 \\
\hline$\Delta \mathrm{CF}$ & 1272 & -0.0000 & 0.0513 & -0.0755 & -0.0177 & 0.0190 & 0.0691 \\
\hline$\triangle \mathrm{ACCR}$ & 1272 & 0.0045 & 0.0831 & -0.1125 & -0.0229 & 0.0239 & 0.1356 \\
\hline Rating & 1273 & 10.3016 & 3.3287 & 5 & 8 & 13 & 16 \\
\hline Speculative & 1273 & 0.5616 & 0.4963 & 0 & 0 & 1 & 1 \\
\hline Negative & 1273 & 0.4344 & 0.4958 & 0 & 0 & 1 & 1 \\
\hline Loss & 1273 & 0.2160 & 0.4116 & 0 & 0 & 0 & 1 \\
\hline
\end{tabular}

AnnRet is the annual raw bond return. $\triangle C F$ is the annual change in cash flow from operations. $\triangle A C C R$ is the annual change in total accruals. Speculative is an indicator variable taking on a value of 1 if the average bond ratings for the firm is below investment-grade (BBB- or less) or 0 otherwise. Negative is an indicator variable taking on a value of 1 if there is a negative earnings surprise (negative earnings change) or 0 otherwise. Loss is an indicator variable taking on a value of 1 if earnings are negative and 0 otherwise.

Table 4.4 presents Pearson/Spearman correlations between raw annual buy-andhold bond returns, changes in annual earnings components and control variables and confirms that multicollinearity is removed in the reduced model. Overall, the results thus indicate that even after the inclusion of additional proxies for macroeconomic fear and changes in idiosyncratic risk, associations remain robust.

\subsubsection{Ordinary-Least Square (OLS) base model}

In a first step I analyze whether information inherent in changes of reported annual earnings components (i.e., changes in cash flows $(\triangle C F)$ and changes in accounting accruals $(\triangle A C C R)$ ) are equally important in different economic environments. Thus, I split the sample into a pre-crisis period (April 200441 through March 2007) and crisis

\footnotetext{
41 To compute bond returns for fiscal year 2005 I also employ flat bond prices (BPijt) starting in 2004.
} 
period (April 2007 through March 2009). The pre-crisis sample contains 1,423 and the global financial crisis sample 1,272 firm-year observations.

Model (1) illustrated in Table 4.5 includes earnings components, $\triangle C F$ and $\triangle A C C R$, as the main variables of interest. Controls consist of Negative, Loss, and Speculative. Further specifications amend the model by adding changes in idiosyncratic risk (i.e., changes in credit ratings) and levels of VIX. ${ }^{42}$ While Speculative captures the effects of market participants limiting themselves to holding investment grade paper, $\Delta$ Rating proxies for subsequent changes in firm-specific risk. I expect the VIX, commonly known as "fear" index, to proxy for macroeconomic (i.e., systematic) risk (Lyle et al., 2011).

Table 4.5 confirms hypotheses $1 \mathrm{a}$ and $2 \mathrm{a}$. Even after inclusion of additional controls for firm-specific and macroeconomic perceptions of risk, the importance of accounting figures for bond investors seems to increase during the financial crisis. Irrespective of market variables, changes in accounting accruals remain significant at least at a $10 \%$ level. Both risk indicators exhibit a negative association with AnnRet ${ }_{j \mathrm{t}}$. Negative rating changes (i.e., increases in the numerical credit rating conversion) result in dropping flat bond prices (BPijt), which in turn reduce annual bond returns. Increases in the level of VIX are also significantly negatively associated with annual bond returns. Additionally, the crisis period regressions explain a significantly larger portion of bond return variation, hence the Adj. $\mathrm{R}^{2}$ increases from about 6\% to 35\%. Following Barth et al. (2008), I interpret this as a further indicator of an increase in the importance of accounting figures for the bond market during the financial crisis.

\footnotetext{
${ }^{42}$ The changes in ratings do not only depict changes from investment-grade to non-investment grade and vice versa, but general ratings changes by comparing the ratings nine months before and three months after the fiscal-year end. S\&P credit ratings are recoded numerically. The entire rating spectrum is as follows: $\mathrm{AAA}=1, \mathrm{AA}+=2, \mathrm{AA}=3, \mathrm{AA}-=4, \mathrm{~A}+=5, \mathrm{~A}=6, \mathrm{~A}=7, \mathrm{BBB}+=8, \mathrm{BBB}=9, \mathrm{BBB}-=10, \mathrm{BB}+=11, \mathrm{BB}=12, \mathrm{BB}-$ $=13, \mathrm{~B}+=14, \mathrm{~B}=15, \mathrm{~B}=16, \mathrm{CCC}+=17, \mathrm{CCC}=18, \mathrm{CC}-=19, \mathrm{CC}=20, \mathrm{C}=21, \mathrm{D}=25$ (cf. e.g., Avramov et al., 2006). Results remain qualitatively unchanged if $\mathrm{D}=22$.
} 


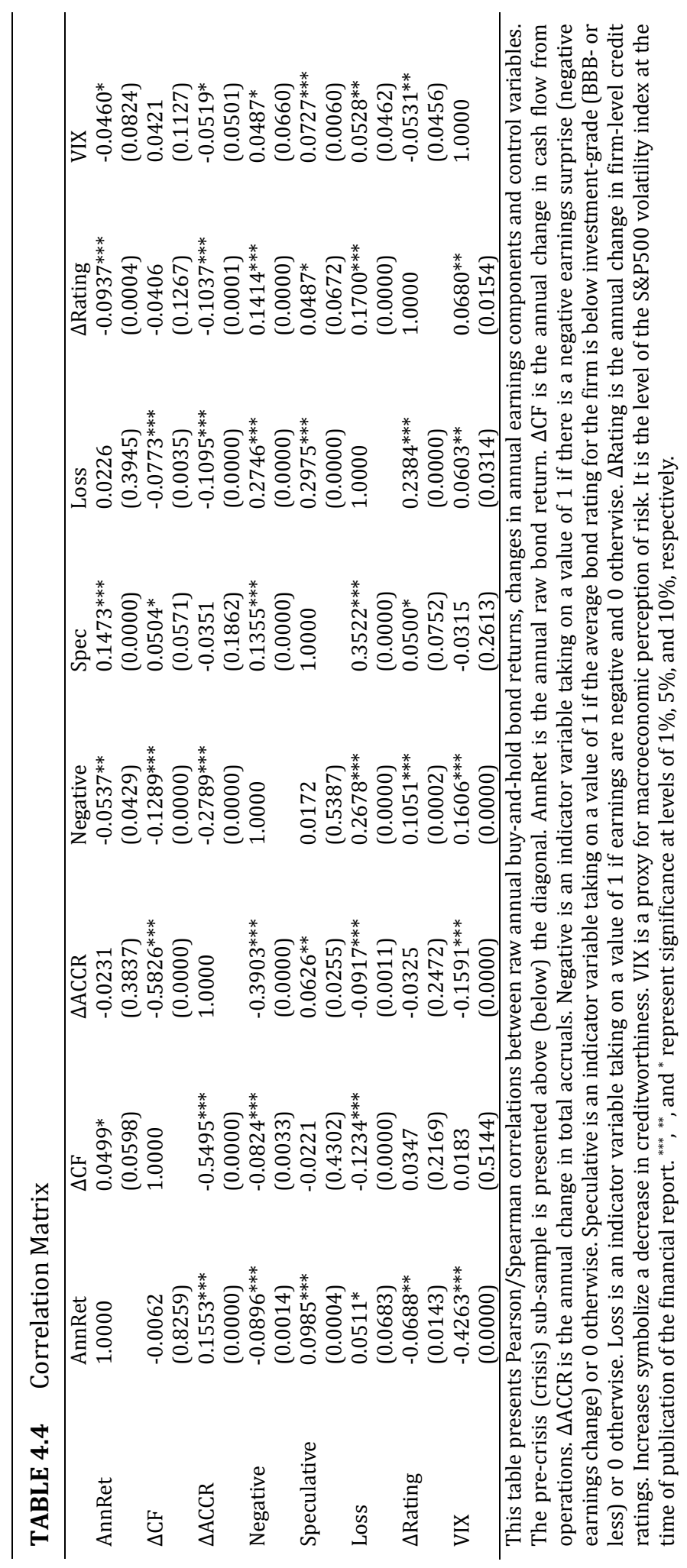




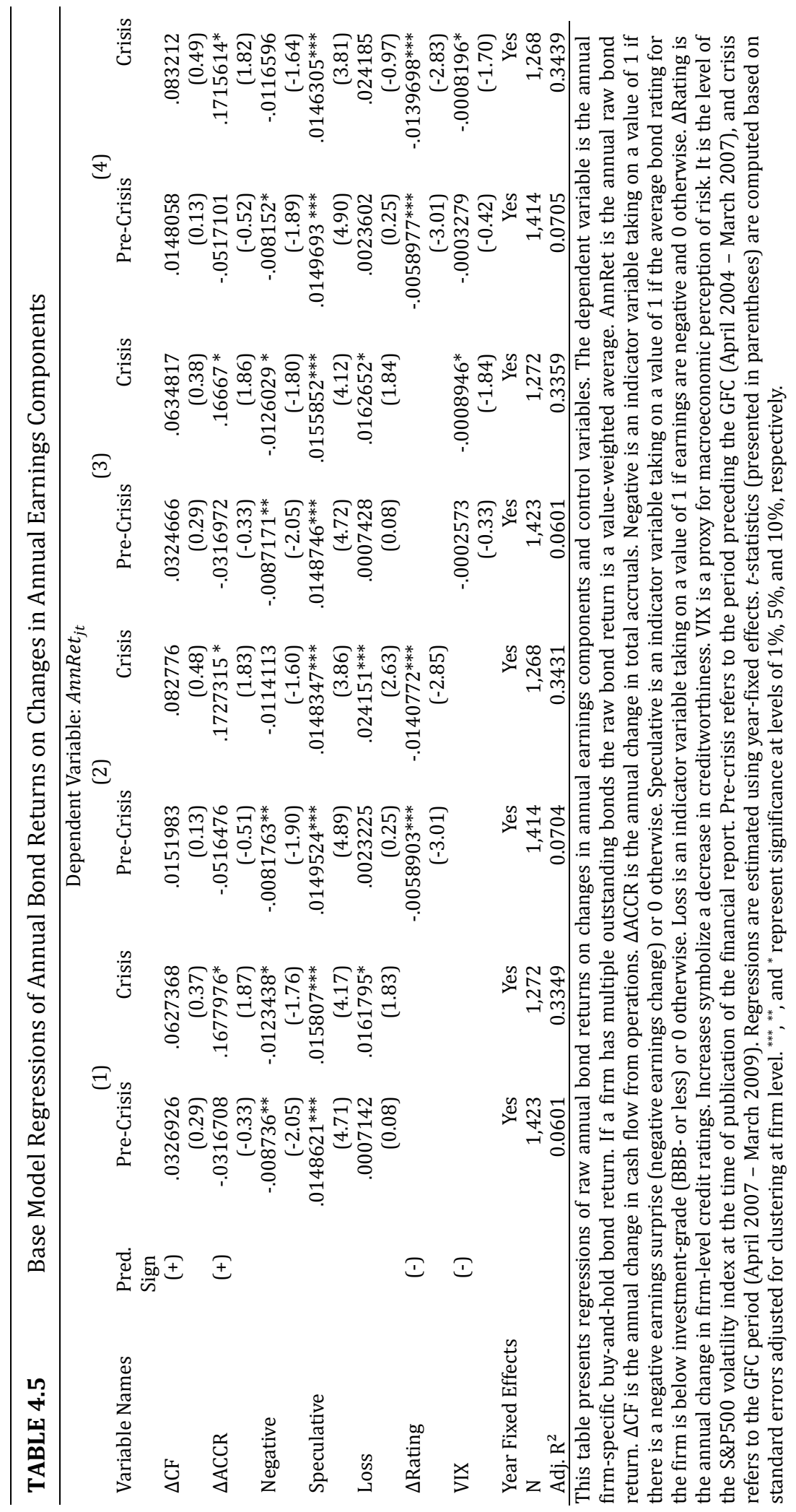


As presented in Table 4.6, the results of the base models are not sensitive to the effects of multicollinearity. ${ }^{43}$ VIFs reach maximum values of just about 2.1 .

\begin{tabular}{|c|c|c|c|c|c|c|c|c|}
\hline \multirow[b]{3}{*}{ Variable Names } & \multicolumn{8}{|c|}{$\begin{array}{l}\text { Variance Inflation Factors of Changes in Annual Earnings Components and } \\
\text { Control Variables }\end{array}$} \\
\hline & \multicolumn{2}{|c|}{ (1) } & \multicolumn{2}{|c|}{ (2) } & \multicolumn{2}{|c|}{ (3) } & \multicolumn{2}{|c|}{ (4) } \\
\hline & Pre-Crisis & Crisis & Pre-Crisis & Crisis & Pre-Crisis & Crisis & Pre-Crisis & Crisis \\
\hline$\Delta \mathrm{CF}$ & 1.7998 & 1.7224 & 1.7568 & 1.7623 & 1.8011 & 1.7253 & 1.7569 & 1.7662 \\
\hline & & 2.00 & & & & & & 2.0709 \\
\hline & 1. & 1.43 & & & & & & 1.4651 \\
\hline Specul & 1.1179 & 1.1650 & 1.11 & 1.1652 & 1.1211 & 1.1663 & 1.1197 & 1.1664 \\
\hline Loss & 1.1879 & 1.2658 & 1.2085 & 1.3349 & 1.1888 & 1.2666 & 1.2096 & 1.3352 \\
\hline$\Delta$ Rating & & & 1.0493 & 1.0740 & & & 1.0541 & 1.0771 \\
\hline VIX & & & & & 1.0 & 1.0 & & 1.0447 \\
\hline $\mathrm{N}$ & 1,423 & 1,272 & 1,423 & 1,272 & 1,423 & 1,272 & 1,423 & 1,272 \\
\hline
\end{tabular}

This table presents Variance Inflation Factors of changes in annual earnings components and control variables. $\triangle \mathrm{CF}$ is the annual change in cash flow from operations. $\triangle \mathrm{ACCR}$ is the annual change in total accruals. Negative is an indicator variable taking on a value of 1 if there is a negative earnings surprise (negative earnings change) or 0 otherwise. Speculative is an indicator variable taking on a value of 1 if the average bond rating for the firm is below investment-grade (BBB- or less) or 0 otherwise. Loss is an indicator variable taking on a value of 1 if earnings are negative and 0 otherwise. $\Delta$ Rating is the annual change in firm-level credit ratings. Increases symbolize a decrease in creditworthiness. VIX is a proxy for macroeconomic perception of risk. It is the level of the S\&P500 volatility index at the time of publication of the financial report.

\subsubsection{Extended OLS-model including interaction terms}

In a second step I extend the base model using interaction terms between the regressors to further investigate the relationships among the independent variables. The sample is again split into a pre-crisis period (April 200444 through March 2007) and crisis period (April 2007 through March 2009) and the pre-crisis sample contains 1,423 and the global financial crisis sample 1,272 firm-year observations.

The results of models (5) through (10) presented in Table 4.7 and 4.8 are hence a split sample application of the regressions of earnings components on annual bond returns by Easton et al. (2009).

Models (5), (6) and (9) exhibit the expected shift in the importance of accounting earnings for bond market participants. In particular, accounting accruals (i.e., the residual of net income before extraordinary items and cash flow from operations) gain statistical significance during the financial crisis (5\%-level). This is quite surprising, as Sloan (1996) argues that $\triangle C F$ are less subject to estimation error and manager bias compared to $\triangle$ ACCR. $^{45}$

\footnotetext{
43 This shows that the multicollinearity in the regressions (26) and (27) is driven by the interaction terms. Although multicollinearity is not problematic as there is no systematic effect between the main effect variables, the quantile regressions approach is based on the reduced model.

${ }^{44}$ To compute bond returns for fiscal year 2005 I also employ flat bond prices (BPijt) starting in 2004.

${ }^{45}$ As operating cash flows are the result from a firm's core business, they have a lower tendency to reverse and are less subject to bias. Thus, operating cash flows exhibit greater persistence than accruals.
} 
Of course, the inclusion of the interaction terms alters the interpretation of all coefficients included in the model. The significant interaction term between $\triangle A C C R$ and Negative in the GFC period indicates that the effect of $\triangle A C C R$ on the bond returns depends on whether an individual firm has positive or negative earnings. Before the crisis neither cash flows nor accruals exhibit any significance. Interestingly, model (6) shows off-setting effects. In the GFC period, $\triangle \mathrm{ACCR}$ is significantly positive if there are no negative earnings surprises. However, if there are negative earnings surprises, the net effect of $\triangle$ ACCR and the interaction term is -0.0496 .

The remaining models (7), (8), and (10) show somewhat peculiar outcomes. There is no significant association of earnings components with bond returns and even a shift in sign. While $\triangle \mathrm{CF}$ and $\triangle \mathrm{ACCR}$ are positively associated with bond returns before the crisis, there is an insignificant, negative association during the financial crisis (model (8)).

Variance Inflation Factors (VIFs) presented in Table 4.9 may shed some light on this phenomenon. The models confirming hypothesis 1a, which states that annual changes in accruals ( $\triangle \mathrm{ACCR}$ ) are incrementally associated with annual bond returns only during periods of severe uncertainty even after controlling for firm-specific distress indicators, do not seem to be affected by multicollinearity. They are uniformly far below standard textbook VIF levels of 10 (e.g., Chatterjee and Price, 1991; Kleinbaum et al., 1987). The models not confirming the hypothesis do not hold in this respect. They exhibit several VIFs far above the standard threshold level. ${ }^{46}$ Multicollinearity, indicating that one or more of the independent variables are highly correlated with other independent variables, results in wider confidence intervals around explanatory variables. ${ }^{47}$ This makes it difficult to single out the influence of each explanatory variable while the models' overall explanatory power may still be relatively high. Wider confidence intervals probably lead to a sign switch in coefficients which conflicts with theory and my expectations. For the time frame of interest, including the pre-crisis 'bull market' and the global financial crisis, this prevalent multicollinearity hence leads to increased standard errors in models (7), (8) and (10). As a remedy I reduce the model and exclude interaction terms.

\footnotetext{
46 Textbook 'rule-of-thumb' levels for VIFs attract some critique (e.g., O'Brien, 2007). Yet, as the VIFs considerably surpass 10 , and go as high as 83 , I nevertheless fear that the models in question suffer from severe multicollinearity.

${ }^{47}$ If only two variables were be highly correlated it would be sufficient to take a look at the correlation between these two variables and decide which one is redundant. In the case of multicollinearity, correlation tables may not signal problems while VIFs indicate multicollinearity.
} 


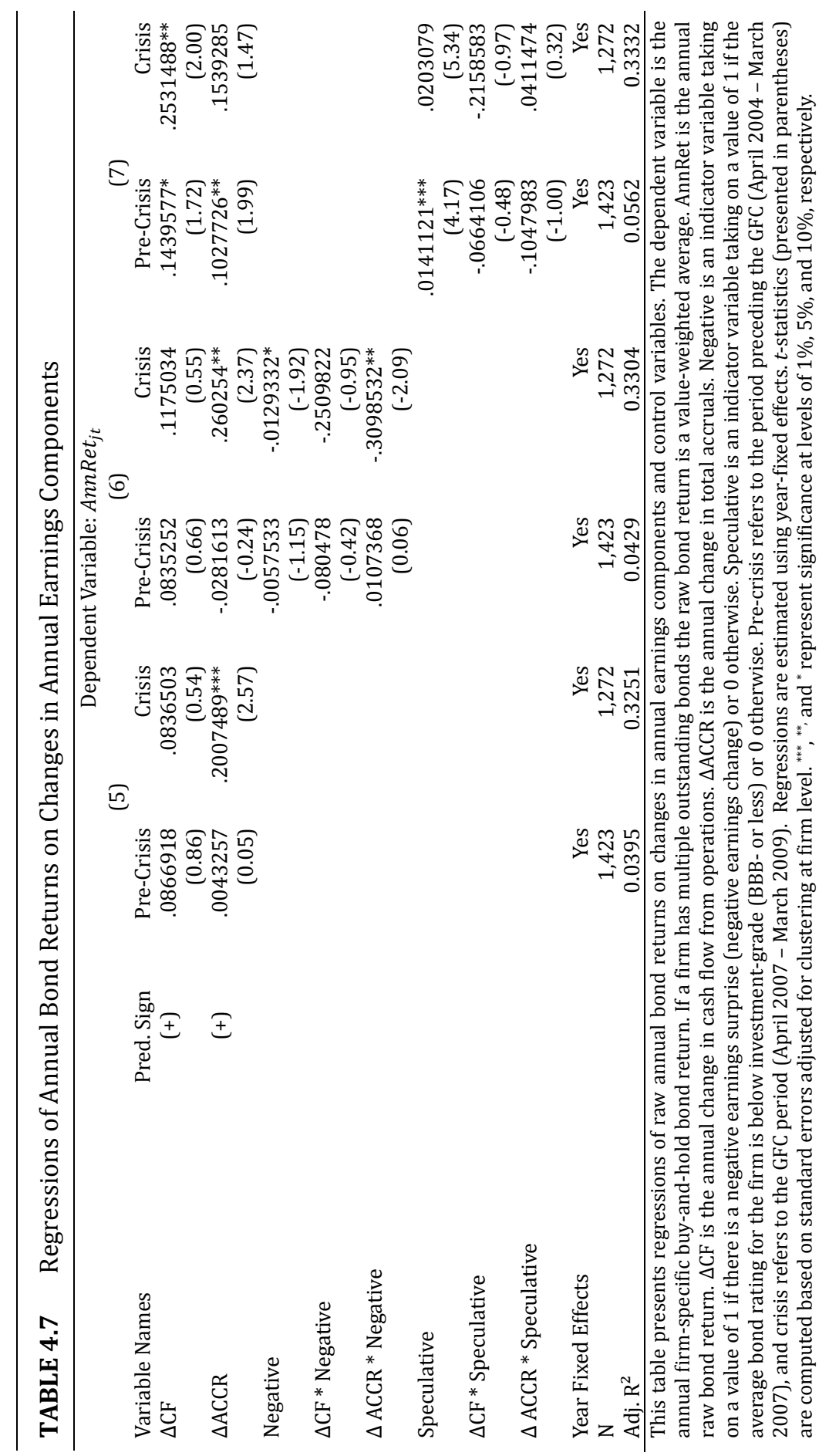




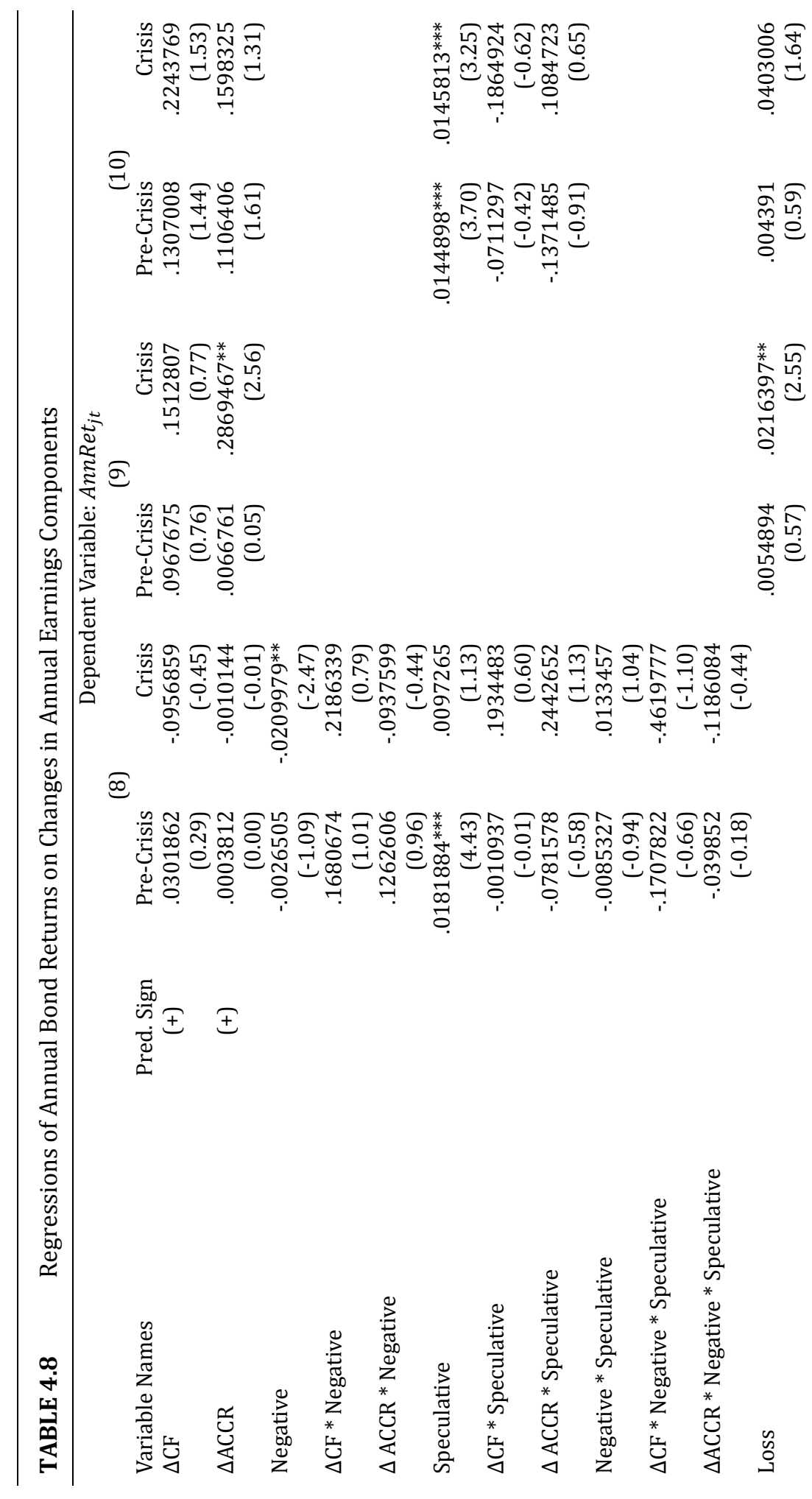




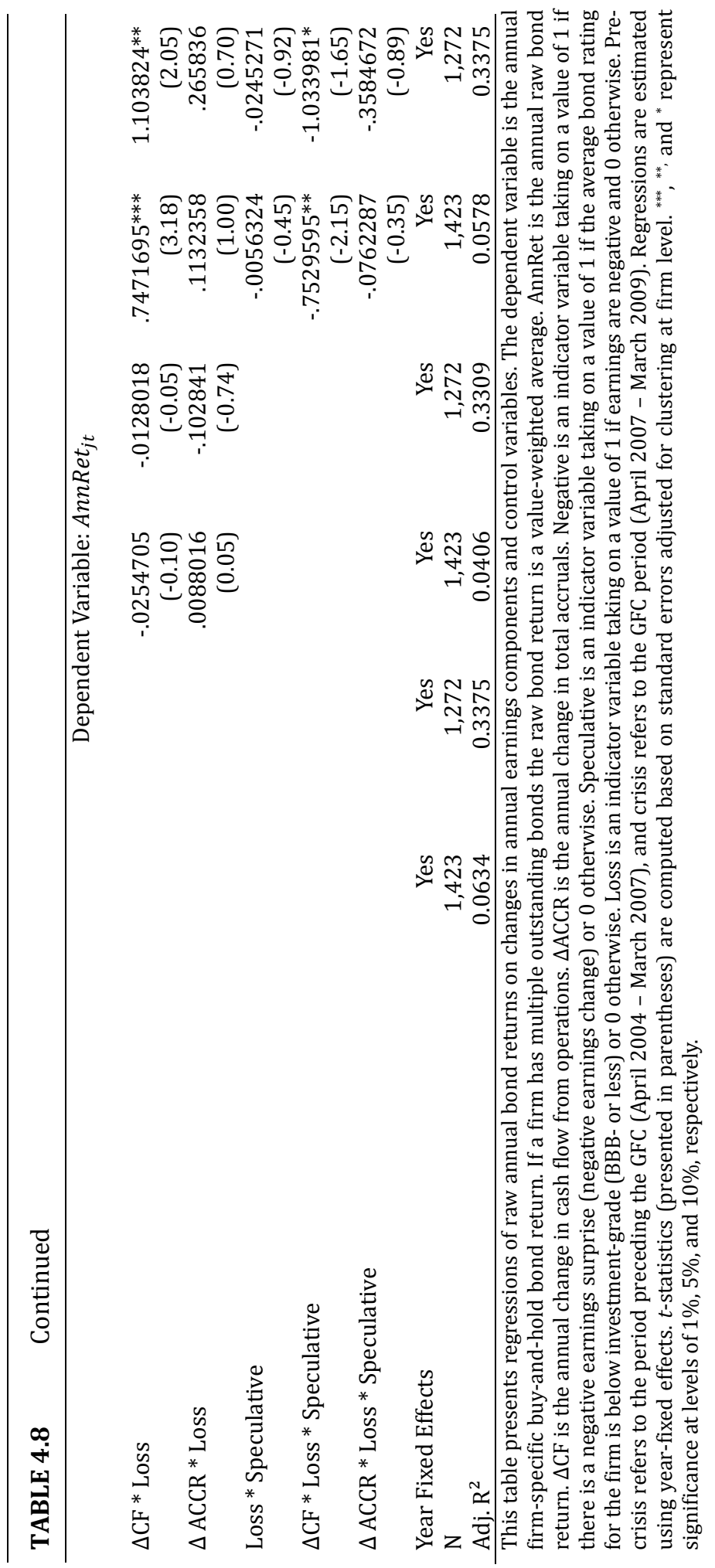




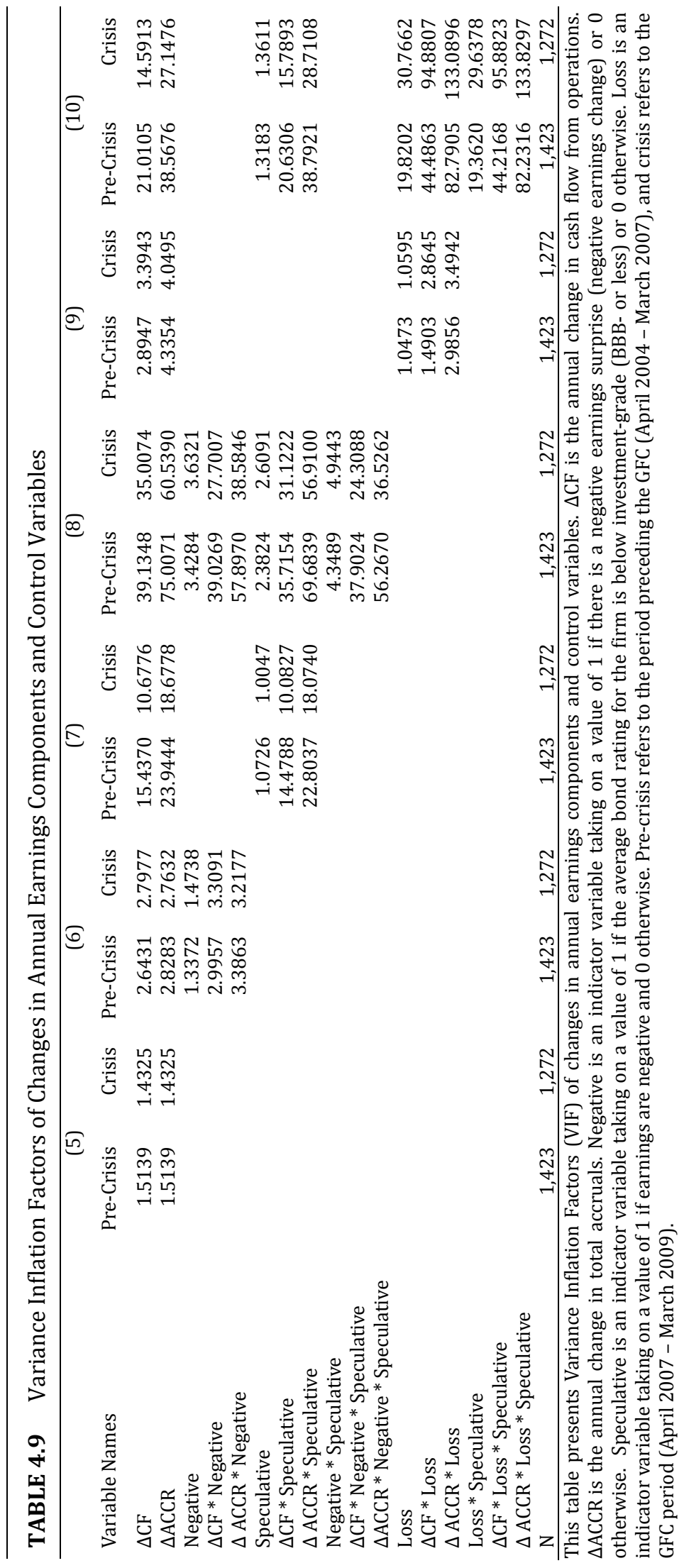




\subsubsection{Semi-Parametric Model}

In an additional analysis, I extend the OLS-regression estimations and introduce a semiparametric estimation technique, referred to as quantile regression. ${ }^{48}$ More specifically, I apply a simplex-algorithm with resampling to exploit the structure of the coefficient matrix. This estimation technique, using linear programming, is especially useful because it is not based on specific distribution assumptions and is robust to extreme outliers of the response variable. It provides a more thorough understanding of the association between annual bond returns and accounting- and market-based information signals not focusing solely on the mean of the dependent variable (Koenker and Bassett, 1978; Koenker and Hallock, 2001). Figure 4.2 shows that the regression coefficients of both variables, changes in cash flows $(\Delta \mathrm{CF})$ and changes in accruals ( $\triangle \mathrm{ACCR}$ ), seem to follow a linear function, especially around the median coefficient. This is not the case for the lowest and highest quantiles where the regression coefficients appear to show large fluctuations.

FIGURE 4.2 Plots of Estimated Parameters by Quantiles of AnnRet with 99\% Confidence Limits

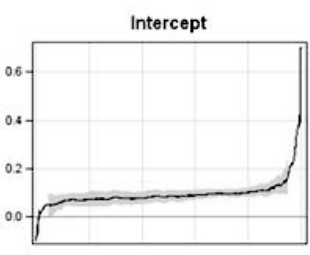

$\triangle \mathrm{CF}$

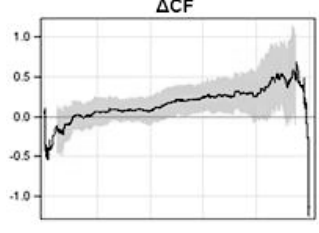

$\triangle A C C R$

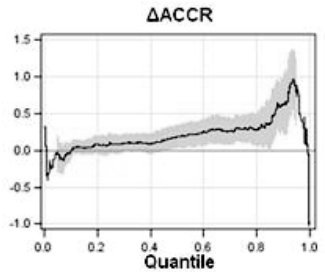

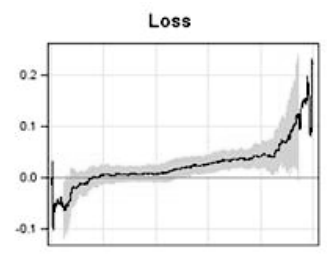

Negative
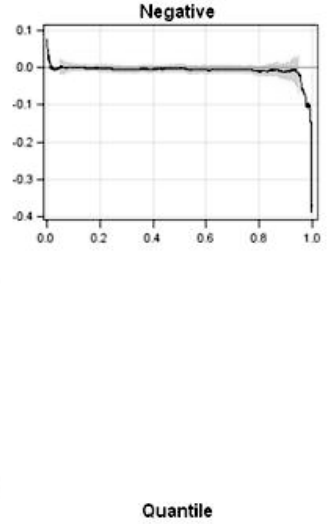
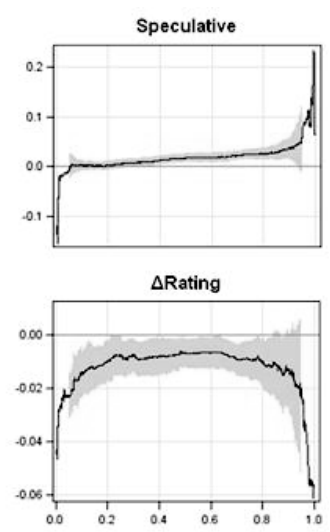

VIX

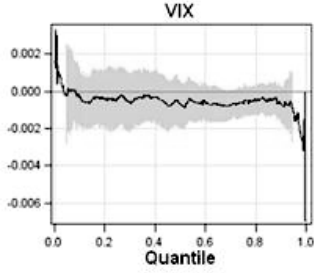

Anchoring the quantile regressions on the median quantile, I find that both accounting-based variables, changes in cash flows $(\Delta \mathrm{CF})$ and changes in accruals $(\triangle \mathrm{ACCR})$, are positively and strongly significantly associated (1\%-level) with firm-

${ }^{48}$ OLS regressions only capture the conditional mean of the dependent variable (i.e., annual firm-specific bond returns). 
specific annual bond returns during the recent financial crisis (Table 4.10). These findings contradict the results of the base OLS model. Apparently, both non-persistent and persistent components of earnings, accounting accruals and cash flows respectively, seem to explain the variation in bond prices during the recent financial crisis. Hence, in chapter four I provide insights about bond investors probably failing to "discriminate between the different levels of the persistence of the accrual and cash components of earnings" (Dechow et al. 2008) as both components seem to be equally important to financial market participants. Overall, it seems that the importance of financial reporting increases the less efficient markets are (Scott 2012).

Credit rating agencies' private information signals capturing the creditworthiness of the issuing company (i.e., changes in credit ratings and information about the investment grade of the debt instrument) are also associated with annual bond returns during the recent financial crisis. Interestingly, these information signals are also associated with bond returns in the three years preceding the recent financial crisis. These findings seem to indicate that debt market investors presumably supplement information provided by credit rating agencies with accounting-based information signals during periods of turmoil and distress, potentially attributable to a perceived lack of reliability and credibility of market-based measures. Surprisingly, the proxy for systematic risk in the economy (VIX) is not associated with firm-specific annual bond returns in the median quantile.

Overall, semi-parametric techniques seem to reveal interesting insights on the association of accounting- and market-based information signals with annual bond returns. As lower quantiles anchor the quantile regressions on average bond returns that are closer to the pre-GFC period, both $\triangle \mathrm{ACCR}$ and $\triangle \mathrm{CF}$ are not significant. Nevertheless, higher quantiles anchor the regressions on average bond returns that are closer to the average return during the GFC. As such, both $\triangle \mathrm{ACCR}$ and $\triangle \mathrm{CF}$ seem to then explain the variation in bond return distribution. Hence, my findings provide evidence on the importance of accounting-based information signals related to cash flows and accruals for bond investors during periods of uncertainty and distress.

\subsubsection{Heteroscedasticity - OLS versus quantile regressions}

Quantile regressions are often used if the dependent variable is not symmetrically distributed around the mean and/or heteroscedasticity is prevalent in the dataset. Figure 4.2 shows the distribution of the quantile regression coefficients of the independent variables, and suggests that heteroscedasticity might be prevalent in the dataset which potentially explains the biased OLS regression results. To test for heteroscedasticity in the dataset I apply the Breusch-Pagan test (King and Roberts, 2012) to both the medium ${ }^{49}$ and complete bond return sample. Tables 4.11 presents Breusch-Pagan tests for heteroscedasticity of the OLS regressions of changes in annual earnings components and control variables on the complete set and medium set of

\footnotetext{
${ }^{49}$ With medium bond return sample, I refer to the $33 \%$ of bond returns around the median.
} 
annual bond returns. I show that heteroscedasticity impacts my results when regressions are based on the complete set of bond returns. If the focus is on the medium return subsample, heteroscedasticity concerns can be neglected. 


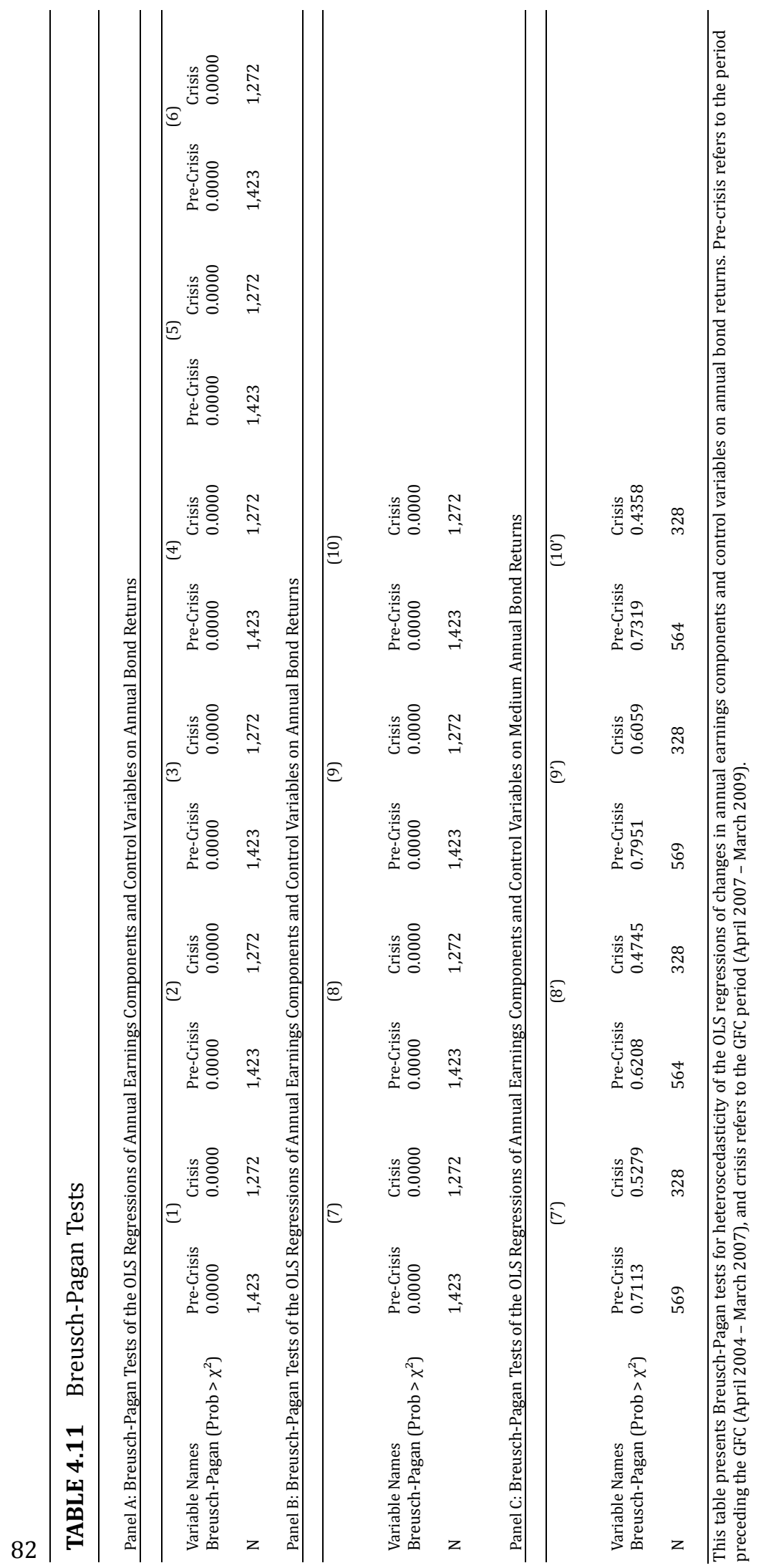




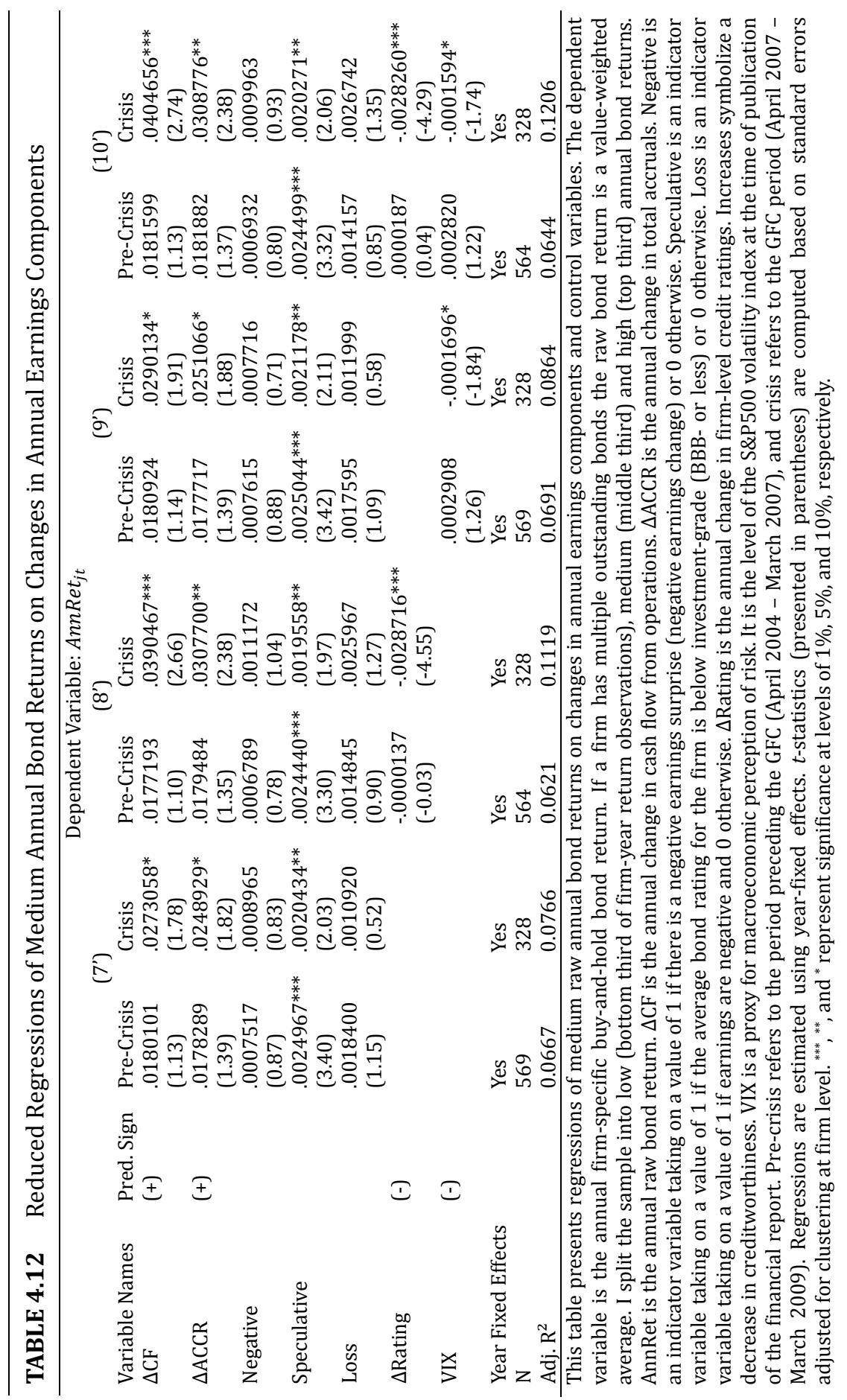




\subsection{Robustness checks}

Building on the non-linearity of changes in earnings components and control variables with respect to the dependent variable and aforementioned heteroscedasticity concerns, I split the full sample into low, medium, and high return subsamples. The low return subsample consists of firm-years in the bottom third of observations in terms of bond returns. The high return subsample includes the top third of firm-year observations in terms of raw buy-and-hold bond returns. I thus repeat the OLS analyses presented in Table 4.12 with the remaining subsample of medium bond returns.

Table 4.12 confirms my prior findings. Depending on the concrete model specification both changes in earnings components are statistically significant at least at the $10 \%$ level during the crisis but not in the pre-crisis period. Attributable to smaller sample sizes and reduced variation of bond returns the $\mathrm{Adj} . \mathrm{R}^{2}$ values are lower but the pattern of higher overall importance of accounting variables during the crisis remains robust.

\subsection{Summary and limitations}

Overall, I extend the study in chapter three by disentangling earnings information into specific components (e.g., accruals and cash flows) to address concerns that net income as a product of the accrual accounting process is comprised of persistent and nonpersistent components (Sloan 1996). Using traditional OLS regression, I find that only the accruals component can explain the variation in annual bond returns. According to accounting theory, I expect the cash component to explain the bond returns in the financial crisis period, as operating cash flows are expected to be a more persistent component of earnings than accruals. Although prior research in the debt market uses OLS regressions, I switch to a semi-parametric test (quantile regression approach) to address concerns related to heteroscedasticity. The OLS technique "gives equal weight to all observations when, in fact, observations with larger disturbance variance contain less information than observations with smaller disturbance variance" (Berry and Feldman 1985).

After controlling for the presence of systematic risk in the economy and acknowledging the distribution of the dependent variable, I provide evidence that accounting accruals and cash flows are surprisingly not associated with corporate bond returns in the three years preceding the financial crisis. However, I find a positive and significant association of accounting accruals with annual bond returns during the recent financial crisis. Furthermore, I provide evidence on the association of marketbased information signals (VIX and credit ratings) with annual firm-specific bond returns. I show that information signals related to changes in credit ratings, which in this study complement the indicator variable Speculative, provide incremental explanatory power with regard to the variation in annual bond returns. Interestingly, 
before the crisis, VIX is insignificantly and negatively associated with annual bond returns. On the contrary, this association increases in magnitude and becomes significant during the recent financial crisis.

In summary, the results suggest that debt market investors presumably shift their focus from market-based information to also include accounting-based signals in times of turmoil and distress, potentially attributable to a perceived lack of reliability and credibility in market-based measures. A limitation of the study, which could impair generalizability, is that the financial crisis is generally viewed as a rare, although not unique, event. The bull market of the pre-crisis period may also be considered an unusual state of the economy. Nevertheless, it is important to note that these stark contrasts provide an ideal environment to explore the link between accounting information and bond returns and its dynamic attributable to the macroeconomic environment and market sentiment. 


\section{CONCLUSION}

\subsection{Summary of results and implications}

The dissertation provides novel insights on various capital market related research questions. More specifically, I investigate whether financial reporting information signals are associated with bond prices and value relevant to bond holders. As research results may not be transferred from the corporate to the financial institution bond market, both settings are examined (Chapter 2 versus Chapter 3 and 4). Furthermore, as an additional information source to typical income statement (e.g., earnings) and statement of financial position information (e.g., capital structure), the importance of tax-related information signals is investigated in the corporate bond market (Chapter 3). As bond returns in the corporate bond market show a larger dispersion (in comparison to bond returns in the banking sector setting), sensitivity tests on varying bond return levels reveal interesting insights. Furthermore, non-parametric estimation techniques are used to shed light on the feasibility of traditional OLS-techniques (Chapter 4) applied in debt capital market settings. In addition, specific income statement information related to earnings and earnings components (e.g., accruals and cash flows) is examined further. These accounting information signals are challenged with market-based information signals (e.g., VIX volatility and credit rating information) as these information sources are more timely and probably anticipate information revealed through financial statements (Chapter 4). Underlying all three studies in the dissertation is the interest in shedding light on the "dynamic" composition of information required by bond holders to make optimal buy/sell decisions. To exploit these differential information needs, this dissertation examines the information set composition during the period preceding the recent financial crisis and the GFC.

Results in chapter two shed light on whether and to which extent bond investors in the financial institution sector use accounting signals in their decision-making process during economic downturns. The recent financial crisis provides a perfect setting to test whether financial institutions' accounting ratios related to the CAMEL framework of the U.S. Federal Bank Regulatory Agencies - capital adequacy, asset quality, earnings ability, and liquidity - if at all, enter into the decision-making process of investors holding a portfolio of debt instruments in financial institutions. Applying a perfect foresight portfolio investment strategy (Abarbanell and Bushee 1998), the results in chapter two provide evidence that cumulative monthly bond returns are associated with changes in "earning power" and changes in credit ratings only when financial markets are illiquid and not transparent. Additionally, bond prices do not fully anticipate accounting signals 
during the recent GFC. To draw causal inferences, a short term window event study is applied and provides evidence on the value relevance of ratios related to changes in "earning power", liquidity, and capital adequacy for bond holders during the recent financial crisis period.

The study in chapter two reveals three contributions to the literature. First, it sheds light on bond investors' different and dynamic informational needs during financial and non-financial crisis periods. Second, it provides evidence that accounting information signals related to the bank regulatory framework are not fully anticipated and incorporated into contemporaneous bond prices during the recent financial crisis. Third, accounting signals related to core business performance, liquidity, and equity cushion are value relevant to bond holders only during the recent financial crisis period stressing the importance of accounting signals to prevent mispricing especially during periods of financial distress and increased uncertainty (e.g., when efficiency in semi strong financial markets deteriorates even more).

Chapter three adds to literature by providing evidence on the relative importance of earnings, liquidation values (capital structure), and estimated taxable income in the corporate debt market. The results indicate that, irrespective of the state of the economy, information related to changes in a firm's liquidation value are significantly associated with bond returns. As assumed, these insights deviate from the findings in the banking sector in chapter two, as investors in the corporate bond market are not downside risk protected by regulation authorities. Furthermore, it is shown that estimated taxable income and not earnings related information is significantly associated with bond prices in the period preceding the GFC.

Chapter four extends the findings in Chapter three by investigating earnings and earnings components (e.g., accruals and cash flows). The objective is to extend prior findings in the debt market and to explore the sensitivity of the value relevance of accounting information to macro-economic scenarios which are linked to the asymmetric payoff function of bond holders. Although well established in the research literature on equity markets, it is an important research question whether transitory and persistent components of earnings are associated with contemporaneous bond returns.

Furthermore, also based on the evidence in chapter three, non-parametric methods (quantile regressions) are used to account for the fact that accounting information signals (accruals and cash flows) influence bond prices differently for debt instruments with low returns than for those with average returns. Controlling for the presence of systematic risk and private information of credit rating agencies, chapter four provides evidence that accounting accruals and cash flows are not associated with corporate bond returns in the three years preceding the financial crisis. However, using a point estimate of the conditional mean of annual bond returns, the study reveals a positive and significant association of accounting accruals with annual bond returns during the recent financial crisis. Additionally, using a semi-parametric technique to include conditional quantiles of bond returns, this study shows that the rate of change in the regression coefficients is dependent on those quantiles. Thus, evidence is provided that, 
conditional on the distribution of bond returns, both changes in cash flows and accruals are positively and significantly associated with annual bond returns during the recent financial crisis. The results suggest that debt market investors base their investment decisions on credible market-based measures (e.g., VIX volatility and credit rating information) during the pre-financial crisis, but complement these information signals with accounting-based measures during the recent financial crisis. Therefore, accounting signals may reflect information about a firm's closeness to default and creditworthiness that is not captured by market-based measures. Overall, my research sheds light on the role of financial reporting and market-based information signals in the bond market.

\subsection{Future research}

The research presented in this dissertation can be extended in multiple ways. Besides testing the association of accounting information signals with security prices and the value relevance of those signals to investors, the stewardship function of financial reporting also presents an interesting research area. For instance, gaining knowledge about bond-specific debt covenants probably reveals new insights which can be incorporated in capital market studies. The language in which debt covenants are provided (e.g., market- versus accounting-based restrictions) in debt contracts may affect whether and how quickly financial reporting information is impounded into bond prices. Furthermore, the impact of debt covenant violations with regard to debt restructuring provides a potential and interesting research area. Such studies could provide standard setters (e.g., IASB and FASB) with new insights on the importance of the stewardship function which has been suppressed by the information approach of decision useful financial reporting in the recent years. Acknowledging differential information needs of different groups of stakeholders may lead to a view that not only shareholders interest should be reflected in new accounting standards. Furthermore, before the GFC hit many economies worldwide, standard setters restricted the expansion of fair value accounting and re-introduced many measurement rules and choices related to historical cost accounting. Attributable to these accounting standard changes, firms were probably able to circumvent debt covenant violations which translated into a relative drawback for debt holders in comparison to equity providers.

Another interesting research extension would be to investigate different types of bond contracts that include embedded derivatives, such as step-up clauses, redeemable features, and other cash-flow changing restrictions. ${ }^{50}$ Financial reporting information signals are probably to a different extent impounded into bond prices as embedded derivatives that improve the position of bond holders in comparison to shareholders provide some sort of downside risk protection. This is especially true when financial markets deteriorate in terms of efficiency.

50 Databases such as Bloomberg provide a complete set of debt instruments that include embedded derivatives. 
Given that a researcher has access to bond specific debt covenants (e.g., through the Dealscan database) and a set of debt instruments that includes those contracts with embedded derivatives, examining the value relevance of fair value accounting (FVA) would be an interesting research extension. With regard to the payoff structure of debt instruments that implies that bond investors do not participate in any firm specific upside potential, unrealized gains, to a larger extent generated through FVA, are a natural threat to bond investors as these gains are cash outflows to shareholders. Nevertheless, market-based debt covenants and bond-specific embedded derivatives may offset these potential cash outflows and thus mitigate bond holders concern with regard to this wealth extraction.

Overall, the results of this dissertation with regard to a "dynamic" information set used by investors, which composition changes as the credibility and precision of all information available in the financial market changes, might be applied to other research settings, for example research in the equity and derivative financial market. In addition, spill-over effects from one capital market to another might provide interesting insights to capital market oversight authorities (in addressing financial stability issues) and accounting standard setters (in drafting new accounting standards). Furthermore, future research may examine whether contagion effects between different capital market are mitigated during periods of financial distress and illiquidity. 


\section{APPENDIX}

\section{A) Statement of Financial Accounting Concepts (SFAC) No.8}

The objective of general purpose financial reporting

OB2. "The objective of general purpose financial reporting1is to provide financial information about the reporting entity that is useful to existing and potential investors, lenders, and other creditors in making decisions about providing resources to the entity. Those decisions involve buying, selling, or holding equity and debt instruments and providing or settling loans and other forms of credit." OB3. "Decisions by existing and potential investors about buying, selling, or holding equity and debt instruments depend on the returns that they expect from an investment in those instruments; for example, dividends, principal and interest payments, or market price increases. Similarly, decisions by existing and potential lenders and other creditors about providing or settling loans and other forms of credit depend on the principal and interest payments or other returns that they expect. Investors', lenders', and other creditors' expectations about returns depend on their assessment of the amount, timing, and uncertainty of is to provide financial information about the reporting entity that is useful to existing and potential investors, lenders, and other creditors in making decisions about providing resources to the entity. Those decisions involve buying, selling, or holding equity and debt instruments and providing or settling loans and other forms of credit." (Source: FASB SFAC No.8) 


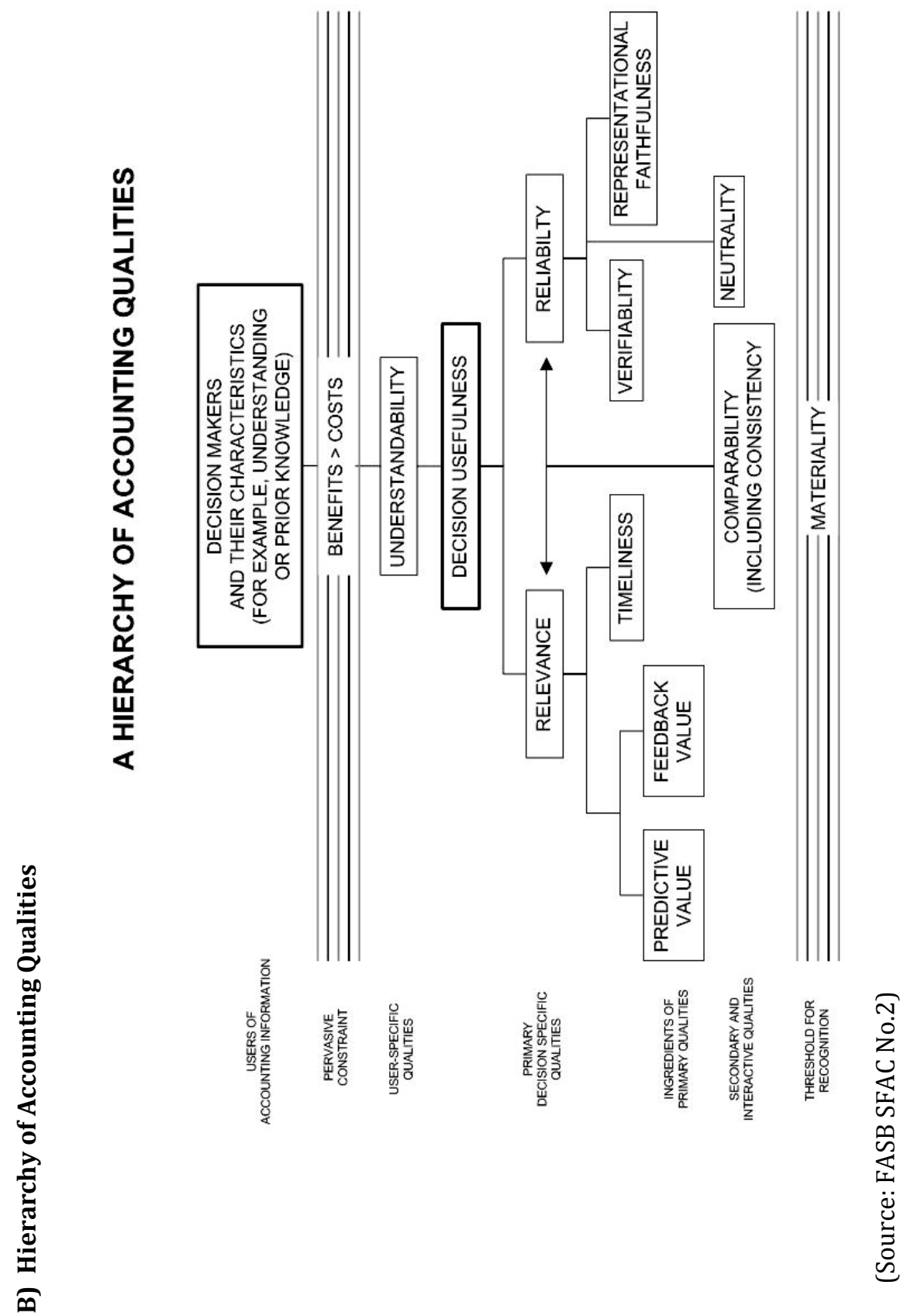




\section{C) The Current US Bank Regulatory Regime}

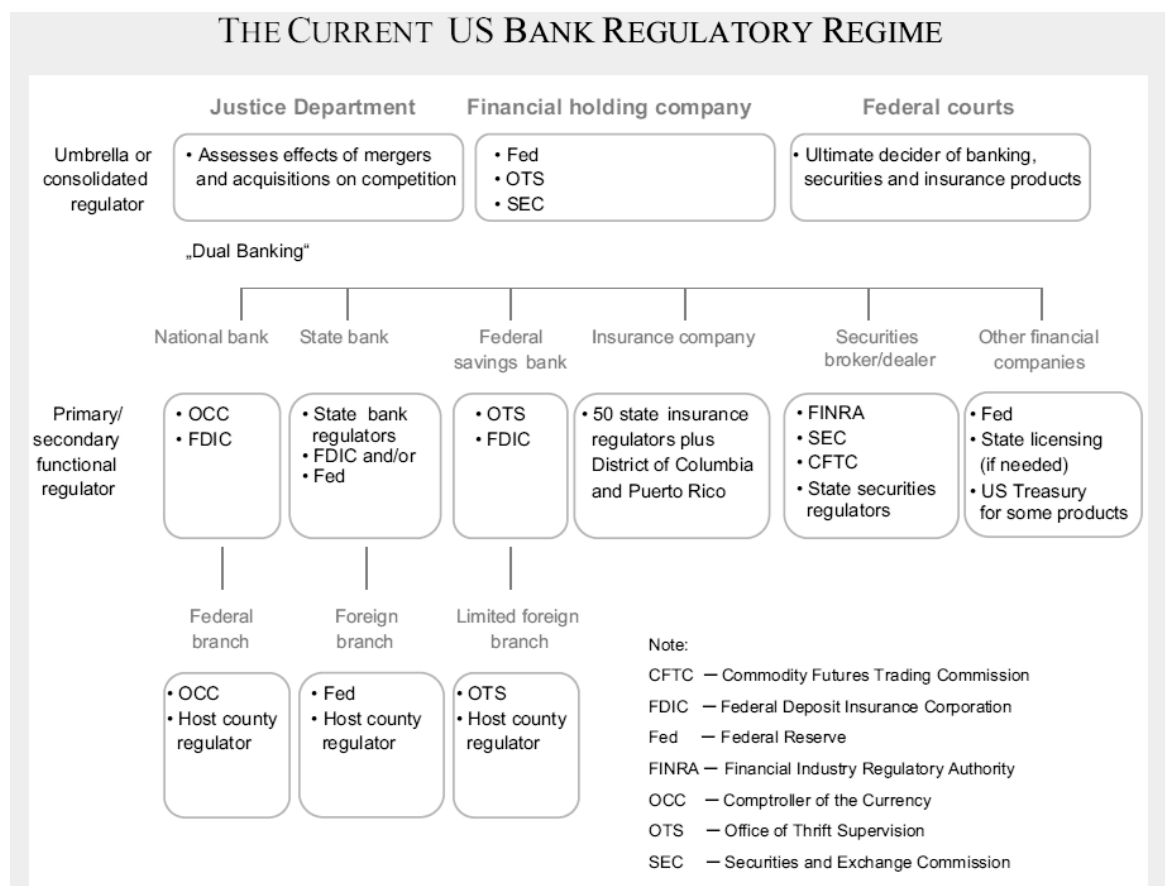

(Source: Barth et al. 2009) 


\section{REFERENCES}

Abarbanell, J.S. and BusheE, B.J. "Abnormal returns to a fundamental analysis strategy." The Accounting Review (1998): 19-45.

Ahmed, A.S., TAKEDA, C. and Thomas S. "Bank loan loss provisions: A reexamination of capital management, earnings management and signaling effects." Journal of Accounting \& Economics (1999): 1-25.

Ahmed, A.S., KILIC, E. and LoBo G.J. "Does recognition vs. disclosure matter? Evidence from value-relevance of banks' recognized derivative financial instruments" The Accounting Review (2006): 567-588.

Amato, J.D., and Remolona E.M. “The credit spread puzzle” BIS Quarterly Review (2003): Bank for International Settlement.

AMIRAM, D., and OWENS E.L. "Earnings smoothness and cost of debt" Unpublished Working paper (2011): University of Rochester.

Avramov, D., Jostova, A., and Philipov G. "Corporate credit risk changes: Common factors and firm-level fundamentals." Unpublished Working Paper (2006): University of Maryland, George Washington University and American University.

AYERS, B.C., LAPlante, S.K., and McGuiRe, S.T. "Credit ratings and taxes: the effect of booktax differences on ratings changes." Contemporary Accounting Research (2010): $359-402$.

AYERS, B.C., JiAnG, X., and LAPLANTE, S.K. "Taxable income as a performance measure." Contemporary Accounting Research (2009): 15-54.

BALAKRISHNAN, K. "Credit supply shocks, financial reporting quality and investments: Evidence from the subprime mortgage credit crisis." Unpublished Working Paper (2011).

BALL, R. and BRown, P. "An empirical evaluation of accounting income numbers." Journal of Accounting Research (1968): 159-178.

BALL, R. and SHIVAKUMAR S.. "How much new information is there in earnings?" Journal of Accounting Research (2008): 975-1016.

BARTH, M.E., BEAVER, W.H., and LANDSMAN, W.R. "Value-relevance of banks' fair value disclosures under SFAS No. 107." The Accounting Review (1996): 513-537.

BARTH, M.E., BEAVER, W.H., and LANDSMAN, W.R. "Relative valuation roles of equity book value and net income as a function of financial health." Journal of Accounting \& Economics (1998): 1-34. 
Barth, M. E. and Landsman, W.R. "Fundamental issues Related to USing Fair value ACCOUNTING FOR FINANCIAL REPORTING." ACCOUNTING HORIZONS (1995): 97-107.

BARTh, M.E, CRAM, D,P. , and NELSON, K.K. "Accruals and the prediction of future cash flows." The Accounting Review (2001): 27-58.

BARTH, M.E., LANDSMAN, W.R. , and LANG, M.H. "International accounting standards and accounting quality." Journal of Accounting Research (2008): 467-498.

BARTH, J.R, LI, T., and Lu, W. "Bank regulation in the United States." The Review of Economic Studies (2009): 112-140.

BERNARD, V.L. and StoBer, T.L. "The nature and amount of information in cash flows and accruals." The Accounting Review (1989): 624-652.

BEAVER, W.H. "The information content of annual earnings announcements." Journal of Accounting Research (1968): 67-92.

BEAVER, W.H. 1998. "Financial reporting - An accounting revolution." third ed. Prentice Hall, Englewood Cliffs.

BeAVER, W.H., McAnalLY, W., and Stinson C.H. "The information content of earnings and prices: A simultaneous equations approach." Journal of Accounting \& Economics (1997): 53-81.

BeAVER, W.H., ShakeSPEARE, C. , and Soliman, M.T. "Differential properties in the ratings of certified versus non/certified bond/rating agencies." Journal of Accounting and Economics (2006): 303-334.

BeCKer, B. and Milbourn, T. "How did increased competition affect credit ratings?" Working Paper (2010).

Black, F. and ScholEs, M. "The pricing of options and corporate liabilities." Journal of Political Economy (1973): 637 - 654.

BILlings, M., Klein, A. , and ZuR, E. "Shareholder class action suits and the bond market." Unpublished Working Paper (2011): New York University.

BoARd OF Governors of the Federal Reserve System (2010) New Security Issues, U.S. Corporations. Retrieved September 2011 from http://www.federalreserve. gov/econresdata/releases/corpsecure/current.htm.

Bolton, P., FreiXas, X. , and Shapiro, J. “The credit ratings game." Unpublished Working Paper (2010): National Bureau of Economic Research (NBER).

Boot, A.W.A., Milbourn, and T.T., SchmeITs, A. "Credit ratings as coordination mechanisms." The Review of Financial Studies (2006): 81-118. 
BOWEN, R.M., BuRgSTAHLER, and D., DALEY, L.A. "The incremental information content of accrual versus cash flows." The Accounting Review (1987): 723-747.

BURGSTAHLER, D. "Discussion of combing earnings and book value in equity valuation." Contemporary Accounting Research (1998): 325-341.

CALOMiris, C.W. and MASON, J.R. "Contagion and bank failures during the Great Depression: The June 1932 Chicago banking panic." American Economic Review (1997): 863-83.

Chatterjee, S. and Price, B. 1991. "Regression analysis by example." second ed. John Wiley \& Sons (1991): New York.

CHEng, L. "Loan loss provisioning and differences of opinion." Unpublished Working Paper (2011).

CHEN, Y. and HASAN, I. "The transparency of the banking system and the efficiency of information-based bank runs." Journal of Financial Intermediation (2006): 307-331.

Chen, L., Lesmond, D.A., and WEI J. "Corporate yield spreads and bond liquidity" The Journal of Finance (2007): 119-149.

Chordia, T., Sarkar, A., and Subrahmanyam, A. "An empirical analysis of stock and bond market liquidity". The Review of Financial Studies (2005): 85-129.

Cole, R.A. ,and Gunther J.W. "A CAMEL rating's shelf life" Unpublished Working paper (2011).

Collins, D.W., MAYDEW, E.L., and WEISS, I.S. "Changes in the value-relevance of earnings and book values over the past forty years." Journal of Accounting \& Economics (1997): 39-67.

Connolly, R., STIVERS, C., and Sun, L. "Stock market uncertainty and the stock-bond return relation." The Journal of Financial and Quantitative Analysis (2005): 161-194.

Cordella, T. and Yeyati, E.L. "Public disclosure and bank failure." Staff Papers (1998): International Monetary Fund (IMF).

Crabtree, A. and MAher, J. "Earnings predictability, bond ratings, and bond yields." Review of Quantitative Finance and Accounting (2005): 223-253.

DAS, S.R., HANounA, P. and SARIN, A. "Accounting-based versus market-based crosssectional models of CDS spreads." Journal of Banking \& Finance (2009): 719-730.

DECHOW, P.M. "Accounting earnings and cash flows as measures of firm performance: The role of accounting accruals." Journal of Accounting \& Economics (1994): 3-42.

DECHOW, P.M. and DicheV, I.D. "The quality of accruals and earnings: The role of accrual estimation errors." The Accounting Review (2002): 35-59. 
Dechow, P.M., GE, W. , and Schrand, C. "Understanding earnings quality: A review of the proxies, their determinants and their consequences." Journal of Accounting \& Economics (2010): 344-401.

DeFond, M.L., RAGHUNANDAN, and K., SubRAmANYAM, K.R. "Do non-audit service fees impair auditor independence? Evidence from going concern audit opinions." Journal of Accounting Research (2002): 1247-1274.

DEFond, M.L. and ZHANG, J. "The timeliness of the bond market reaction to bad news earnings surprises." Unpublished Working Paper (2011): University of Southern California.

De Franco, G, Vasvari, R.P., and WitTenberG-Moerman, R. "The informational role of bond analysts." Journal of Accounting Research (2009): 1201-1248.

Desai, M., Dyck, I., and Zingales, L. "Theft and taxes." Journal of Financial Economics (2007): 591-623.

De Servigny, A. and Renault, O. 2004. "Measuring and managing credit risk." first ed. Standard \& Poor's.

EASTON, P.D., MONAHAN, S.J., and VASVARI, F.P. "Initial evidence on the role of accounting earnings in the bond market." Journal of Accounting Research (2009): 721-766.

FAMA, E.F. and MALKIEL, B.G. "Efficient capital markets: A review of theory and empirical work." Journal of Finance (1970): 383-417.

FAMA E.F. and MACBETH J.D. "Risk, return, and equilibrium: Empirical tests." Journal of Political Economy (1973): 607-636.

FEDERAL Deposit InSURANCE CoRPoRATION (FDIC). Risk Management Manual of Examination Policies. Retrieved September 2011 from http://www.fdic.gov/regulations/safety/ manual/section3-1.html.

FEDERAl Deposit InSURANCE CoRporation (FDIC). Financial Institution Letters. Retrieved September 2011 from http://www.fdic.gov/news/news /financial/ 2008/ fil08084.bhtml.

FELTHAM, G. and OHLSON, J.A. "Valuation and clean surplus accounting for operating and financial activities." Contemporary Accounting Research (1995): 689-731.

FinANCIAL ACCOUnTING STANDARDS BoARD (FASB). Objectives of Financial Reporting by Business Enterprises. Statement of Financial Accounting Concepts No. 1. Norwalk, CT: FASB, 1978.

FinANCIAL ACCOUnTING STANDARDS BoARD (FASB). Objectives of Financial Reporting by Business Enterprises. Statement of Financial Accounting Concepts No. 2. Norwalk, CT: FASB, 1980. 
FinANCIAL ACCOUNTING STANDARDS BoARd (FASB). Objectives of Financial Reporting

by Business Enterprises. Statement of Financial Accounting Concepts No. 8. Norwalk, CT: FASB, 2010.

FinAnCial Crisis Advisory Group. Report of the Financial Crisis Advisory Group: Norwalk, CT/London, 2009.

FinANCIAL Crisis InquiRY Commission. Final Report of the National Commission on the Causes of the Financial and Economic Crisis in the United States: Washington, 2011.

FISCHER, P., and VerReCCHIA, R. "The effect of limited liability on the market response to disclosure." Contemporary Accounting Research 14 (1997): 515-541.

GILBERT, R.A. and VAUGHAN, M.D. "Does the publication of supervisory enforcement actions add to market discipline?" Research in Financial Services: Public and Private Policy (1998): 259-280.

GolDSTEIN, I. and SAPRA, H. "Should banks' stress test results be disclosed? An analysis of the costs and benefits." Unpublished Working Paper (2012): University of Chicago.

GRAHAM, J.R., LI, S., and QIU, J. “Corporate misreporting and bank loan contracting." Journal of Financial Economics (2008): 44-61.

Hand, J.R.M., Holthausen, R.W., and Leftwich, R.W. "The effect of bond rating agency announcements on bond and stock prices." The Journal of Finance (1992): 733-752.

HANLON, M. "The persistence and pricing of earnings, accruals and cash flows when firms have large book-tax differences." The Accounting Review (2005): 137-166.

Hanlon, M., Laplante, S.K., and Shevlin, T. "Evidence for the possible information loss of conforming book income and taxable income." Journal of Law and Economics (2005): 407-442.

HANLON, M., HoOPES, J.L., and SHROFF, N.O. "The effect of tax authority monitoring and enforcement on financial reporting quality." Unpublished Working Paper (2011).

HAO, L. and NAIMAN, D.Q. 2007. "Quantile regression." first ed. SAGE Publication, Hopkins University.

HATFIELD, G. and LANCASTER C. "The signaling effects of bank loan-loss reserve additions." Journal of Financial and Strategic Decisions (2000): 57-73.

HAYN, C. "The information content of losses." Journal of Accounting and Economics 20 (1995): 125-153.

Healy, P.M. and Palepu, K.G. "The effect of firms' financial disclosure strategies on stock prices." Accounting Horizons (1993): 1-11. 
HuLl, J.C. "Options, futures, and other derivatives." eighth ed. Prentice Hall, Upper Saddle River (2011).

Hull, J., Predescu, M., and White A. "Bond prices, default probabilities, and risk premiums" Journal of Credit Risk (2005): 53-60.

ILMANEN, A. “Stock-bond correlations.” Journal of Fixed Income (2003): 55-66.

Jarrow, R.A. and Turnbull, S.M. "Pricing derivatives on financial securities subject to credit risk." Journal of Finance (1995): 53-85.

Jensen, M. and MecKLing, W. „Theory of the firm: Managerial behavior, agency costs and ownership structure." Journal of Financial Economics (1976): 305-360.

JoNES, J.J., 1991. “Earnings management during import relief investigations.” Journal of Accounting Research (1991): 193-228.

KAUFMAN, G.G. "Bank contagion: A review of the theory and evidence." Journal of Financial Services Research (1994): 123-150.

KHURANA, I.K. and RAmAN, K.K. "Are fundamentals priced in the bond market?" Contemporary Accounting Research (2003): 465-494.

KING, G. and RoBerTs, M. "How robust standard errors expose methodological problems they do not fix." Unpublished Working Paper (2012): Harvard University.

KLEIN, A. and ZuR, E. “The impact of hedge fund activism on the target firm's existing bondholders." Review of Financial Studies (2011): 1735-1771.

Kleinbaum, D.G., KuPPER, L.L., and MulleR, K.E. „Applied regression analysis and other multivariable methods." second ed. Duxburry Press (1987): Belmont.

KoEnKER. R. and BASSETT, G. “Regression quantiles.” Econometrica (1978): 33-50.

Koenker. R. and Hallock, K.F. “Quantile regression.” Journal of Economic Perspectives (2001): 143-156.

KOTHARI S.P. "Capital markets research in accounting." Journal of Accounting \& Economics (2001): 105-231.

Kothari, S.P., Ramanna, K., and Skinner, D.J. "What should GAAP look like? A survey and economic analysis." Unpublished Working Paper (2009).

KRAFT, P. "Do rating agencies cater? Evidence from rating based contracts." Unpublished Working Paper (2011): New York University.

LAMBERT, R. "Financial reporting research and standard setting." Unpublished Working Paper (1996): Stanford University. 
LANGOHR, H.M. and LANGOHR, P.T. "The rating agencies and their credit ratings." John Wiley \& Sons Ltd (2008).

LEV, B. and Nissim, D. "Taxable income, future earnings, and equity values." The Accounting Review (2004): 1039-74.

LONGSTAFF, F.A., MithaL, S., and Neis, E. “Corporate yield spreads: Default risk or liquidity? New evidence from the credit default swap market." Journal of Finance (2005): 2213-2253.

LYLE, M.R., CALLEN, J.L., and ElliotT, R.J. "Dynamic risk, accounting-based valuation and firm fundamentals." Unpublished Working Paper (2011): University of Toronto and University of Calgary.

MANSo, G. "Feedback effect of credit ratings." Unpublished Working Paper (2011): MIT Sloan School of Management.

MATHIS, J., McAndREwS, J., and Rochet, J.C. "Rating the raters: Are reputation concerns powerful enough to discipline rating agencies?" Journal of Monetary Economics (2009): 657-674.

McKinsey Global InStitute. “Capital Market Update” (2011).

MERTON, R.C. "On the pricing of corporate debt: The risk structure of interest rates." Journal of Finance (1974): 449-470.

MinNIS, M.C. "The value of financial statement verification in debt financing: Evidence from private U.S. firms." Journal of Accounting Research (2011): 457-506.

Moody's InVESTORS SERvice. The bond rating process: A progress report: Moody's Investors Service Global Credit Research: (2002): New York.

MYERS, S.C. "Determinants of corporate borrowing." Journal of Financial Economics (1977): 147-175.

National Bureau of Economic Research (NBER). 2010. Report of the Business Cycle Dating Committee. Retrieved September 2011 from http://www.nber.org/ cycles/ sept2010.html.

NIER, E.W. "Bank stability and transparency." Journal of Financial Stability (2005): 342354

O'BRIEN, R.M., 2007. "A caution regarding rules of thumb for variance inflation factors." Quality \& Quantity (2007): 673-690.

OHLSON, J.A. "Earnings, book values and dividends in equity valuation." Contemporary Accounting Research (1995): 661-687. 
Plummer, E. and TSE, S. "The effect of limited liability on the informativeness of earnings: Evidence from the stock and bond markets." Contemporary Accounting Research 16 (1999): 541-74.

PutNAM B.H. "Early warning systems and financial analysis in bank monitoring: Concepts of financial monitoring." Federal Reserve Bank of Atlanta Economic Review (1983): 6-13.

REYNOLDS, J.K. and FRANCIS, J.R. 2000. "Does size matter? The influence of large clients on office-level auditor reporting decisions." Journal of Accounting \& Economics (2000): 375-400.

RichaRDSON, S.A. SlOAN, R.G., SOliman, M.T., and Tuna, I. "Accrual reliability, earnings persistence and stock prices." Journal of Accounting \& Economics (2005): 437-485.

ScотT, W.R. "Financial accounting theory." Third ed. Upper Saddle River: Prentice Hall (2011).

SLOAN, R.G. 1996. "Do stock prices fully reflect information in accruals and cash flows about future earnings." The Accounting Review (1996): 289-315.

SORTER, G.H. "An 'events' approach to basic accounting theory." The Accounting Review (1969): 12-19.

SMITH, C.W. and WARNER, J.B. "On financial contracting: An analysis of bond covenants." Journal of Financial Economics (1979): 117-161.

TADESSE, S. "The economic value of regulated disclosure: Evidence from the banking sector." Journal of Accounting and Public Policy (2006): 32-70.

THOMAS, J. and ZHANG, F. “Tax income momentum." Journal of Accounting Research (2011): 791-821.

Venkatachalam, M. "Value-relevance of banks' derivatives disclosures." Journal of Accounting and Economics (1996): 327-355.

WAHLEN J.M. "The nature of information in commercial bank loan loss disclosures." The Accounting Review (1994): 455-478.

WEBER, D.P. "Do analysts and investors fully appreciate the implications of book-tax differences for future earnings?" Contemporary Accounting Research (2009): 11751206.

WILSON, G.P. "The relative information content of accruals and cash flows: Combined Evidence at the Earnings Announcement and Annual Report Release Date." Journal of Accounting Research (1986): 165-200. 
YANG, J., ZHOU, Y., and WANG, Z., 2009. "The stock-bond correlation and macroeconomic conditions: One and a half centuries of evidence." Journal of Banking \& Finance (2009): 670-680. 


\section{CURRICULUM VITAE}

Ronny Karl Hofmann was born on 15th of February 1973 in Maxdorf, Germany. He received a Bachelor of Business Administration (BBA) in Management from Francis Marion University, USA, a Master of Business Administration (MBA) from the Vienna University of Economics and Business Administration, Austria, and an International Master of Business Administration (IMBA) in Finance from the University of South Carolina, USA. He gained practice experience at Deloitte \& Touche's IFRS Centre of Excellence in Frankfurt, Germany and worked as Assistant Manager for KPMG'S Accounting Advisory, Financial Institutions Risk Management (FIRM), and Audit Financial Services in Frankfurt, Germany. After his professional career, he joined Maastricht University's PhD program (Department of Accounting and Information Management, AIM). He conducted part of his research as a Visiting Scholar at the University of North Carolina at Chapel Hill and the University of Western Australia. His work was presented and discussed at various universities and international conferences in Europe, North America, Asia, and Australia. Since September 2013, Ronny is Assistant Professor at the Accounting \& Management Control Department at IE Business School in Madrid. 